\title{
What's the room got to do with it?
}

Citation for published version (APA):

Hoogesteyn, K. (2020). What's the room got to do with it? Examining the influence of environmental aspects in investigative interviews. [Doctoral Thesis, Maastricht University]. Maastricht University. https://doi.org/10.26481/dis.20200706kh

Document status and date:

Published: 01/01/2020

DOI:

10.26481/dis.20200706kh

Document Version:

Publisher's PDF, also known as Version of record

\section{Please check the document version of this publication:}

- A submitted manuscript is the version of the article upon submission and before peer-review. There can be important differences between the submitted version and the official published version of record.

People interested in the research are advised to contact the author for the final version of the publication, or visit the DOI to the publisher's website.

- The final author version and the galley proof are versions of the publication after peer review.

- The final published version features the final layout of the paper including the volume, issue and page numbers.

Link to publication

\footnotetext{
General rights rights.

- You may freely distribute the URL identifying the publication in the public portal. please follow below link for the End User Agreement:

www.umlib.nl/taverne-license

Take down policy

If you believe that this document breaches copyright please contact us at:

repository@maastrichtuniversity.nl

providing details and we will investigate your claim.
}

Copyright and moral rights for the publications made accessible in the public portal are retained by the authors and/or other copyright owners and it is a condition of accessing publications that users recognise and abide by the legal requirements associated with these

- Users may download and print one copy of any publication from the public portal for the purpose of private study or research.

- You may not further distribute the material or use it for any profit-making activity or commercial gain

If the publication is distributed under the terms of Article $25 \mathrm{fa}$ of the Dutch Copyright Act, indicated by the "Taverne" license above, 


\section{What's the room got to do with it?}

Examining the influence of environmental aspects in investigative interviews

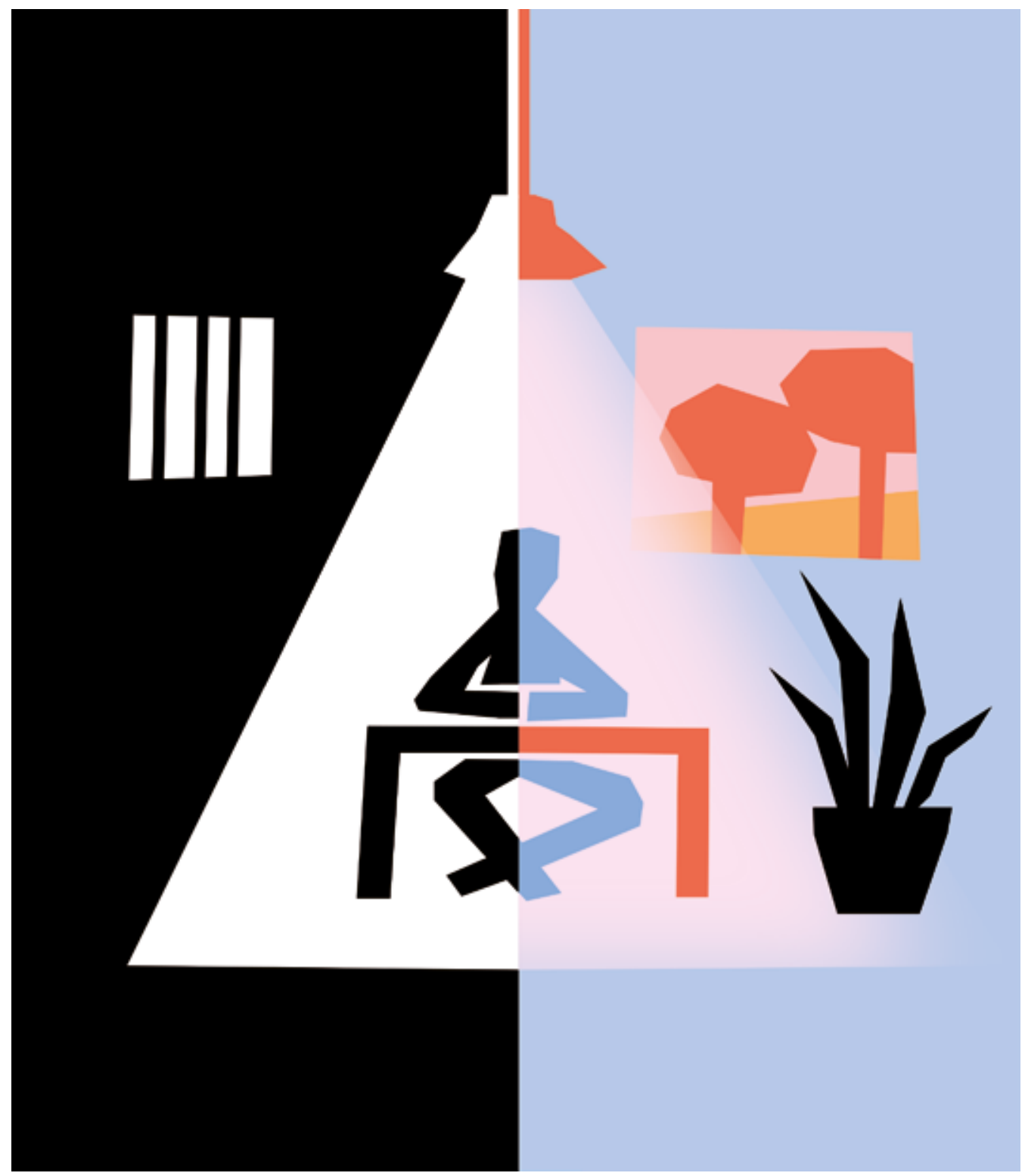

Katherine Hoogesteyn 
What's the Room Got to Do With it?

Examining the Influence of Environmental Aspects in Investigative Interviews

Katherine Hoogesteyn 
(C) Katherine Hoogesteyn, Maastricht 2020

ISBN: 978-94-6402-354-1 


\title{
Maastricht University
}

\section{What's the Room Got to Do With it? \\ Examining the Influence of Environmental Aspects in Investigative Interviews}

\author{
Doctoral Dissertation
}

To obtain the degree of Doctor of Philosophy from the University of Portsmouth and the degree of Doctor at Maastricht University, on the authority of Rector Magnificus Prof. dr. Rianne M. Letschert, according to the decision by the Board of Deans, to be defended in public on Monday July $6^{\text {th }}, 14: 00 \mathrm{hrs}$ in Maastricht

by

Katherine Hoogesteyn 


\section{Supervisors}

Dr. E.H. Meijer, Maastricht University

Prof. dr. A. Vrij, University of Portsmouth

Prof. dr. C. de Ruiter, Maastricht University

\section{Doctoral Dissertation Committee}

Prof. dr. M. Jelicic, Maastricht University (chair)

Prof. dr. E. Giebels, University of Twente

Dr. C.E. Kelly, Saint Joseph's University

Dr. C. Nee, University of Portsmouth 


\section{TABLE OF CONTENTS}

CHAPTER 1 General Introduction

CHAPTER 2 Utility and Effectiveness of The Context Manipulation Techniques: 23 Police Investigators' Perspectives

CHAPTER 3 The Influence of Room Spaciousness in Investigative Interviews 39

CHAPTER 4 Examining Witness Interviewing Environments 57

CHAPTER 5 Detainee and Layperson's Perspectives and Preferences Regarding 73 Police Interview Rooms

CHAPTER 6 General Discussion

References

Appendices

English Summary

Resumen en Español

Valorisation Addendum

Acknowledgements

Curriculum Vitae

Dissemination 
CHAPTER 1

GENERAL INTRODUCTION

This chapter draws from the following paper:

Hoogesteyn, K., Meijer, E.H, Vrij, A., \& Merckelbach, H.L.G.J. (2018). Improving the disclosure of information in an investigative interview: Rapport building and the physical environment. The Inquisitive Mind Magazine, 36/2018. 


\section{General Introduction}

Tommy was sweating and dizzy and trying desperately to think rationally. He kept his responses short. No, I didn't do it. No, I wasn't involved. A few times he wanted to lash out with sarcastic comments, but he was scared. Smith and Rogers were erupting, and armed, and Tommy was locked in a room with them. His interrogation showed no signs of ending anytime soon.

- John Grisham, The Innocent Man, 2006

The above excerpt describes Tommy Ward's first interview with the Ada police in 1984, Oklahoma. Upon confessing, Tommy was convicted of robbery, abduction, and the murder of Donna Denice Haraway. Over 30 years later, despite evidence that investigators coerced Tommy's confession through intimidation, deception, and lengthy interrogations, as of early 2020 Tommy remains in prison (Adcock, 2020; Grisham, 2006).

Over the past decades, cases such as Tommy's galvanized a reformation in police interrogations, acknowledging the need for ethical methods to obtain the necessary information while decreasing the likelihood of false confessions. A representation of this shift is the replacement of the term "interrogation" in favour of "investigative interviewing" (Williamson, 1993), which will be adopted throughout the remainder of this thesis. The shift from interrogation to investigative interviewing has also been supported by the abundance of scientific research uncovering what interviewing techniques are most effective, and ethical, for eliciting information. To this end, non-coercive interviewing techniques that reflect a non-accusatorial, non-guilt presumptive, and relationship-oriented dynamic are recommended (Alison et al., 2014). Of the many techniques, this thesis focuses on one aspect that has thus far been neglected in the literature - that is, the environment in which the investigative interviewing takes place.

Grisham's The Innocent Man illustrates the importance of investigating the physical environment, where he described the many hours of abuse and desperation Tommy Ward experienced inside the 'small' interrogation rooms. The feeling of being 'locked in' is quite poignant, it encapsulates the inherent intimidation of the situation, in which the physical environment plays a key role. Grisham's account shows the reader that intimidating 
custodial environments are not just what is portrayed on crime television shows, these environments are real. However, while they appear conventional, whether they are actually effective has yet to be empirically established.

Despite the high practical relevance of interviewing environments, it is only recently that legal psychologists have begun to study whether the physical environment is influential during interviews. More specifically, whether the environment can be used as a non-coercive tool to foster cooperation and facilitate information elicitation, rather than instilling intimidation (e.g., Kelly et al., 2019). This dissertation addresses this gap in the psycholegal literature. First, we examined police investigators' beliefs about the effectiveness of environmental manipulations as interviewing techniques, as well as the thoughts of current detainees and laypersons on differing interview environments. Further, through experimental paradigms, we also examined whether specific alterations of the interview environment can facilitate key aspects of investigative interviewing, namely informationelicitation and rapport-building. The purpose of this introductory chapter is to place this dissertation in context by (1) summarizing the current scientific consensus regarding investigative interviewing approaches, and (2) discussing the available literature related to the physical environment and investigative interviewing practice.

\section{Investigative Interviews}

Through investigative interviews, investigators are able to collect critical information (e.g., potential leads) and evidence toward the advancement of a criminal case. For this reason, the foremost goal of all interviews is to elicit a complete and accurate account from the interviewee (Shepherd \& Griffiths, 2013; Vrij et al., 2014).

Two main styles of interviewing dominate the field: the accusatorial and informationgathering. While both interviewing styles aim at eliciting cooperation from the interviewee, their approaches are fundamentally different (Vrij et al., 2014). An accusatorial style functions under the premise that the interviewee is guilty, and therefore the intention is to manipulate their belief about the consequences of confessing in order to obtain a confession (Kelly \& Meissner, 2015; Vrij et al., 2014). Kassin and Gudjonsson (2004) summarized the three overall components of an accusatorial style: custody and isolation (i.e., the interviewee is detained in a small room, left to experience the anxiety and stress associated with a police 
interview); confrontation (i.e., the interviewee is assumed guilty and is told about the evidence against them, is warned of the consequences concomitant with their guilt, and is prevented from denying their involvement in the crime); and minimization (i.e., a tactic in which a sympathetic interviewer attempts to gain the interviewee's trust, offers them moral justifications or excuses for the crime, and implies more lenient consequences should $\mathrm{s} / \mathrm{he}$ confess to the crime; Meissner et al., 2014). Since the goal of an accusatorial interview is to obtain a confession, the tactics investigators use can be psychologically manipulative and coercive, seeking to establish control over the interviewee, and relying on confirmatory questions in order to obtain one (Meissner et al., 2012).

Critics of the accusatorial approach argue that its methods can lead to more abusive tactics by encouraging a harsher and control-based atmosphere in the interview room, leading suspects to confess to crimes they did not commit (Brimbal et al., 2019). Over the past decades, criminal investigations carried out in an accusatory manner have received substantial criticism due to the staggering number of false confessions resulting in wrongful convictions (and consequently miscarriages of justice). As of 2018 , in the United States, $62 \%$ of the wrongful conviction murder cases involved a false confession (see https://www.innocenceproject.org/dna-exonerations-in-the-united-states/). Tommy Ward is just one of too many. Central to many of these false confession cases is the use of accusatorial methods (Meissner et al., 2012). Another distinct example comes from the the much publicized Central Park jogger case, in which five juvenile males served between six and 13 years in prison based on confessions that were later proven to be false. Prior to falsely confessing, the juveniles were subject to stressful and severe interviews lasting between 14 and 30 hours, and were led to believe that they could go home if they confessed (Nesterak, 2014).

Notably, besides increasing the chances of obtaining false confessions, accusatorial methods may actually elicit resistance rather than cooperation (Vrij et al., 2017). Research suggests that certain accusatorial tactics, such as emotional provocation and confrontation, can increase interviewees' resistance and refusal to cooperate (Goodman-Delahunty et al., 2014; Kelly et al., 2015). Such resistance is, predictably, counter-productive to the goal of obtaining accurate and useful information. 
Thus, in light of the problematic nature of accusatorial methods, both academics and practitioners began advocating an information-gathering style to investigative interviewing. In 1984 the Police and Criminal Evidence Act (PACE) was created in the United Kingdom (UK), which limited the use of psychologically manipulative tactics and required all interrogations to be audio recorded (Bull \& Milne, 2004a). Further, in 1993, the Royal Commission on Criminal Justice in the UK proposed the PEACE model, developed by a team of experienced detectives, in conjunction with the available empirical evidence on recommended interviewing methods (British Psychological Society, 2016).

The PEACE model includes five phases, each represented by a letter of the acronym. In the "Preparation and planning" phase, interviewers focus on consolidating the evidence and constructing a plan for the interview. This can also include choosing the location of the interview (Brandon et al., 2018). In the "Engage and explain" phase, the goal is to build rapport and inform the interviewee of the purpose of the interview. The third phase, "Account" is the core of the interview, when the questioning takes place. The model recommends two interviewing protocols here: The Cognitive Interview (Fisher \& Geiselman, 1992) for interviewing cooperating interviewees, and Conversation Management (Shepherd \& Griffiths, 2013) for uncooperative interviewees. In the Account phase, the interviewer clarifies -and if needed challenges- the information provided by the interviewee. The following phase, "Closure" is when the interviewer summarizes what has been said throughout the interview. Lastly, in the "Evaluation", interviewers analyze their performance after the interviews are concluded. This phase emphasizes the need for investigators to continuously work on improving their interviewing skills (Walsh \& Milne, 2010).

The PEACE model underlined the shift from an accusatorial approach to an information-gathering approach. The latter approach emphasizes the development of rapport, explaining to the suspects the seriousness of the offense, and the need for honesty when requesting their version of events (Meissner et al., 2012). The information-gathering approach employs a neutral framework where the interview becomes a tool to gather information rather than to seek inculpatory evidence. Thus, the main goal shifts from obtaining a confession to gathering as much useful and reliable information as possible to advance the investigation (Evans et al., 2010; Evans et al., 2013; Hartwig et al., 2014; Vrij et al., 2017). One essential component of the information-gathering approach is rapport and 
relationship building (Kelly et al., 2013; St. Yves, 2009), which is a construct of relevance throughout this dissertation.

\section{Rapport and Relationship Building}

Rapport-building can be defined as a positive and constructive relationship between investigator and interviewee (Walsh \& Bull, 2012). It generally consists of personalizing the interview (Fisher \& Geiselman, 1992), establishing a common ground, as well as engaging in active listening and attentiveness (Collins, Lincoln, \& Frank, 2002). By building rapport, investigators are able to create an atmosphere that encourages cooperation, which supports the task of obtaining information (Abbe \& Brandon, 2013; Evans et al., 2010; Hartwig et al., 2005). Whilst through an accusatorial approach the investigator seeks control of the interrogation, a rapport-building approach only works if investigators relinquish some of their control and share it with the suspect (Brimbal et al., 2019).

The positive effects of building rapport have been reiterated by academics as well as practitioners (e.g., Kelly et al., 2015; Russano et al., 2014; Vallano et al., 2015). Studies show that rapport-building increases the likelihood and accuracy of disclosure from witnesses (Kieckhaefer et al., 2014; Vallano \& Schreiber-Compo, 2011, 2015), and suspects (Alison et al., 2013; Holmberg \& Christianson, 2002; Snook et al., 2015; Wachi et al., 2018). An example of the benefits of rapport-building with suspects comes from the recent case of a British man arrested for planning to kidnap and murder a soldier. The man refused to cooperate during interviews, stating that he would only talk "openly and honestly" to the "right person". After failing to elicit cooperation, a new investigator took charge, using a friendly approach: "[...] Only you know these things [suspect's name]. If you are willing, you'll tell me, and if you're not, you won't. I can't force you to tell me - I don't want to force you. I'd like you to help me understand. Would you tell me about what happened?". Faced with this approach, the suspect responded positively: "That is beautiful," he said. "Because you have treated me with consideration and respect, yes, I will tell you now [...]" (Leslie, 2017). 


\section{The Role of the Environment in Communication}

Successful information elicitation largely relies on the interpersonal dynamic and quality of communication between the investigators and interviewees (Yeschke, 1997). One aspect of this dynamic that has been largely unexplored is the physical environment in which the interview occurs (Goodman-Delahunty et al., 2014). Nevertheless, the physical environment can be influential, as contemporary communication research explains (Hartley, 2002; Knapp et al., 2013). Hartley (2002) emphasized the importance of the environment in his model of interpersonal communication (see Figure 1). In this model, social context encompasses the social structure of the communication (i.e., social norms, relationships), as well as the environment (which he then divides into social or/and physical environment). According to Hartley, the physical environment is the collection of physical aspects surrounding the communication, such as shape and size of the room, lighting, and colors. These aspects can then influence behavior in conscious and unconscious ways. He illustrates this influence by the example of lighting, which is seemingly inconsequential. However, harsh lighting can lead to eyestrain or fatigue, in turn making people feel irritable or unsettled, these feelings of irritability can lead to grumpiness, which in turn can lead to arguments during a conversation. 


\section{Figure 1}

Hartley's (2002) model of interpersonal communication. Social structure and Environment added for this dissertation's purpose.

Social Context

(Social structure \& Environment)

Person A
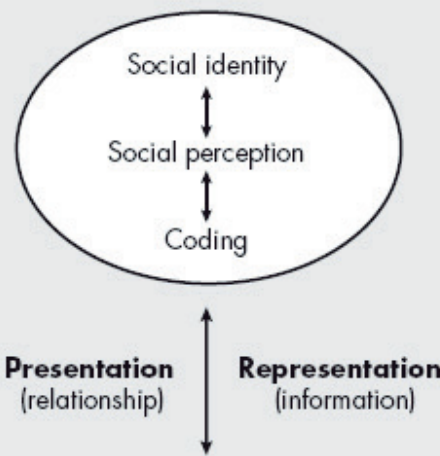

Person B

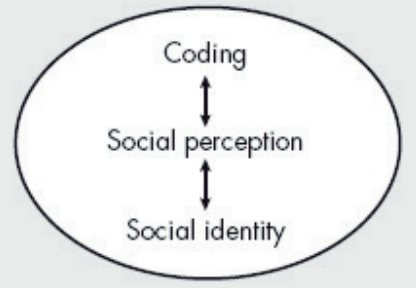

Other researchers have also argued that different physical aspects can help create an atmosphere that facilitates communication and is conducive to obtaining information (Knapp et al., 2013). This has been examined in fields outside of [legal] psychology, such as in counseling and healthcare settings. Similar to an investigative interview scenario, the disclosure of accurate information from clients is vital for counselors to make appropriate diagnoses (Okken et al., 2013). For this reason, a number of health care-related studies examined whether alterations of the physical environment can facilitate client disclosure with their counselors (e.g., Cohen \& Schwartz, 1997; Lecomte et al., 1981). Such physical aspects can be architectural, such as the room size. Across two studies, Okken, Rompay, and Pruyn $(2012,2013)$ found that clients interviewed in a larger room provided more 
information about sensitive topics and reported more positive feelings of comfort than clients interviewed in a smaller room. They also found that a larger interpersonal distance between interviewer and clients facilitated higher disclosure.

Other studies have found influences of room décor. One study showed disclosure to be substantially higher in a 'warm', intimate room (decorated with pictures, soft cushioned furniture, soft lighting) compared to a 'cold', non-intimate environment with fluorescent lighting (Chaikin et al., 1976). Similarly, another study found that interviews conducted in a room decorated more home-like (as opposed to office-like) led to increased written communication concerning both general and intimate topics (Gifford, 1988). The author attributed this to the prospect that homey décor is not just more physically comfortable, but can also be more psychologically comfortable, inducing a sense of shelter that is associated with home. These studies provide support for the influence of architectural aspects, such as room size, as well as aspects more feasibly manipulated (i.e., seating distance, type of decoration) on the interviewee's comfort and information disclosure.

\section{Environmental Manipulations and Legal Psychology}

Research on the role of the environment specific to investigative interviews has recently gained momentum, and researchers are expressing a need to delve more into this topic (Evans et al., 2010; Goodman-Delahunty et al., 2014; Meissner et al., 2015). Kelly and colleagues (2013) illustrated the importance of the environment in their taxonomy of interrogation methods (see Figure 2). At the heart of the taxonomy is rapport and relationship building, which, as aforementioned, are vital components of an informationgathering interview style. Rapport can, according to this taxonomy, be influenced by the other domains, Collaboration (e.g., appealing to sense of cooperation, making bargains with the interviewee), Confrontation/competition (e.g., lying to interviewee, emphasizing authority), Evidence presentation (e.g., presenting false incriminating evidence, reveal evidence that interviewee was unaware the investigator had), and Emotional provocation (e.g., appeal to self-interests of interviewee, instill hopelessness, use flattery). 


\section{Figure 2}

Taxonomy model from Kelly, Miller, Redlich, and Kleinman (2013)

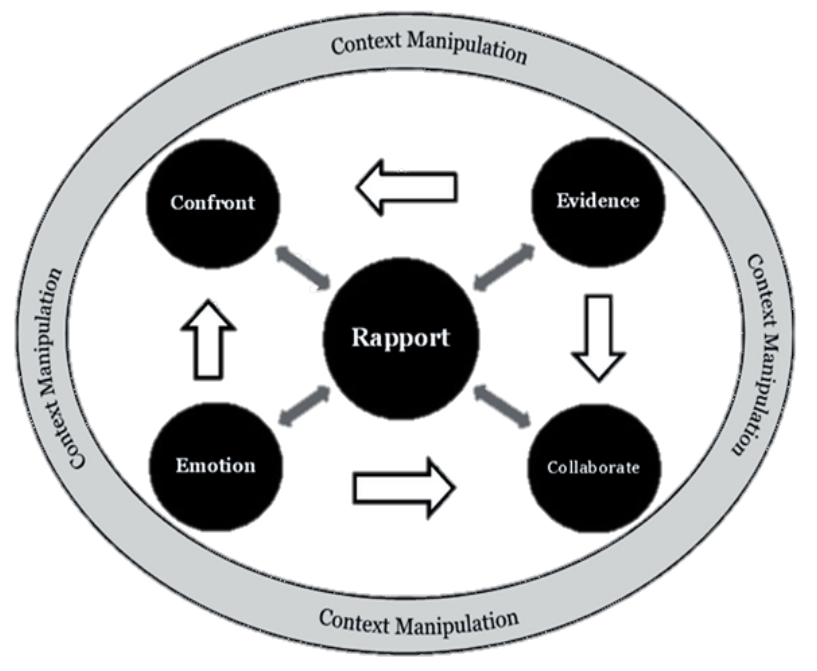

Kelly and colleagues (2013) emphasized the role of context manipulation in investigative interviews. In this model, context manipulation refers to the altering of the physical and/or temporal space of the interrogation room, to increase the probability of a successful interview. Examples of contextual manipulations include considering the size of the interview room, the time of day of the interview, the seating arrangement, and room temperature. Context manipulation is composed solely of techniques based on noninterpersonal and environmental factors rather than communicative ones.

Academics have begun to experimentally examine the effects of certain physical environmental aspects in investigative interview settings. Apart from the studies reported in this dissertation, only two studies ${ }^{1}$ - reported in Dawson et al. (2017) - have looked at the effects of environmental manipulations on disclosure in lab-based experiments. Following a metaphoric priming framework, Dawson and colleagues (2017) proposed that aspects of the physical environment (i.e., spaciousness) can prime cognition in metaphoric ways (i.e.,

\footnotetext{
${ }^{1}$ A third study, ten Brinke, Khambatta and Carney (2015), examined the effects of altering interview room characteristics. However, as these authors were primarily interested in lie detection accuracy rather than disclosure, we decided not to discuss it.
} 
activating concepts of openness), consequently influencing behaviors (i.e., encouraging disclosure). In both studies, participants were interviewed about a staged crime they took part in. The size of the interview rooms was manipulated, with one room twice the size of the other. The larger room was helpful in eliciting disclosure: participants who were interviewed in the larger room provided more overall and critical details regarding the crime than participants who were interviewed in the smaller room. The authors suggested a simple explanation for this; a larger room elicits more comfort and thus fosters a more positive dynamic between the investigator and the interviewee. This is consistent with the previous health care literature on room size and client disclosure. Further, self-reported ratings showed that participants interviewed in the larger room reported wanting to leave less than those interviewed in the smaller room (Dawson et al., 2017).

Additionally, in a study evaluating both interviewers' and high-value detainees' perceptions of coercive and non-coercive strategies for eliciting cooperation, GoodmanDelahunty and colleagues (2014) found the physical setting to be linked to perceptions of non-coercion. The detainees, held in custody for terrorism-related activities, were asked to recall a recent interview experience and to report their perceptions of the impact of different types of interview strategies, including ones related to the physical environment, on their levels of cooperation, disclosure, and willingness to make incriminating admissions. Detainees' reports suggested that interviews conducted in a comfortable setting were associated with an increase in their disclosure of incriminating information. The authors note that the comfortable setting may have fostered rapport, which in turn facilitated disclosure.

Goodman-Delahunty and colleagues (2014)'s findings showed detainees' preference for a comfortable, non-coercive interviewing environment. This preference seems obvious, however, Dawson et al. (2017) found somewhat contrasting results. Beside room spaciousness, Dawson and colleagues also manipulated the room's decorations. Their idea was that the decorations, metaphorically consistent with feelings of openness (e.g., a picture of an ocean, an open book) would prime higher disclosure. Instead, in their second study, they found that the presence of the decorations led to higher feelings of suspicion, which in turn hindered disclosure. One explanation for these findings was that the decorated room contrasted with the participants' expectations of what an investigative interviewing room should look like, thus eliciting suspicion about the investigator's intentions. The contrast 
with Goodman-Delahunty et al.'s (2014) findings lie on the likelihood that detainees also do not expect an interview room to be nice and comfortable, yet, their preference was clear - a comfortable environment would entice them to be more forthcoming. While the two studies have obvious distinctions, with one testing student participants while the other interviewed high-value detainees, Dawson and colleague's (2017) findings show that, although seemingly counterintuitive, a nicely decorated environment, expected to be more appeasing and comfortable than a drab and stark room, does not necessarily mean it is more effective.

\section{Environmental Manipulations in Police Practice}

In police practice, some suspect interviewing manuals take contextual, or environmental, manipulations into account. Concerning criminal investigations, the Reid manual provides specific recommendations for how to arrange the interview room. For example, the lighting should not be excessive or glaring, there should also be no distractions present (e.g., no wall decorations, no loose objects like paperclips). Moreover, the seating arrangement between the suspect and interviewer should be at a close distance (approximately $122 \mathrm{~cm}$ ). The Reid manual also suggests the investigator should sit at eyelevel and directly in front of the suspect with no desk or table separating them, to facilitate the detection of deception through the suspect's body movements. Additionally, the investigator should be dressed in civilian clothes if possible, rather than in uniform, to reduce the suspect's stress level (Inbau et al., 2013). In the military setting, the US Army Field Manual $(2-22.3,2006)$ cites the change-of-scenery approach as a recommended tactic to obtain information. This approach consists of removing the suspect from a formal and intimidating atmosphere (i.e., interview room) and placing them in a setting where they may feel more comfortable talking. While the Reid and the US Army Field manual incorporate some context manipulation techniques, to what goal - and extent - these techniques are actually used in the field remains a largely open question.

Furthermore, little is known about non-custodial interviews. Not all investigative interviews take place in formal rooms inside police stations, particularly interviews conducted with victims and/or witnesses. According to a national review of interviewing practice in the UK, it is common to conduct interviews at witnesses' homes and workplaces (Clarke \& Milne, 2001). For example, a senior investigator from The Hague's Police Unit in 
the Netherlands stated that when handling uncooperative witnesses, he does not interview them at the police station, but rather takes them out for a coffee or meets them at home. He does this to instill trust and create rapport with the witnesses:

"[....] First be a friend and after being a friend, start talking. And then convince someone it is very important to talk. So, go to a place where you can have coffee or have lunch. And then you build the relationship, after you can talk to them about the case" (De La Fuente Vilar et al., 2018).

\section{Outline of This Dissertation}

Based on the literature reviewed here, there is reason to believe that the interview environment can be influential in investigative interviews, and while some interviewing manuals take environmental considerations into account (e.g., the Reid manual), we still know very little about their use and effectiveness. To obtain a more complete picture of the possible role of investigative interviewing environments in investigative interviews, we conducted two experimental and two survey studies.

In this dissertation, we first examined the practical relevance of interview environment research through a police survey. We gathered police investigators' beliefs about context - or environmental interviewing tactics and questioned them about their thoughts of the context manipulation techniques outlined by Kelly et al.'s (2013) taxonomy, as well as their use and perceived efficacy (Chapter 2).

We then present two experimental studies, in which we examined if and how the interview setting can facilitate information elicitation and rapport-building - two constructs of interest throughout this thesis. More specifically, in Chapter 3, we examined two aspects related to physical spaciousness. Drawing from previous research (i.e., Dawson et al., 2017; Okken et al., 2012, 2013), we manipulated room size and seating - or interpersonal - distance between interviewer and interviewee. Both Dawson et al. (2017) and Okken et al. (2012, 2013) found that greater spaciousness promoted higher disclosure of information from interviewees. Thus, we sought to replicate these findings, as well as to explore how spaciousness interplays with rapport-building.

In Chapter 4, we tested the influence of the physical environment more broadly by comparing interviews conducted in two different settings. Based on police practice, we know 
that interviews often take place outside of the police station (i.e., at interviewees' work, at home, on the street; Clarke \& Milne, 2001), this is particularly relevant for interviews conducted with witnesses. Therefore, in this study we compared interviews conducted at witnesses' homes with interviews in a more formal, typical police interview room.

In Chapter 5, we explored a rather counterintuitive finding from previous research on interview environments. While some research on interview environment hints that a room made to be comfortable is optimal (Goodman-Delahunty et al. 2014), other studies have found that interviewees become suspicious and wary of the investigator's intentions if the environment does not confirm their expectations, which can be counter-productive (e.g., Dawson et al., 2017). Considering the premise of the Expectancy Violation Theory (EVT; Burgoon, 2015), we explored people's expectations about police interview environments in a sample of current detainees, who are going through the criminal justice system, and individuals from the general population, who have had no contact with police before. Lastly, in our discussion (Chapter 6), we present a summary of the key findings, followed by implications for research and police practice, as well as an overview of this dissertation's limitations and suggestions for future research on interviewing environments. 


\section{CHAPTER 2}

\section{UTILITY AND EFFECTIVENESS OF THE CONTEXT MANIPULATION TECHNIQUES:}

POLICE INVESTIGATORS' PERSPECTIVES

This chapter is published as:

Hoogesteyn, K., Meijer, E.H., \& Vrij, A. (2020). Utility and effectiveness of the context manipulation techniques: Police investigators' perspectives. Journal of Police and Criminal Psychology, 1-8. https://doi.org/10.1007/s11896-020-09374-2 


\begin{abstract}
The foremost goal of conducting an investigative interview is to obtain as much accurate information as possible. To achieve this, investigators employ a variety of interviewing techniques. Kelly, Miller, Redlich, and Kleinman (2013) proposed a taxonomy of interviewing techniques, grouping them into six domains (i.e., Rapport and Relationship Building, Context Manipulation, Emotion Provocation, Collaboration, Confrontation/Competition, and Presentation of Evidence). In this study, we focused on assessing the Context Manipulation domain (e.g., considering seating arrangements, time of day, investigator's clothing). Specifically, we sought to examine police investigators' use of and beliefs about the effectiveness of context manipulation techniques. A sample of 81 police investigators completed the survey.

Our findings provide evidence that investigators believe the interview setting to have importance, and are already employing some context manipulation techniques in their practice, particularly related to seating arrangement, investigators' clothing, and item availability for suspects (e.g., water, coffee). Furthermore, this survey provides evidence that investigators are receptive to using context manipulation techniques in their practice, despite how little they are currently taught during trainings. Understanding what context manipulation techniques investigators use and believe to be useful in their interviewing practice may have implications for future training, as well as for the (re)design of interview rooms.
\end{abstract}

Keywords: context manipulation techniques, interview environment, interview context, police survey, interviewing techniques 


\section{Utility and effectiveness of the context manipulation techniques: Police investigators' perspectives}

Investigative interviews are complex and dynamic social interactions (Kelly et al., 2016) and investigators must prepare how to best manage the flow of information with the suspect. Part of this preparation involves considering the setting in which the interview occurs - or context management (Brandon et al., 2018). Contextual aspects are thus related to the physical environment, and examples include, the furniture arrangement within the interview room, the room size, physically isolating the suspect, and the investigators' physical appearance. Kelly and colleagues (2013) referred to these contextual aspects as context manipulation techniques, because police investigators can manipulate these aspects to aid their interviewing practice.

Context management is mentioned in some North American police manuals. In criminal investigations, the Reid manual (Inbau et al., 2013) provides specific recommendations for how to arrange the interview room. For example, the lighting should not be excessive or glaring, and there should be no distractions (e.g., no wall decorations, no loose objects like paperclips). Moreover, the seating arrangement between the suspect and interviewer should be at a close distance (approximately $122 \mathrm{~cm}$ ) with no desk or table separating them - so to facilitate the detection of deception through the suspect's body movements. Additionally, the investigator should be dressed in civilian clothes if possible, rather than in uniform, to reduce the suspect's stress level (Inbau et al. ,2013). Besides Reid, other interviewing manuals also consider contextual manipulations. In the military setting, the US Army Field Manual $(2-22.3,2006)$ cites the changeof-scenery approach as a recommended technique to obtain information. Contrary to the Reid method, this approach consists of removing the suspect from a formal and intimidating atmosphere (i.e., interview room) and placing them in a setting where they may be more comfortable.

To what extent context manipulation is used in police interviewing practice has been a subject of a few police surveys. For example, Kassin and colleagues (2007) questioned 631 North American investigators on the most frequently used interrogation techniques, and found the two most used were, in fact, contextual techniques. These techniques corresponded well with the Reid method: physically isolating the suspect from family and friends (66\%) and conducting the interrogations in a small, private room (42\%). In a more recent international survey, Miller, Redlich, and Kelly (2018) found that police investigators from European countries (i.e., UK, Finland, Ireland, the Netherlands, and Norway) and Oceania (i.e., Australia and New Zealand) reported 
manipulating the context at a lower rate than US and Canadian investigators. As for specific contextual manipulations, across all countries, the most frequently used were considering the time of day for the interview, strategically positioning the suspect in a specific part of the room, and, similar to Kassin et al. (2007), conducting interviews in a small room.

While these studies provide important information on the prevalence of context manipulation techniques, it remains unclear why investigators employ these techniques or what their beliefs are on their usefulness and effectiveness. The goal of the present study was thus to provide a focused assessment of police investigators' use and beliefs regarding contextual aspects. To achieve this, we asked investigators the degree to which they consider the interview context to be important, and to report on contextual aspects they already consider prior to conducting interviews. We then focused on the specific contextual manipulation techniques proposed by Kelly et al. (2013), to gauge the degree to which investigators consider these techniques useful and effective.

The findings from this survey are important for two reasons. First, emerging research hints at positive effects of context manipulations on interview quality. Dawson and colleagues (2017) manipulated the interview room's size and found that larger physical spaciousness resulted in higher information disclosure. Similarly, Hoogesteyn et al. (2019) found that interviewees who perceived the interview room as more spacious reported more positive perceptions of rapportbuilding. Yet, these studies have focused on just one (i.e., physical spaciousness) of the many contextual aspects relevant to investigative interviewing practice. The data from this survey may yield useful insight into what other contextual aspects are deemed important by police investigators and could be considered for future research. Secondly, contextual aspects should be accounted for when designing interview rooms. If useful, contextual aspects are feasible to manipulate (e.g., re-arranging the room's furniture), and may not require extensive training efforts for investigators. Again, data from this survey may yield important information on what aspects to consider when (re)designing interview rooms.

\section{Method}

\section{Participants}

A total of $81^{2}$ respondents were included in this study. The majority of the sample were male $(n=49)$, with an average age of 44 years $(S D=9.80, n=79)$. The sample comprised officers from

\footnotetext{
${ }^{2} 124$ officers began the survey; only 81 provided any information beyond demographics. Two of the final 81 recruited officers did not report their age.
} 
five countries. The majority were from Sweden $(n=31,38.3 \%)$, and the Netherlands $(n=29$, $35.8 \%)$, the rest included investigators from the United States $(n=12,14.8 \%)$, Canada $(n=8$, 9.9\%), and one response came from England (1.2\%). All participants had interviewing experience, ranging from 1 to 40 years ( $M=15$ years, $S D=10.30, n=79$ ). Fifty-four participants (66.7\%) reported receiving special training in conducting investigative interviews. When asked to specify, some reported having received a general interviewing/interrogation course $(n=22)$, followed by Reid training $(n=6)$, PEACE training $(n=5)$, the Royal Canadian Mounted Police's Phased training $(n=5)$, High-value Detainee group training $(n=5)$, Cognitive Interview training $(n=4), \operatorname{RIMOZ}^{3}(n=$ $3)$, and Motivational Interviewing training $(n=3)$.

Moreover, we asked if they were up to date with the scientific literature on interviewing: $18.5 \%(n=15)$ of participants reported not being at all up to date, 33.3\% $(n=27)$ reported being somewhat up to date, $27.2 \%(n=22)$ reported being moderately up to date, $13.6 \%(n=11)$ reported being mostly up to date, and $7.4 \%(n=6)$ reported being extremely up to date.

\section{Procedure and Materials}

For recruitment, we approached contacts we had in each country who then distributed the online survey link among colleagues (i.e., snowball sampling). Participants received the link to the survey's secure website, along with a short explanation of the purpose of the study. The survey was offered in three different languages: English, Dutch, and Swedish. After consenting, participants first completed a number of demographic queries (e.g., age, years of experience, current rank). The rest of the survey was divided into three sections (see Appendix A for full survey).

Section 1 of the survey first asked investigators "Is there anything you do on purpose, in relation to the interview environment/setting, to prepare for a suspect interview? For example, arranging the chairs in a particular way, deciding on a specific location to conduct the interview, changing out of uniform to wear something informal, etc." Participants first generated their own list of techniques, and then assigned an effectiveness rating on a 7-point Likert-scale ( $1=$ not effective to 7 = very effective) to each technique. Further, participants described the purpose, or the reason why they considered the technique effective, for each technique they generated. We also asked them: "How important do you consider the environment/setting of the interview to be

\footnotetext{
3 "Broadening of questioning" ('RIMOZ') is an interviewing training officers receive as part of their Police Academy training in the Netherlands.
} 
during an investigative interview?" with possible responses ranging from 1 = not at all important to 7 = extremely important. Following that, participants were presented with an open-ended question "Thinking about the aims and purposes of an interview, what do you consider to be the most important characteristics when designing an interview room?"

Section 2 of the survey included the context manipulation techniques provided by Kelly et al. (2013). Four techniques were added to the original list: "Sitting at a close, intimate distance", "Make interview room appear warm and comfortable", "Make interview room appear cold and authoritarian", and "Interview suspects outside of police station". Participants were asked to respond with a "Yes" or "No" on the following questions: "Do you consider this a technique?" and "Is this a useful technique?" If the participants thought the technique was useful, they were prompted, "For what purposes? Explain". Further, they were asked, "Was [the technique] taught during your trainings?" and "Is this technique available to you? Meaning this is something you can control". Participants were also requested to rate on a 7-point Likert-type scale $(1=$ never to $7=$ always), how often they use the selected techniques on a regular basis. Finally, participants were asked, "Are you currently satisfied with the interview rooms at your station?" and if not, to elaborate why not. At the end, participants were debriefed and thanked for their participation. Completion of the online survey took approximately 20 minutes.

\section{Coding}

All qualitative responses to open-ended questions were first translated into English by research assistants who were native Dutch and Swedish speakers. The first author initially reviewed all responses for each question and devised appropriate general categories that best represented the data. Categories were initially informed by the context manipulation domain of Kelly et al.'s (2013) taxonomy, including categories such as seating arrangement, clothing, conducting interview in a formal location. Data-derived categories were also formed to account for responses that did not fit into any category of the taxonomy, and included, for example, checking the auxiliary equipment and ensuring the room's cleanliness (see Table 1 and 2 for all categories). For interrater reliability purposes, an independent coder verified $20 \%$ of the responses, achieving between $85 \%$ and $100 \%$ agreement across all categories. 


\section{Results}

Due to attrition and omission of responses, the number of respondents differs for some survey items. The number of respondents $(n)$ is therefore reported and all percentages represent the proportion of respondents who answered the question.

\section{Overall Importance of Interview Setting/Environment}

Out of our total sample, 72 participants reported on how important they considered the interview setting to be on a 1 to 7 ( 1 = not at all important, 7 = extremely important) Likert-type scale. The majority (54.2\%) considered the setting to have moderate importance. The rest of participants reported it to be extremely important (15.3\%), very important (25\%), slightly important (4.2\%) and not important at all (1.4\%).

\section{Interview Setting/Environment Preparations for an Investigative Interview}

Participants reported on contextual aspects they consider at the planning stage, prior to the interviews, these resulted in 17 categories (displayed in Table 1). The three most frequently mentioned were: Seating arrangement (i.e., interpersonal distance, chair positions), clothing (i.e., wearing informal clothes, uniform), and having items such as water, coffee, cigarettes and tissues to provide suspects with. Looking into the effectiveness scores (ranging from $1=$ not at all, to $7=$ extremely), the techniques were overall judged as moderately effective (the means ranged between 4.62 and 5.85 ; see Table 1 ).

The three techniques judged as most effective were: limiting distractions (i.e., papers, personal items, noise; $M=5.85, S D=1.38$ ), the investigator's clothing (i.e., wearing casual or formal clothes depending on their aims; $M=5.48, S D=1.16$ ), and how the room is set up (i.e., furniture available; $M=5.30, S D=.95)$. Of note, the "room set up" category was broad, it was assigned to responses that alluded to arranging the room but were not specific (i.e., "two chairs and a table") as opposed to the "seating arrangement" category which was assigned to investigators' responses that specifically mentioned the positioning of chairs or interpersonal distances.

Participants also provided the purposes for why they considered each contextual aspect. Overall, investigators took into account the suspect's physical comfort, especially when providing purposes for considering the seating arrangements, having items to provide suspects with, and for conducting interviews in either a formal or more neutral location. 
Table 1

List of Reported Contextual Considerations Prior to Interview.

\begin{tabular}{|c|c|c|c|}
\hline Category & $\begin{array}{l}\text { Number of } \\
\text { times } \\
\text { mentioned }\end{array}$ & $\begin{array}{c}\text { Effectiveness } \\
\text { Mean (SD) }\end{array}$ & Purposes for using \\
\hline Seating arrangement & 40 & $\begin{array}{l}5.18(1.43) \\
\quad n=25\end{array}$ & $\begin{array}{l}\text { For suspect's visibility }(n=7) \\
\text { To facilitate the interaction }(n=7) \\
\text { To increase overall comfort }(n=6)\end{array}$ \\
\hline Clothing & 36 & $\begin{array}{c}5.48(1.16) \\
n=23\end{array}$ & $\begin{array}{l}\text { To facilitate the interaction }(n=7) \\
\text { To show professionalism }(n=5) \\
\text { To maintain control }(n=5)\end{array}$ \\
\hline $\begin{array}{l}\text { Have items to provide suspect } \\
\text { with (water/coffee/ } \\
\text { cigarettes/tissues) }\end{array}$ & 19 & $\begin{array}{l}5.21(1.25) \\
\quad n=14\end{array}$ & To increase suspect's comfort $(n=19)$ \\
\hline $\begin{array}{l}\text { Ensure there are no } \\
\text { distractions }\end{array}$ & 15 & $\begin{array}{l}5.85(1.38) \\
\quad n=10\end{array}$ & To limit distractions $(n=6)$ \\
\hline $\begin{array}{l}\text { Conduct interview in a formal } \\
\text { or neutral location }\end{array}$ & 14 & $\begin{array}{l}4.62(2.56) \\
\quad n=4\end{array}$ & To increase overall comfort $(n=3)$ \\
\hline $\begin{array}{l}\text { Check auxiliary equipment } \\
\text { (audio, video) }\end{array}$ & 12 & $\begin{array}{c}4.67(1.22) \\
\quad n=9\end{array}$ & Shows professionalism $(n=3)$ \\
\hline The room set up (broad) & 12 & $\begin{array}{l}5.30(.95) \\
n=10\end{array}$ & $\begin{array}{l}\text { To facilitate seating re-arrangement }(n= \\
\text { 3) } \\
\text { To increase overall comfort }(n=3)\end{array}$ \\
\hline
\end{tabular}

Note. Categories with less than 10 mentions were omitted. These included: the interview location $(n=7)$, the number of people inside the room $(n=7)$, removing barriers between suspect and investigator $(n=6)$, the room cleanliness $(n=5)$, the size of the room $(n=4)$, the room's safety $(n=3)$, seating suspects in a comfortable chair $(n$ $=3$ ), illustrating evidence on the room's walls $(n=1)$, considering the temperature $(n=1)$, the room lighting $(n=1)$, and removing weapons $(n=1)$.

We note the number of people who provided an effectiveness measure under the mean and standard deviation. We provide the top three most cited purposes for each category, purpose categories that reached less than 3 mentions were omitted.

Effectiveness was measured via a 1 (not effective) to 7 (very effective) Likert-type scale. 


\section{Important Aspects When Designing Interview Rooms}

Further, we asked participants to describe the characteristics they consider most important when designing interview rooms. These were unstructured, open-ended responses, which we then coded into data-derived categories to best represent our data. Participants most commonly reported the importance of creating a comfortable, informal, or relaxing setting $(n=21)$, to account for the investigator's safety $(n=19)$, designing a setting free of distractions (e.g., clocks, noise from neighboring rooms, obstacles in the room; $n=15$ ), considering chair placements (i.e., to facilitate seating arrangements; $n=10$ ), and for the interview room to be of an appropriate size (i.e., a size that is not too small to feel oppressive and not too big as to not be intimate; $n=10){ }^{4}$

\section{Beliefs about Context Manipulation Techniques}

Participants were asked about 13 contextual manipulations adapted from Kelly et al.'s (2013) taxonomy. The results are displayed in Table 2. All the proposed manipulations, except conducting the interview in a small room, were perceived as actual interviewing techniques by the majority of respondents. Considering their physical appearance (i.e., wearing formal or casual clothing), the seating distance, and making the room appear warm and comfortable, were reported to be the three most useful techniques, respectively. Conducting the interview in a small room was reported as the least useful technique, followed by the effects of sounds and colors. These two were also the least frequently taught during trainings.

Paying attention to the physical appearance and seating distance were the most reported as being taught during trainings, as well as the most frequently used. Making the room appear warm and comfortable, although rated as third most useful, was one of the least reported as being taught in trainings.

\section{Current Satisfaction with Interview Rooms}

Lastly, 69.2\% ( $n=52$ ) of participants reported not being satisfied with the interview rooms at their current station. Among the participants who provided reasons for why they were not satisfied, the most cited reason was that the rooms were too sterile $(n=11)$, followed by the rooms being too small $(n=6)$, and not having enough options to adapt within the rooms $(n=5)$.

\footnotetext{
${ }^{4}$ Other aspects mentioned for designing an interview room included: creating a setting that is flexible and easy to adapt depending on the suspect and/or circumstances $(n=9)$, a neutral setting $(n=9)$, ensuring auxiliary equipment is functional $(n=9)$, having good conditions, such as ventilation and lighting $(n=6)$, privacy $(n=3)$, comfortable furniture $(n=3)$, and a room that reinforces the investigator's authority or control $(n=3)$. We report these in a footnote as they were cited fewer than 10 times.
} 

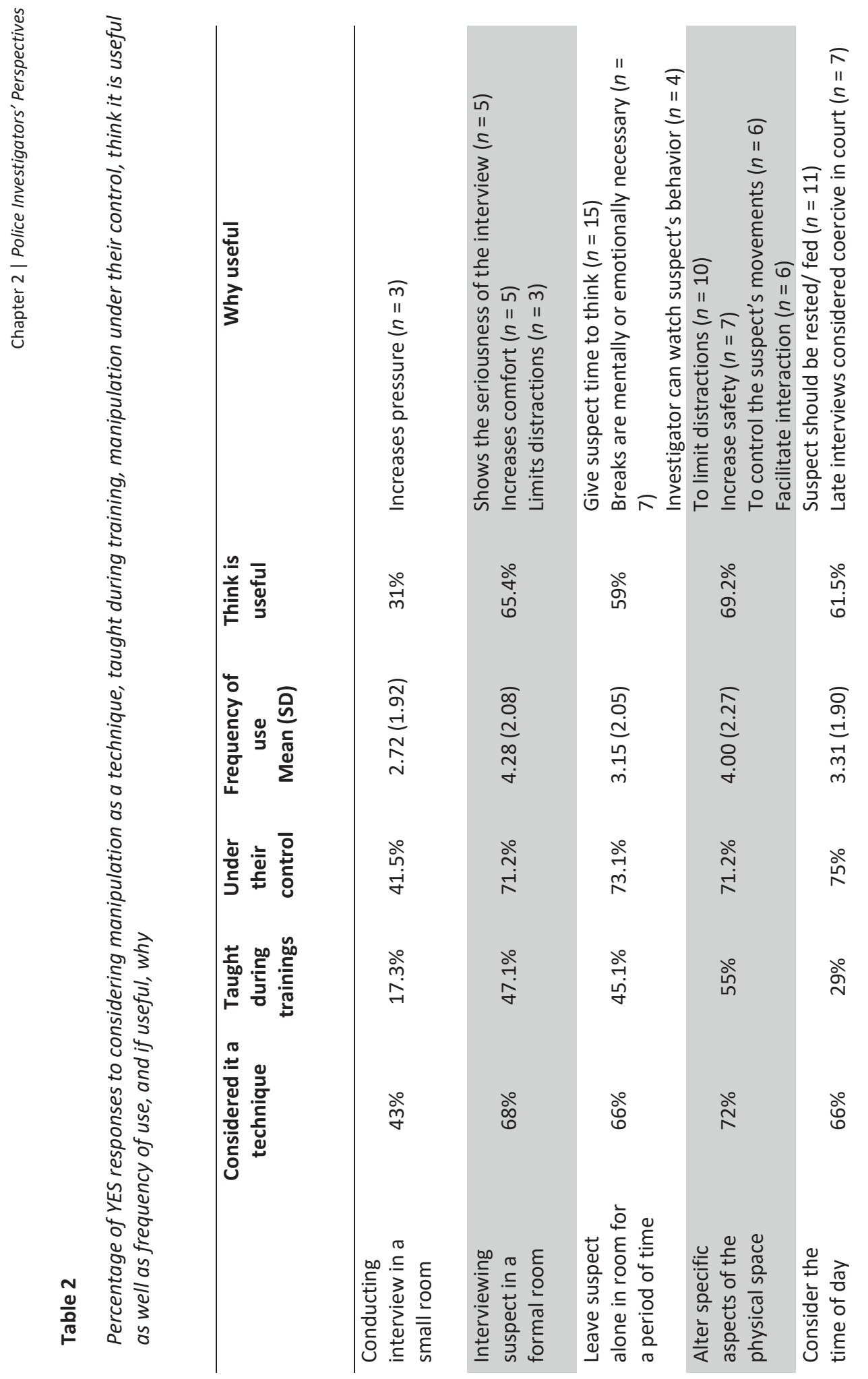


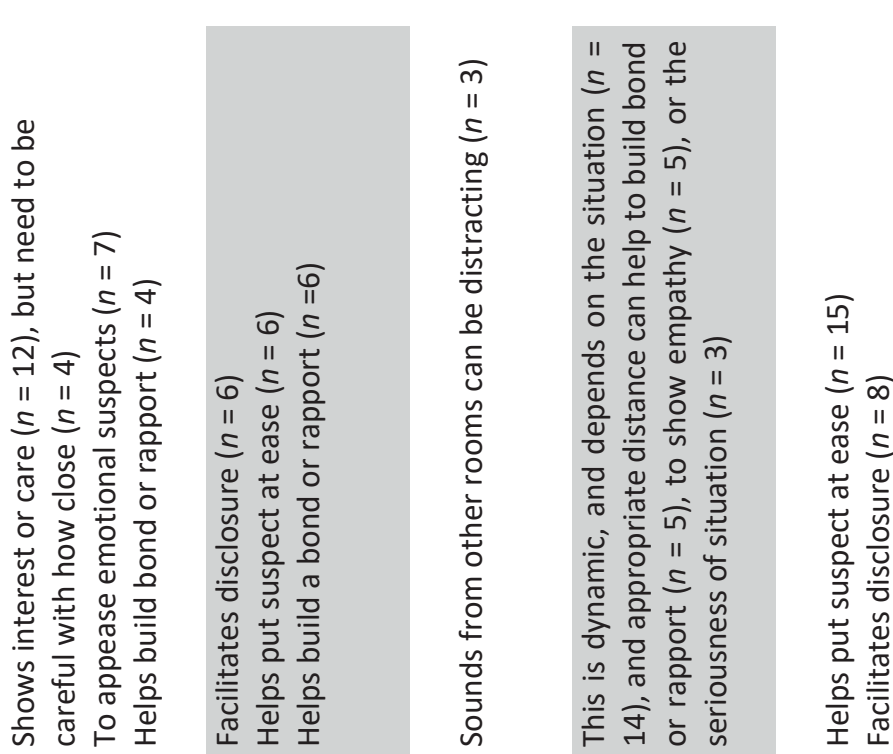

ํํำ

ํํำ

ํํำ

ลำ

$\stackrel{ }{\wedge}$

$a$
$\stackrel{-}{d}$
$\sigma$
$\infty$
$\dot{n}$

ָָ

ज्ञ

옴

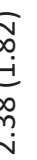

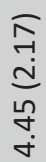

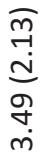

ํํํ

ํํำ

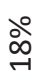

ํํำ

$\stackrel{\text { \̊ }}{\text { Jे }}$

จั

¿̊ำ

$\stackrel{\circ}{\infty}$

ठั่

$\stackrel{\stackrel{\circ}{m}}{\text { ñ }}$

ํํํ

ฌ̊

ํำ

กิ

ํํํ

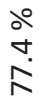

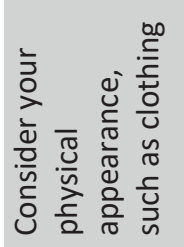

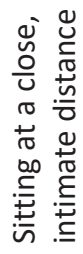

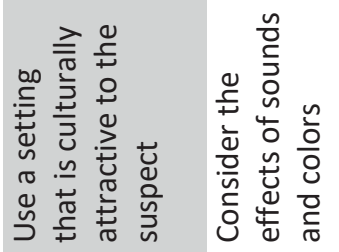

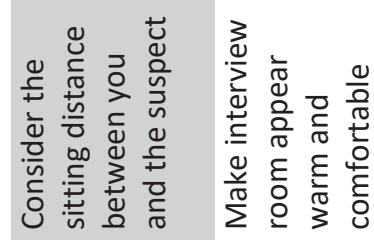




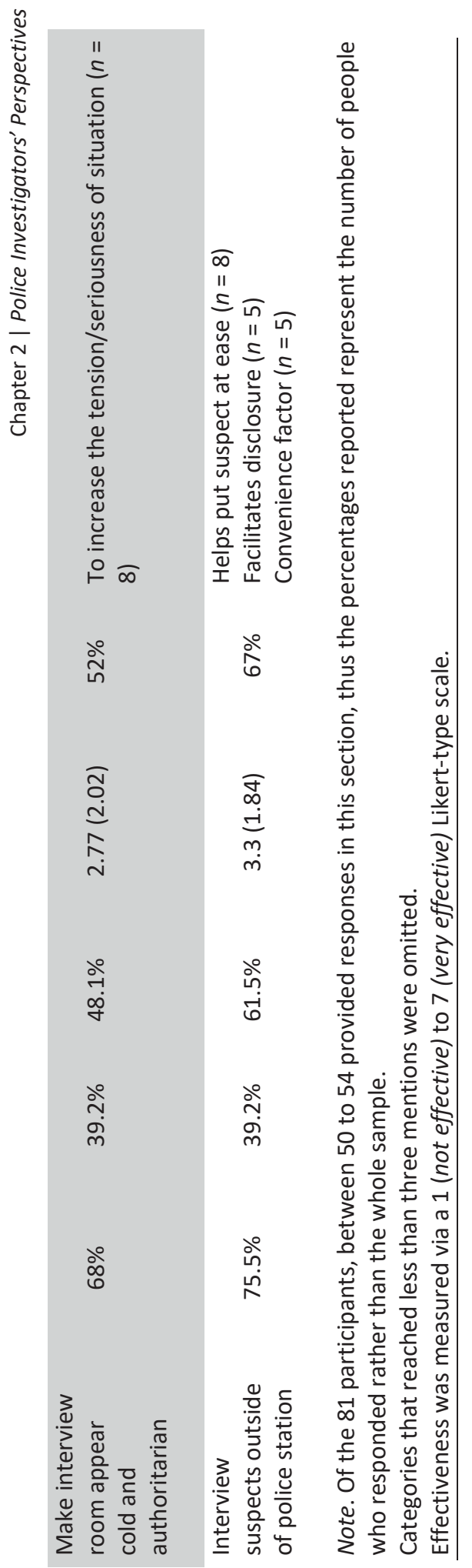




\section{Discussion}

In this survey, we explored police investigators' use of context manipulation techniques and beliefs on their effectiveness. Overall, the majority of respondents indicated the interview setting to be of importance, and to employ a number of context manipulation techniques in their practice, such as considering the seating arrangements, their clothing (i.e., formal vs. casual), and having items such as water and coffee handy to provide suspects with. Investigators also indicated contextual considerations to be effective. More specifically, removing distractions (i.e., no papers, clocks, personal items), considering their clothing, and considering the room's set up (i.e., location of table) were rated as the three most effective contextual considerations.

Regarding the specific context manipulation techniques outlined in Kelly et al.'s (2013) taxonomy, the majority of respondents indicated all but one (conducting interviews in a small room) to be actual techniques, but their usage frequencies were rated moderate to low. This aligns with Kelly and colleagues' (2015) findings, where the context manipulation techniques were reported among the least used. This is not surprising considering how little the context manipulation techniques were reported to be taught during trainings. Actively thinking about, and using contextual aspects of the interview as techniques, may be a relatively recent notion. Rather than thinking of them as techniques, some contextual aspects may be thought of as routine matters (Kelly et al., 2015). Nonetheless, the majority of the techniques were rated to be useful, and while this may be a result of afterthought, it shows that investigators are receptive to the use of context manipulation techniques. Therefore, contextual manipulations could be potential targets for interviewing training reform because of the positive beliefs that investigators already have.

Investigators' responses appeared to align more with an information-gathering approach to interviewing over an interrogative or accusatorial approach (Kelly et al., 2019). For example, making the room "appear warm and comfortable" was reported among the most useful techniques, whereas conducting the interview in a small room was reported as the least useful technique. Further, investigators reported that leaving suspects alone in the interview room was helpful for allowing them time to think and take a mental break from the interview. This alignment with an information-gathering style is noteworthy because, for the most part, the contextual manipulations outlined in existing interviewing manuals, such as Reid, can be interpreted as an attempt to exert control over suspects (Kelly et al., 2019). For example, isolating suspects and interviewing them in small rooms can create a sense of being trapped, instilling a sense of loss of 
control, and lean toward psychological manipulation (Gudjonsson, 2003). Nonetheless, context manipulation techniques can be used to foster a productive investigator-suspect relationship, rather than control, and research examining this idea is moving forward (Kelly et al., 2019).

The results from this survey offer insight into which context manipulation techniques require further empirical examination. For example, based on the contextual considerations most reported, future research should examine what seating arrangements are optimal in an investigative interviewing scenario. While the Reid manual recommends a close proximity and instructs investigators to gradually move closer to the suspect because "the closer a person is to someone physically, the closer he becomes to that person psychologically" (Inbau et al., 2013, p. 283), there is no empirical evidence to support this specific statement, nor the benefits of close proximity more generally. To examine contextual influences, future research will need to tease apart the dynamic nature of interviews, and isolate the effect originating from contextual aspects (e.g., seating arrangements) while controlling for suspects' individual differences and/or other situational factors (e.g., lack of sleep).

Furthermore, this survey offers considerations for (re)designing interview rooms. The majority of investigators reported being unsatisfied with their current interview rooms, mostly due to the rooms' sterility. Considering that investigators spend a significant amount of their working time inside these rooms, future research should explore how such sterile environments affect investigators, their interviewing procedures, and their well-being. When asked what they considered most important for designing an interview room, most investigators mentioned creating a comfortable, informal, or relaxing setting. Creating a more comfortable setting may actually be beneficial for interviewing suspects as well. Goodman-Delahunty and colleagues (2014) found features of the interview setting to be linked to perceptions of non-coercion. Interviews that were conducted in a comfortable setting were associated with an increase in detainees' disclosure of incriminating information. Goodman-Delahunty and colleagues noted that the comfortable setting may have fostered rapport, which in turn facilitated disclosure.

Of note, $77 \%$ of investigators rated making the interview room "appear warm and comfortable" as a useful technique, while, in contrast, 52\% also reported making interview room "appear cold and authoritarian" as useful. This finding may represent a heterogeneity of opinions among investigators, but also suggests that investigators may view the usefulness of the room's coldness/warmth as adaptable between different suspects and interview goals. This speaks for the need for adaptability within the interview context, and lack of adaptability was a reason for 
investigators' dissatisfaction with their current station's rooms. Investigators may only be provided cold and authoritarian spaces without any influence over the room's design. Future research could further examine the characteristics of interviewing settings that investigators would design if they had the influence to do so.

This survey was subject to limitations. First, it was limited in its scope and length. While this was intended to maintain the survey's brevity, some respondents may have needed further explanation of probes, or additional data could have been collected using other methods, such as interviews. Second, we relied on a snowball recruitment method starting with police contacts who had previous experience with other researchers we knew. Therefore, our sample largely comprised investigators who were, to some degree, familiar with the investigative interviewing literature. This could clarify why the responses aligned with an information-gathering (as opposed to accusatorial) style of interviewing. Further, we relied on investigators' self-reports. Studies that use alternative approaches, such as shadowing investigators as they prepare for interviews or observing recorded interviews, are needed to more accurately assess the use of contextual manipulation techniques in actual practice.

In sum, we found that a majority of investigators in our sample believed the interview setting to be of importance, with most investigators already employing some context manipulation techniques in their practice (i.e., considering seating arrangements, their clothing). This highlights the need for future research to consciously and systematically examine how investigators could effectively use context manipulation techniques. Moreover, this survey provides evidence that investigators are receptive to using context manipulation techniques in their practice, as they consider them useful despite how little they are taught during trainings. Communicating evidencebased findings on context manipulations techniques that, to some degree, investigators already employ, or on an aspect that they already consider to have importance, increases the feasibility of investigators incorporating them into their practice 
CHAPTER 3

THE INFLUENCE OF ROOM SPACIOUSNESS ON INVESTIGATIVE INTERVIEWS

This chapter is published as:

Hoogesteyn, K., Meijer, E.H., \& Vrij, A. (2019). The influence of room spaciousness on investigative interviews. Legal and Criminological Psychology, 24(2), 215-228.

https://10.1111/lcrp.12156 


\begin{abstract}
The quality of information obtained from investigative interviews largely relies on the quality of communication between the interviewee and interviewer. One aspect of the communication process that has yet to be well examined is the environment in which the interviews take place. The present study examined the influence of physical spaciousness - manipulated as room size and interpersonal sitting distance between interviewer and interviewee - on the disclosure of crime related information, as well as perceptions of rapport and overall interview experience. Participants engaged in a virtual reality scenario depicting a crime, and were interviewed as suspects in either a larger or smaller room, at a closer or larger distance. Results showed no links between room size or sitting distance on disclosure rates. However, an exploratory analysis did reveal that participants interviewed in the larger room reported a more positive interview experience in terms of spaciousness, and consequently higher perceptions of rapport, compared to those interviewed in the small room. We found no evidence for an influence of room size and interpersonal distance on disclosure. Still, our study does provide initial evidence that manipulating room size in an interview context can positively impact rapport building.
\end{abstract}

Keywords: Investigative interviewing, room spaciousness, context manipulation, disclosure, rapport-building 


\section{The Influence of Room Spaciousness on Investigative Interviews}

The purpose of an investigative interview is to obtain as much accurate information as possible (Shepherd \& Griffiths, 2013). The amount of information disclosed largely relies on the communication process between the investigator and the interviewee (Yeschke, 1997). It is therefore recommended for investigators to develop a positive and constructive dynamic - or rapport - with the interviewee as an important first step during all interviews (i.e., Bull \& Milne 2004; Fisher \& Geiselman, 1992). Through rapport building, investigators are able to develop a relationship with the interviewee, creating an atmosphere that encourages cooperation and supports the task of obtaining information (Abbe \& Brandon, 2013). Rapport consists on showing empathy, personalizing the interview (Fisher \& Geiselman, 1992), as well as engaging in active listening, attentiveness, and friendliness (Collins, Lincoln, \& Frank, 2002).

While rapport building has received substantial attention in the literature and interviewing manuals (i.e., UK's PEACE model for interviewing), one aspect of the communication process that has been neglected is the environment in which the interview takes place. When we communicate, aspects of our environmental surroundings exert an influence on our behavior, and the way we perceive our environment can in turn influence how we communicate with others (Ignatius \& Kokkonen, 2007; Knapp, Hall, \& Horgan, 2013; Lebaron \& Streeck, 1997). For example, a constraint environment can be associated with feelings of discomfort and apprehension, potentially causing us to become distant and withholding, while a warm and inviting environment can help us relax and feel at ease (Knapp et al., 2013). In the present study we specifically examined if and how physical spaciousness - manipulated as room size and interpersonal seating distance - influences rapport-building and the disclosure of information.

The room size and interpersonal seating distance aspects are relevant because of three reasons. First, they are incorporated in investigative interview models. For example, in the taxonomy of interview methods by Kelly, Miller, Redlich, and Kleinman (2013), context manipulation refers to techniques that alter the physical and/or temporal space of the interview room to maximize the probability of a successful interview (i.e., obtaining accurate and reliable information from the interviewee). Examples of context manipulations include considering the size of the interview room, the seating arrangement, the time of the day, and room temperature (see Kelly et al., 2013 for a complete list of proposed techniques). 
Notably, in their taxonomy Kelly and colleagues operationalize the relationship between context manipulation and interview quality as interactive and indirect. Rapport building is at the center of their model (i.e., Abbe \& Brandon, 2013; Vallano \& Schreiber Compo, 2011), which then interacts with the other domains (i.e., evidence presentation, confrontation, collaboration, emotional provocation, and context manipulation). The authors illustrated the importance of context manipulation, encompassing the model, because they argued that the context - or environment - should always be considered. The context can influence the rest of the domains, starting with rapport-building. It is, for example, easily imaginable that a pleasant and comfortable setting can facilitate the interviewer-interviewee dynamic and thereby interview quality.

The second reason that room size and interpersonal seating distance aspects are relevant is because some investigative interviewing guidelines take them into account. For example, the Reid manual recommends the seating proximity between suspects and interviewers to be at a close distance (approximately $1.22 \mathrm{~m}$ ) arguing that sitting physically close translates to feeling psychologically close, creating a more intimate environment conducive to obtaining information (Inbau, Reid, Buckley, \& Jayne, 2013). In line with these recommendations, a police survey showed that conducting interviews in a small, private room was the second highest rated technique out of 16 interview practices used by North American law enforcement officials, with $42 \%$ of respondents stating to always use this technique (Kassin, Leo, Meissner, Richman, Colwell, Leach, \& La Fon, 2007).

Lastly, room size and interpersonal distance are relevant to investigate because they determine physical spaciousness, and spaciousness has been shown to be promising for improving interviewees' affective experience and self-disclosure in the fields of communication and healthcare. Spaciousness can be manipulated through architectural aspects (i.e., room size) and the interior design (i.e., seating arrangement; see Okken, 2013 for a taxonomy of environmental factors). Limited physical space could induce perceptions of crowding and constraint, in turn decreasing interpersonal communication (Sundstrom, 1975). Moreover, a study found that when communicating about intimate topics, participants placed at a closer distance to the interviewer spent less time in self-disclosure than those at a further distance (Johnson \& Dabbs, 1976).

In two studies examining spaciousness, participants were interviewed about intimate topics in either a small or larger room, with a smaller or larger desk (measuring interpersonal distance; Okken, Rompay, \& Pruyn, 2012; 2013). Results showed that the larger room size increased participants' perceptions of spaciousness, and higher perceptions of spaciousness in 
turn led to more positive interview experience. Moreover, the larger room and larger interpersonal distance resulted in higher amount of self-disclosure provided for certain topics.

Despite the established use of environmental techniques in practice and other research fields, to our knowledge only two studies - reported in Dawson, Hartwig, Brimbal, and Denisenkov (2017) - have looked at the effects of environmental manipulations on disclosure specific to investigative interviews. In both studies, participants took part in a mock crime and were subsequently interviewed regarding their involvement. Two interview rooms were examined; a larger and spacious one designed to appeal to their sense of forthcomingness, and a small and enclosed custodial interview room. Results showed that participants who were interviewed in the larger room provided more overall details than those interviewed in the smaller room. Moreover, in one of their studies, these results were mediated by participants' perceptions of spaciousness, so that perceptions of greater spaciousness increased the odds of disclosure. Further, selfreported ratings showed that participants interviewed in the larger room reported wanting to leave less than participants interviewed in the smaller room. Notably, this finding challenges the Reid technique's assumption that a smaller room is more efficient for investigative interviewing by fostering intimacy between the interviewer and interviewee, and eliciting more disclosure (Inbau, Reid, Buckley, \& Jane, 2013).

Theoretically, the aforementioned studies applied an embodied cognition account, which posits that cognition is dependent and shaped by the subjective experience of our body, like the motor system, perceptual system, and interactions with the environment (Dijkstra, Eerland, Zilmans, \& Post, 2014). Essentially, cognition does not begin and end with the brain; rather it draws upon physical experiences. More specifically, an area of embodied cognition focuses on metaphorical thought, and how metaphoric concepts can arise from physical correlates of emotion. As Lakoff (2012) exemplified, feelings of anger cause our skin temperature and blood pressure to increase, therefore, metaphors such as "his blood was boiling" conceptualize the emotion of anger. In this regard, Dawson et al. (2017) proposed that aspects of our physical environment (i.e., spaciousness) can prime cognition in metaphoric ways (i.e., activating concepts of openness), consequently influencing behaviors (i.e., encouraging disclosure). Similarly, Okken (2013) suggested a strong connection between physical experiences and mental concepts. By manipulating the amount of physical space (i.e., room size, interpersonal distance), participants experienced more or less psychological space, which influenced their willingness to self-disclose. 
The purpose of the current study was to take a step towards examining if physical spaciousness improves rapport building and the disclosure of information. Stemming from previous literature, we sought to expand Okken et al.'s $(2012,2013)$ results to an investigative interview setting by manipulating the interpersonal sitting distance between interviewer and interviewee. Moreover, we sought to conceptually replicate Dawson et al.'s (2017) findings of room size and information disclosure, while also examining the influence of spaciousness on rapport building. Given the influence of spaciousness on affective experience in the aforementioned studies, and the robust association between rapport and information disclosure reported in the psycholegal literature, we expected rapport to be a mediator between the spaciousness manipulations (room size and interpersonal distance) and disclosure. That is, participants in the larger room and larger sitting distance conditions would perceive the interview process, as well as the interviewer more positively, hence promoting higher disclosure. Our hypotheses follow as:

Hypothesis 1: Participants in the larger room will rate the interview and interviewer more positively.

Hypothesis 2: Participants in the larger room will disclose more information.

Hypothesis 3: Participants with larger distance between interviewer and interviewee will rate the interviewer and interview more positively.

Hypothesis 4: Participants with larger distance between interviewer and interviewee will disclose more information.

Hypothesis 5: We expected the relationships in $\mathrm{H} 2$ (room size and disclosure) and $\mathrm{H} 4$ (sitting distance and disclosure) to be mediated by rapport building.

\section{Method}

The present study was pre-registered and approved via the Open Science Framework (https://osf.io/rjv8m/). The study was approved by the standing ethical committee of our University.

Design. We used a 2 (Room size: large vs. small) $\times 2$ (Sitting distance: close vs. further) between-subjects design with the following dependent variables: (i) quantity of disclosure, measured by the number of units of information (ii) quality of disclosure, measured by the amount of crime-related details provided. Further, we have the following dependent variables gathered from participants' self-reported data: (iii) perceived room spaciousness, (iv) perceived ease of self- 
disclosure, (v) perceived affective experience, and (vi) perceptions of rapport. We used participants' perceptions of spaciousness as subjective measures alongside our manipulations of room size and sitting distance.

Participants. One hundred and fifty-nine participants were recruited from our university to partake in a study concerning memory for events in exchange for one research credit (SONA Systems) or a $€ 5$ voucher. Out of the total sample, 20 participants had to be excluded due to different reasons, such as knowing the purpose of the study $(n=8)$, poor English proficiency $(n=$ $4)$, not looking at part of the stimulus video $(n=4)$, knowing the interviewer $(n=2)$, and moving their chair during the interview, thus altering their distance conditions $(n=2)$. All decisions about data exclusions were made irrespective to condition and prior to data analysis. Our final sample consisted of 139 participants $^{5}$ ( 25 male and 114 female), with an average age of 21.2 years ( $S D=$ 3.37). Seventy-one were randomly assigned to the small room condition and 68 to the large room condition; 70 participants were assigned to the close distance condition and 69 to the far distance condition.

Procedure. Upon arrival to the lab, participants were greeted by an experimenter who provided the consent form and instructions. All participants were explained that they would participate in a virtual reality task in which they would meet a friend of theirs, and together they were supposed to find a third person. They were instructed to pay close attention to all details. Once participants granted that they understood their objective, they were asked to put on the virtual reality equipment (headset and headphones) and begin the VR experience. In the VR experience, participants found themselves in an alleyway, and were given a minute to familiarize with the environment. Shortly after, they were approached by the friend who began conversing about the previous night, alluding that they were hanging out together. Consequently, a third man approached, looking to cross over to the other side of the alleyway. The friend then proceeded to rob the man of his watch. The man refused to hand over the watch and addressed the participant directly, asking to help control his friend. After this, the friend becomes frustrated and pulls out a gun, demanding the watch to be handed over. Ultimately, the friend pulls the trigger, shooting the victim who falls to the floor. The friend then advises the participant to start running, as he flees the scene. That is the end of the VR experience, which lasted 1 minute and 44 seconds.

\footnotetext{
${ }^{5}$ In our pre-registration we stated we would recruit 100 participants. However, this was due to a power miscalculation. We continued to test participants prior to data analysis after an updated calculation revealed we needed 138 total participants to detect a medium effect size (.3) with power set at .95 and $\alpha=.05$, for a correlation bivariate normal two-tailed model.
} 
Next, participants were randomly allocated to either a small or larger interview room, with either a close or larger sitting distance between them and the interviewer. The experimenter walked the participants to the interview room, informing them they were considered suspects to the crime, and needed to be interviewed. They were also told they would receive an extra $€ 5$ voucher if the interviewer believed them to be innocent; this was to incentivize participants to take the task more seriously. In reality, all participants received the extra voucher. Once the experimenter left, the interviewer (who had no previous contact with the participants) entered the room and began the interview. The interview script included a phase of rapport building, and then proceeded to ask open-ended questions related to the crime. Interviews were audio recorded. After the interview ended, the interviewer left the interview room and the experimenter returned, who then instructed participants to complete a post-interview questionnaire. Participants were also asked both on the questionnaire and by the experimenter if they had been aware of the study's purpose prior to participating (e.g., from a friend who previously participated), assuring them that if they had they would still receive compensation. We used these questions to exclude aware participants from the analyses. Lastly, they were debriefed, thanked, and compensated for their participation.

Interview room manipulation. Following the VR experience, participants were escorted to either the larger or small interview room, which were previously arranged according to the sitting distance condition assigned. The two rooms were not identical in structure (one was squared and the other rectangular) and floor coloring (one had beige tiles and the other had green tiles), however, they both had one desk, a desktop computer, and two chairs, university style fluorescent lighting, no windows, and bare walls. The larger room measured $9.3 \mathrm{~m}^{2}$ (3.72 length $\times 2.5$ width) and the small room measured $5 \mathrm{~m}^{2}$ (2.73 length $\times 2.03$ width). The sitting distances were arranged by the distance between the two chairs (close distance $1.65 \mathrm{~m}$, and further distance $2.10 \mathrm{~m}$ ). These distances were chosen based on what felt natural within the two rooms. The participants always sat on the chair against the wall, to prevent them from moving and altering the distance assigned. The interviewer and participants sat facing each other, with no desk in between them.

Interview. All interviews were conducted by four female trained research assistants. Prior to data collection, interviewers engaged in practice trainings to ensure they were familiar with the script and their behaviors were consistent. Interviewers were instructed to engage in active listening (i.e., using affirmations such as $\mathrm{mhm}$, okay, and eye contact), to speak professionally, and that the conversation should sound natural and fluid throughout the interview. Once interviewers 
entered the room, they introduced themselves by shaking the participants' hands, informed them they would begin the audio recording, and engaged in a structured interview script. The script began with a rapport-building phase where the interviewer asked participants four questions about themselves (i.e., "How is your day going so far?", "How is your experience as a student at [university]", "What year are you in school?", and "What do you want to do with your degree?"). Interviewers were instructed to respond accordingly to each question, but to not self-disclose. Consequently, the interviewer informed participants they were to be interviewed about what happened as a person of interest. The interviewer began with an open-ended question (i.e., "Please tell me from the very beginning to the very end what happened today") and followed up with five more specific questions (e.g., "Please tell me everything you can remember about the crime-scene/victim/people involved in the crime/conversation that took place/shooting"). After each question, participants were prompted once with "Is there anything else you remember?" On average interviews lasted 7 minutes and 24 seconds $(S D=2.48)$, of which the average time spent on rapport was 63 seconds $(S D=36)$.

Disclosure. Disclosure was measured by the quantity and quality of the statements. For quantity of information we looked at word count and total units of useful information. For example, the following sentence: "I was standing in an alleyway, and I was meeting a friend. And we were going to go for a walk" had three units of information. Regarding quality of information, we coded crime-related details, such as details specific to the description of the shooter (i.e., clothing, gender). For example, the following statement: "[...] I believe there was only one gunshot. So it was only shot the once. [The gun was] held sort of hip-ish height, so it wasn't sort of aimed upright or anything. It was definitely a threatening position" was coded as having four crime-related details. Two research assistants were trained on coding using a random subsample of the responses; coders discussed any discrepancies they encountered until they reached an acceptable interrater reliability. Consequently, one main coder, blind to the conditions, coded all participant responses, and the second randomly coded $20 \%$ of the sample. Both coders reached acceptable agreement for total units of information provided, average measures intraclass correlation coefficient (ICC $=.87)$, and total of crime-related details (ICC $=.85)$.

Interview experience. All participants were asked to complete a self-report questionnaire about their perception of the room setting, how they felt throughout the interview, and how they perceived the rapport with the interviewer. Adapted from the questionnaire used by Okken et al. (2012), perceived room spaciousness was measured using the items: "I feel confined inside this 
room," "I have enough freedom of movement inside this room," "I would easily feel suffocated inside this room" and "I was physically comfortable throughout the interview". The items were added up to provide an overall room spaciousness-measure, which reached acceptable internal consistency with a Cronbach $\alpha$ of .71. Perceived ease of self-disclosure was measured with the items: "Inside this room I felt able to speak freely," "I felt uncomfortable providing information inside this room," and "I felt inhibited from speaking inside this room," and averaged for one selfdisclosure measure $(\alpha=.77)$. To measure participants' affective experience, an affect-measure was used comprising the items: "Inside this room, I feel at ease," "I feel uncomfortable inside this room," and "This room gives me a pleasant feeling" ( $\alpha=.77)$.

To examine participants' perceptions of the interpersonal distance, we included the following self-report questions: "I liked the distance between me and the interviewer", "The sitting distance made it easier for me to talk to the interviewer, "I would have preferred to be seated at a larger distance to the interviewer", and "I would have preferred to be seated at a closer distance to the interviewer". All questions were rated on a seven-point Likert-type scale (1 = low amount of characteristic, 7 = high amount of characteristic).

To measure rapport, we used a measure containing all items of the interaction questionnaire by Vallano and Schreiber Compo (2011). The questionnaire is comprised of an interviewer and interaction subscales, for a total of 27 rapport-related characteristics $(\alpha=.87)$. The questionnaire is rated on a seven-point Likert-type scale (1 = low amount of characteristic, $7=$ high amount of characteristic). Participants used the interviewer subscale to rate the interviewer on characteristics, such as friendliness and positivity. The interaction subscale was used to rate the interaction on characteristics, such as cooperativeness and coordination.

\section{Results}

\section{Self-report}

\section{Room size and interview experience}

We hypothesized that participants interviewed in the larger room would rate the interview and interviewer more positively $(\mathrm{H} 1)$. We conducted Pearson bivariate correlations between room size on perceptions of spaciousness, ease of disclosure, affective experience, and rapport (displayed in Table 3). We did not find a correlation between room size and rapport $(r=.000, p=$ $.999)$. 
However, as expected, we found that room size was correlated with perceived spaciousness $(r=.215, p=.011)$, participants in the larger room $(M=19.14, S D=4.22)$ reported more overall spaciousness comfort compared to those in the smaller room $(M=17.28, S D=4.59$, $t(139)=-2.51, p=.013, d=0.42)$. Similar to Dawson et al. (2017), we also found that participants interviewed in the small room $(M=4.24, S D=1.34)$ reported wanting to leave more than those in larger room $(M=3.40, S D=1.64, t(139)=3.27, p=.016, d=0.56)$.

\section{Table 3}

Correlations between room size and interpersonal distance on perceptions of spaciousness, ease of disclosure, affective experience, and rapport.

\begin{tabular}{lcccc} 
& \multicolumn{2}{c}{ Room Size } & \multicolumn{2}{c}{ Interpersonal Distance } \\
\hline & $r$ & $p$ & $r$ & $p$ \\
Spaciousness & .215 & .011 & -.055 & .522 \\
Ease of Disclosure & -.060 & .486 & -.066 & .442 \\
Affective Experience & .142 & .096 & -.057 & .502 \\
Rapport & .000 & .999 & -.071 & .409
\end{tabular}

Additionally, we found that participants' perceived spaciousness correlated with perceptions of ease of disclosure $(r=.544, p=.000)$ and affective experience $(r=.694, p<.001)$, thus suggesting that participants in the larger, as opposed to the smaller room felt more overall comfort throughout the interview. Notably, perceived spaciousness and rapport were also significantly correlated $(r=.362, p<.001)$.

\section{Interpersonal distance and interview experience}

We expected participants interviewed at a larger interpersonal distance would perceive the interview and interviewer more positively (H3). We found no significant correlations between the sitting distance and the rest of the measures, including rapport (Table 1). Therefore, we rejected our third hypothesis. ${ }^{6}$ However, participants in the closer distance condition reported

\footnotetext{
${ }^{6}$ Similar effects were found when conducting a MANOVA with room size and sitting distance as independent variables, and perceived spaciousness, ease of disclosure, affective experience, and rapport as dependent variables. We found no significant interaction between room size and distance condition, Wilk's $\lambda=.99, F(4,132)=.11, p=.98$,
} 
preferring to sit at larger distance to the interviewer $(M=2.99, S D=1.39)$ than those in the larger distance condition $(M=2.52, S D=1.26, t(137)=-2.06, p=.041, d=.35,95 \% \mathrm{Cl}[-.91,-.02]$. This provides some indication that participants did perceive the smaller distance as less comfortable than the larger.

\section{Disclosure}

\section{Room size and disclosure}

We expected participants in the larger room to provide more disclosure than those interviewed in the smaller room (H2). The correlations between room size and the disclosure measures were all non-significant (see Table 2). Additionally, participants' perceived spaciousness did not significantly correlate with word count $(r=-.144, p=.091)$, total units of information ( $r=$ $.016, p=.849)$, or crime-related units of information $(r=-.010, p=.908)$.

\section{Interpersonal distance and disclosure}

Furthermore, we hypothesized that participants interviewed with a larger interpersonal distance between them and the interviewer would provide more information ( $\mathrm{H} 4)$. We found no evidence for this; interpersonal distance did not significantly correlate with any of the disclosure measures (see Table 4), and thus we rejected our fourth hypothesis.

partial $\eta^{2}=.003$. There was a significant multivariate effect of room size, Wilk's $\lambda=.90, F(4,132)=3.54, p=.009$, partial $\eta^{2}=.097$ and no multivariate effect for interpersonal distance, Wilk's $\lambda=.99, F(4,132)=.23, p=.92$, partial $\eta^{2}$ $=.007$. In follow up ANOVAS, we only found a significant effect of room size on perceived spaciousness, $F(1,132)=$ $6.66, p=.011$, partial $\eta^{2}=.047$. 


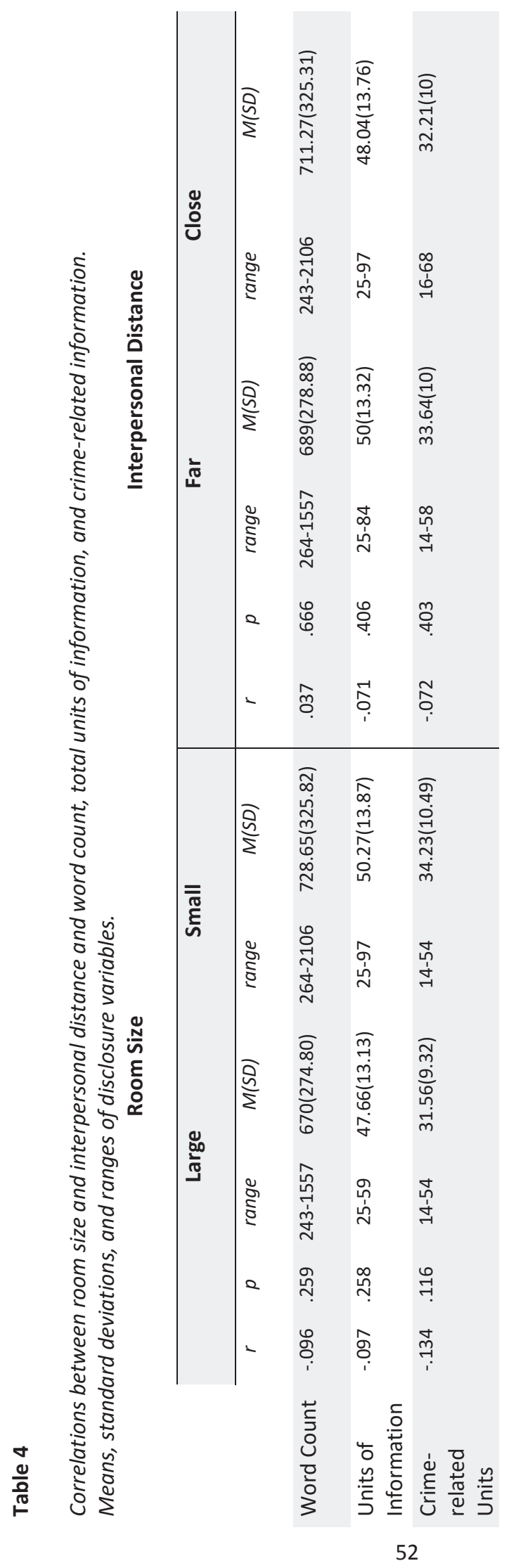


Lastly, since we did not find an association between room size or interpersonal distance and any of the disclosure measures, we did not conduct a mediation analysis with rapport as mediator. Thus, our fifth hypothesis was also rejected.

\section{Exploratory Analyses}

Because we found a significant correlation between room size and perceived room spaciousness, and a significant correlation between perceived spaciousness and rapport, we decided to run a mediation analysis with room size as our predictor, perception of spaciousness as our mediator, and rapport as our outcome, the different interviewers were added as covariates in this model (Figure 3). Results indicated that room size was a significant predictor for perceived spaciousness (path a') and that perceived spaciousness was a significant predictor for perceptions of rapport (path $\left.b^{\prime}\right)$. Room size was not a significant predictor of rapport when controlling for the mediator, perceived spaciousness, which is consistent with full mediation (path a* path b). Therefore, participants perceived rapport more positively, when they also perceived the room spaciousness more positive. We tested the mediation using the PROCESS macro for IBM SPSS (Preacher \& Hayes, 2008). PROCESS uses a nonparametric resampling procedure with $n=5,000$ bootstrap resamples to derive a $95 \%$ confidence interval and a point estimate for an indirect path. This technique yielded confidence intervals that did not include zero, therefore suggesting that perceptions of rapport were mediated by perceived spaciousness. 


\section{Figure 3}

Mediation model with room size as predictor, perceived spaciousness as mediator, and rapport as outcome variable. Interviewers were added as covariates.

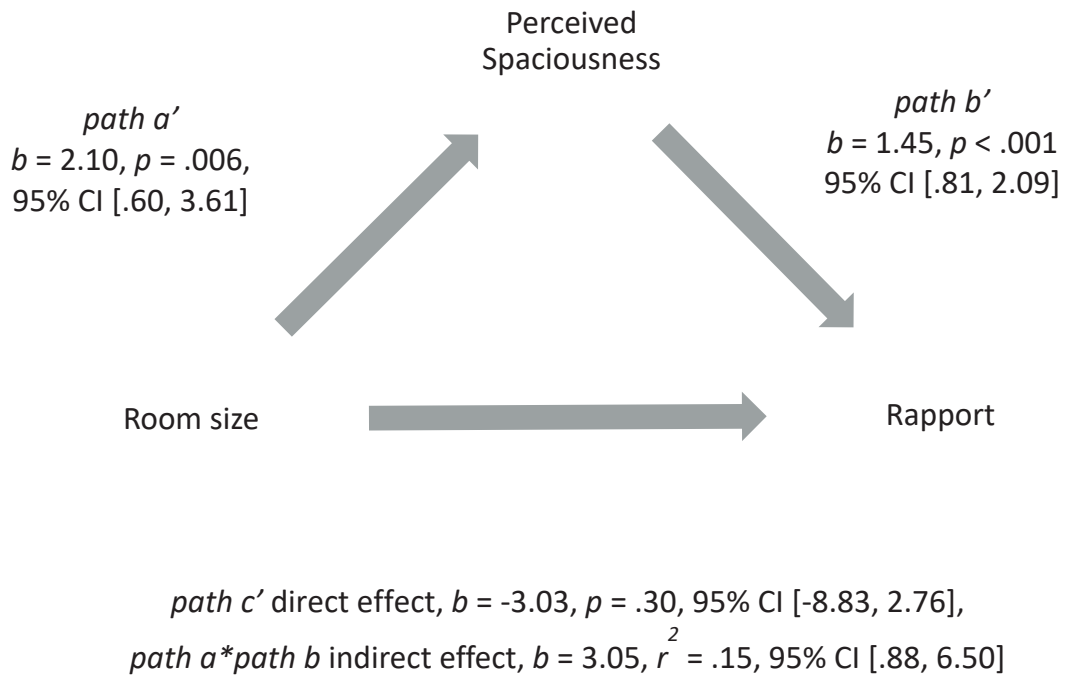

\section{Discussion}

We found that our manipulations of spaciousness (room size and interpersonal distance) did not result in significantly different perceptions of rapport, or in an increased disclosure rate. An explorative analysis revealed that room size was positively associated with rapport via perceived spaciousness. At minimum, the findings suggest that our room size manipulation was effective in affecting participants' perception of room spaciousness, and that this perception of spaciousness is in turn associated with positive rapport building. These results contradict the Reid technique's assumption that smaller rooms foster closeness with the interviewer (Inbau et al., 2013). This also highlights the importance of considering the interviewees' perceptions and personal experience in relation to their comfort and overall interview experience.

We did not find the hypothesized influence of room spaciousness on disclosure of crimerelevant information, thus failing to replicate Dawson et al.'s (2017) findings. While our study differed from Dawson et al.'s in several aspects, the core elements were consistent. We had similar sample sizes, lab-based paradigms (involvement in a mock crime by delivering a flash drive with sensitive information vs. involvement in a shooting via VR), and in both studies disclosure was measured by total details and crime-related (or critical) details. Most importantly, room 
spaciousness was successfully manipulated in both lab studies via room size, with participants interviewed in the larger room conditions reporting more positive perceptions of spaciousness.

Given the disparate results, more studies are needed to establish if spaciousness can indeed facilitate disclosure in an investigative interviewing context. Particularly, future studies should carefully examine the mechanisms behind the effect. Dawson et al.'s (2017) approach stemmed from a metaphoric priming approach, however, such priming research should be approached with caution, as it has generated substantial scepticism in the social psychology field due to failures to replicate (e.g., Bower, 2012; Camerer et al., 2018; Verschuere et al., 2018; Yong, 2012). For example, in an effort to replicate Dawson et al.'s (2017) findings and other well-known priming measures, Dianiska and colleagues (2019) examined the influence of lexical (i.e., word scrambles related to openness concept), contextual (e.g., room decorative posters depicting open settings) and embodiment primes (e.g., interviewers' open or closed off body postures) on information disclosure, failing to find convincing evidence of their influence.

Our results need to be interpreted in the light of several limitations. First, given our experimental paradigm, ecological validity is limited. The mock crime and subsequent interview may have failed to elicit feelings of discomfort associated with a police interview. Similarly, the rooms we used were within the university, and thus familiar for the participants. This may have affected participants' initial comfort levels, expecting them to already feel comfortable in a familiar environment.

Another point qualifying the conclusion that there was no influence of seating distance is that the two distance conditions we employed may not have differed enough to elicit differences. Research on proxemics suggests there are four different interpersonal distance zones which people choose, often unconsciously, depending on how intimate they want the interaction to be. Those zones include the intimate ( 0 to $0.5 \mathrm{~m})$, personal $(0.5$ to $1.2 \mathrm{~m})$, social $(1.2$ to $3.7 \mathrm{~m}$ ) and public (greater than $3.7 \mathrm{~m}$ ) zones (see Hall, 1990). Our interpersonal distance manipulations of $1.65 \mathrm{~m}$ and $2.10 \mathrm{~m}$ were both in the social zone. Future studies may derive more from proxemics research by employing a larger range of distances to determine what is more appropriate for police interviewing practices. For example, by directly testing the Reid manual's recommendation of $1.22 \mathrm{~m}$, which lies closer to the personal zone according to Hall (1990). Besides examining different distances, future studies could examine different seating arrangements. In our study, participants were seated against a wall with the interviewer directly in front of them. It is possible for such an arrangement to hinder positive perceptions of spaciousness and overall comfort. 
Further, in this study we primarily focused on examining if spaciousness influenced participants, and not the interviewers. The interviewers in our study were aware of the participants' conditions (from the room size and interpersonal distance). In our method section we noted that the interviews were highly scripted, and we found no effect of interviewer on our outcomes, nonetheless, it is necessary for future research to examine if and how the environment influences the interviewers' behavior.

Lastly, in this study we expected spaciousness to positively influence participants' perceptions of rapport, and higher rapport to lead to higher information disclosure (H5). We hypothesized this mediation due to the association between spaciousness and affective experience (i.e., comfort, ease of disclosure) from previous studies (e.g., Okken et al., 2012, 2013), yet how rapport and elements of affective experience interplay remains to be empirically established. Currently, the literature on rapport lacks a consensus of what interviewees consider rapport to be, and thus there is room to explore how other aspects - such as physical comfort relate to the construct of rapport. This presents an avenue for future research.

In sum, our simulation study yielded a lack of evidence for an influence of room size and interpersonal distance on disclosure. Still, our study does provide initial evidence that manipulating room size in an interview context could positively impact rapport building. Moreover, the effect on rapport was mediated by perceived spaciousness. This suggests that simple manipulations like increasing merely the perceived spaciousness may positively affect the interview. In this study we looked at room size and seating distances, yet there are other aspects related to architecture and interior design - that influence interviewees' perceptions of spaciousness which remain to be tested within an investigative interview context, for example lighting (Okken et al., 2013; Gifford, 1988) as well as the room's color (Oberfel et al., 2010) and ceiling height (Meyers-Levy \& Zhu, 2007).

Environmental manipulations can be feasible to implement, offering simple tactics for improving the interviewing process, while steering away from problematic accusatorial techniques. Environmental factors can be considered when constructing or re-modeling interview rooms, and through training practitioners on how to use the environment to their advantage, these factors have the potential to offer practical recommendations that could aid in rapport building effort. 


\section{CHAPTER 4}

\section{EXAMINING WITNESS INTERVIEWING ENVIRONMENTS}

This chapter is published as:

Hoogesteyn, K., Meijer, E.H., \& Vrij, A. (2020). Examining Witness Interviewing Environments.

Journal of Investigative Psychology and Offender Profiling. Advance online publication.

https://doi.org/10.1002/jip.154 


\begin{abstract}
The literature on the disclosure of information in psycholegal settings has predominantly focused on the dynamic between the investigator and the interviewee, while little attention has been given to the environment in which the interview takes place. The present study compared the impact of two interview locations on the disclosure of crime-related information and perceptions of rapport building. Participants experienced a virtual reality mock crime, and one week later were interviewed at either their homes, or in a formal room akin to a real-world police interview room. Participants in the home interview setting reported feeling more at ease and in control than participants interviewed in the formal interview room. However, we found no differences between conditions on the quantity and quality of information disclosure and participants' perceptions of rapport building. Based on our findings, we found no advantages or disadvantages for conducting witness interviews at their homes. However, these results underscore the practicality of interviewing witnesses outside the police interview room if deemed more convenient.
\end{abstract}

Keywords: Witness interviews, interview environment, interview location, information disclosure, rapport-building. 


\section{Examining Witness Interviewing Environments}

Many authors have argued that the main goal of an investigative interview is to gain as much reliable information as possible (Evans et al., 2010; Shepherd \& Griffiths, 2013; Vrij et al., 2017). To achieve this, investigators must create an atmosphere that promotes the disclosure of information, for example, by employing tactics such as rapport-building and by asking appropriate, information-gathering questions (Vallano \& Schreiber-Compo, 2011). While most of the literature on maximizing information disclosure has focused on the verbal and non-verbal communication between investigator and interviewee, little research has examined how the interview environment may help in eliciting information.

The environment in which an interview takes place affects its quality. This has been investigated in fields outside of legal psychology. For example, studies in the healthcare field found that clients' self-disclosure about personal topics was substantially higher in a 'soft', intimate room (decorated with pictures, comfortable chairs, soft-lighting) than in a 'hard', nonintimate environment (block walls, uncomfortable chairs, fluorescent lighting; Chaikin et al., 1976) Another study indicated an influence of room décor on interpersonal communication, with a room decorated more home-like (as opposed to office-like) fostering more communication concerning general and intimate topics (Gifford, 1988). Gifford argued that a homey décor is not just more physically comfortable, but can also be more psychologically comfortable, inducing a sense of shelter that is associated with home. The overarching model in these studies is that comfortable, pleasant environments encourage more social interaction (Gifford, 1988).

It may well be possible that the effects of environment on interview quality in healthcare settings translate to investigative interview scenarios. For example, in a study evaluating highvalue detainees' perceptions of coercive and non-coercive strategies for eliciting cooperation, Goodman-Delahunty and colleagues (2014) found the physical setting to be linked to perceptions of non-coercion. Detainees self-reported that interviews that were conducted in a comfortable setting were associated with an increase in their disclosure of incriminating information. The authors note that the comfortable setting may have fostered rapport, which in turn facilitated disclosure. In addition, across two studies, Dawson and colleagues (2017) found the physical spaciousness of the interview room to foster information disclosure regarding a mock terrorism conspiracy. In the present study we will expand the literature to a witness scenario. 
Aside from specific aspects of the interview room, another environmental factor of interest is interview location. Investigative interviews do not always take place in formal rooms inside police stations, particularly interviews conducted with witnesses (Fisher \& Geiselman, 1992). According to a national review of interviewing practice in the UK, it is common to conduct interviews at witnesses' homes and workplaces (Clarke \& Milne, 2001). The introduction of bodyworn cameras by frontline officers also allows witness interviews to be conducted in several different environments, including homes, roadsides and workplaces. By using cameras to audio and video record the interviews, officers can focus on maintaining the flow of the information disclosure (Westera et al., 2011), while also obtaining more complete witness accounts with stronger evidentiary value (Westera \& Powell, 2015) .

The UK's College of Policing also recommends investigators to thoroughly consider the interview's location prior to the interview, and how the interview rooms' formality may affect witnesses (College of Policing, 2013). Akin to the healthcare studies outlined above, home-like interview settings could be more effective for information disclosure as opposed to interviews conducted in formal and scarcely decorated police stations. Although we know that in practice police interviews take place in the field, little to no scientific research has specifically examined the potential advantages or disadvantages of conducting witness interviews outside the station. Therefore, in the present study we aimed to compare disclosure in interviews conducted at participants' homes to interviews conducted in a more typical, formal room resembling a police interview room.

A second aim of this study was to examine how the interview location influences witnesses' perceptions of rapport. Rapport-building has received substantial attention in the psycholegal literature, emphasizing its importance for improving the quality of communication and disclosure of information between witnesses and investigators (e.g., Clarke \& Milne, 2001; Collins et al., 2002; Fisher \& Geiselman, 1992; Gudjonsoon, 2003; Powell et al., 2005). Rapportbuilding consists of showing empathy, personalizing the interview (Fisher \& Geiselman, 1992), as well as engaging in active listening, attentiveness, and friendliness (Collins et al., 2002). The goal of rapport building is to develop a positive and constructive investigator-interviewee relationship, creating an atmosphere that encourages cooperation and supports the task of obtaining information (Abbe \& Brandon, 2013; Collins et al., 2002; Hartwig et al., 2005). Rapport has been shown to increase the likelihood as well as the accuracy of disclosure from witnesses (Vallano \& 
Schreiber-Compo, 2011; Alison et al., 2013; Kieckhaefer et al., 2014). In practice, police officers also acknowledge the vital role of establishing rapport (e.g., Kassin et al., 2007; Kelly et al., 2015).

To date, the literature on rapport has mainly focused on the communication between the witness and investigator, but has neglected the role of the physical environment in which the interaction occurs. Altman (1990) discussed the conceptualization of rapport, suggesting it to be a contextual phenomenon that varies according to the relationship of the individuals involved, the social context, and the physical context. Different physical contexts do not necessarily cause changes in rapport, but rather, individuals develop rapport that is appropriate to different contexts. According to Altman (1990), social relationships are linked to the physical environments in which they occur, where the environment contributes to the social dynamic. Thus, the development and establishment of rapport varies across different physical contexts. This raises an interesting question of how investigators and interviewees perceive and develop rapport in different interview environments.

A third exploratory variable of interest relates to anxiety and whether participants interviewed at home experience less state - or situational - anxiety compared to those placed in a formal environment. Anxiety can be prompted by the fear of being in police custody, in view of the police investigation, and/or by phobic symptoms, such as claustrophobia (Geijsen, 2018). Since stress and anxiety can interfere with a witness' ability to recall an event (Resiser, 1980; Kieckhaefer et al., 2014), some interview protocols (e.g., the Cognitive Interview) take into consideration the situational anxiety that witnesses may experience (Fisher et al., 1989). A key assumption is that a relaxed and comfortable witness will be more compliant and cooperative than an anxious and uncomfortable witness, and therefore a relaxed and comfortable witness will try harder to recall the event. For that reason, it is recommended that interviews be conducted in pleasant surroundings (see Collins et al., 2002).

An example of pleasant surroundings are the "soft" police interview rooms some police stations have. Feld (2014) interviewed US police officers who distinguished between interviews conducted with juveniles in "hard or cold" and "soft and warm" rooms. The "hard and cold" rooms were bare, stark, and small, resembling what is typically depicted in police television shows, primarily used for suspect interviews. The "soft and warm" rooms were furnished with rugs and comfortable sofa chairs to provide a more relaxed setting for witnesses and victims. Similarly, according to the Oregon Interviewing Guidelines for children, the interview setting should aim to reduce the stress inherent to being interviewed by the police, and facilitate the disclosure of 
information (Bohannan, 2004). However, guidelines on what makes a child friendly environment are scarce (Newlin et al., 2015), and even then, the few sources available on interviewing environment, anxiety, and memory performance have mostly focused on child rather than adult testimonies.

The detrimental effects of anxiety on memory are also evident from the literature on the benefits of rapport-building, which suggests that rapport aids witness recall as it reduces the anxiety associated with being interviewed by the police (e.g., Almerigogna et al., 2007; Vallano \& Schreiber-Compo, 2011, 2015). Therefore, we were interested in testing whether interview location served as another aid for managing witness anxiety levels. Given that home-like environments are associated with more ease and comfort (e.g., Gifford, 1988), we expected witnesses interviewed at home to report less situational anxiety coming into the interview scenario compared to those interviewed in the formal environment.

Thus, in the present study we examined the influence of the physical environment in witness investigative interviews by comparing interviews conducted in two different locations; witnesses' homes and a more formal police interview room. Our hypotheses are as follows:

Hypothesis 1 - Participants interviewed at their home will provide more critical and more complete information than those interviewed in the formal interview room.

Hypothesis 2 - Participants interviewed at their home will perceive rapport with the investigator more positively than those interviewed in the formal interview room. Hypothesis 3 - Participants interviewed at their home will experience less state anxiety than those interviewed in the formal interview room.

\section{Method}

\section{Design and Participants}

Participants were interviewed either at their own home or in a formal interview setting about a virtual reality (VR) experience. The dependent variables were: (i) quantity of disclosure measured by the number of units of information, (ii) quality of disclosure, measured by the number of crime-related details provided and statement completeness, (iii) perceptions of rapport, and (iv) state anxiety index. Given the applied nature of our research question, we aimed to achieve enough power to detect a large effect size. Based on a G*Power calculation, given alpha $=.05$, and power $=0.95$ the projected sample size needed for a large effect size $(.80)$ was approximately $N=70$. Eighty-six student and staff members (staff were administrative and naïve to forensic psychology research) were recruited from a university. Twelve participants had to be 
excluded from the analysis due to dropping out after the first session $(n=9)$, and not looking at parts of the virtual reality video $(n=3)$. All exclusions were removed prior to data analysis. The final sample consisted of 74 participants (35 in the home condition, 39 in the formal interview room condition); six of the participants were staff members. Participants' age range was 18 to 51 years $(M=21.70$ years, $S D=6.21)$, and the majority were women (53 women, 21 men).

\section{Procedure}

This study was reviewed and approved by the standing ethical committee at Maastricht University. Participants were recruited via the University's recruitment system (SONA Systems) or via email invitations and signed up either for one SONA credit or a $£ 5$ gift card. All participants signed up for two sessions, one week apart and were randomly assigned to one of the two interview settings (i.e., own home vs. formal interview setting). In the first session, all participants provided written consent and engaged in the VR scenario, which depicted an attempted robbery and shooting.

Prior to starting the VR scenario, participants were told that in the scenario they would meet a close friend, and that together they would look for a third person. At the beginning of the scenario, participants found themselves in an alleyway. They were given a minute to familiarize themselves with the environment before they were met by the alleged friend. The friend proceeded to converse about last night and how they had fun, insinuating that they were indeed friends. Shortly after, a third man approached, and the friend proceeded to talk to the man about his watch, attempting to rob him. The man refused to hand over the watch and addressed the participant directly, asking to help control his friend. After this, the friend became frustrated and pulled out a gun, demanding the watch to be handed over. Ultimately, the friend pulled the trigger, shooting the victim who fell to the floor. The friend then advised the participant to start running, as he fled the scene. After the VR portion, participants were reminded they would be interviewed about what they witnessed in the following week and were given a reminder sheet with their appointment date and the location, either at their home or the formal interview room.

On the day of the interview, participants arrived at the formal interview location, which was located at the University's Center for Forensic Interviewing, or the investigator met the participants at their homes. The formal interview room was bare, with a large window (blinds kept closed to avoid distractions), a one-way mirror, two purple single sofa chairs, and a small table in between. Upon arrival, participants filled out the state anxiety portion of the State Trait Anxiety 
Inventory (STAI; Spielberger et al., 1983). All participants were then interviewed by the same investigator who was female, in her mid-twenties and had no prior interaction with any of the participants. The investigator was not blind to the study's purpose or conditions. All interviews were conducted according to a structured protocol and a script to reduce variability between the interviews. The investigator interviewed all participants in a information-gathering interview style, which began with a rapport-building phase by asking four scripted, general questions derived from Kieckhaefer, Vallano, and Schreiber-Compo (2014; i.e., "How is your day going?”, "How is your experience at the university"?, "What year are you in school?", and "What do you want to with your degree?"). The investigator responded to each answer accordingly without self-disclosing.

The investigator then moved to the questioning phase, using a standardized script that consisted of seven open-ended non-suggestive questions. The investigator began by asking the witness to tell from the very beginning to the very end what had happened, followed by a series of cued questions asking about everything they could remember about the crime scene, the victim, the people involved in the crime, and the conversation that took place during the crime. The investigator then asked participants about their involvement in the crime ("I understand you were involved in the [shooting/or crime if they did not mention shooting]. Could you tell me more about that?") and finished the interview by asking if there was anything else the participant would like to share about what happened. After each question, participants were probed once with "Is there anything else you remember about [the victim/the conversation/etc.]". The investigator was instructed to engage in active listening (i.e., using affirmations such as $\mathrm{hmm}$, okay) throughout the entire interview. All interviews were audio recorded for transcribing and coding purposes. Once the interview was completed, participants filled out a rapport focused questionnaire and a questionnaire regarding their general experience throughout the interview. Lastly, they were thanked and compensated for their participation.

\section{Materials}

Rapport questionnaire. We measured rapport via the interaction questionnaire developed by Vallano and Schreiber Compo (2011). The questionnaire contains 27 rapport-related characteristics rated on a 7-point Likert-type scale ( $1=$ low amount of characteristic, $7=$ high amount of characteristic). Participants rated the level of rapport they experienced with the investigator, including characteristics such as friendliness and positivity. They also rated the level of rapport pertaining to the interaction between themselves and the investigator, including 
characteristics such as cooperativeness and coordination. After some items were reverse coded, we aggregated all 27 questions to obtain an overall rapport measure (Cronbach's $\alpha=.91$ ).

Interview experience questionnaire. The questionnaire was adapted and extended from Okken, Van Rompay and Pryun (2013), and included the following queries: "I felt confined in this environment", "I would easily feel suffocated in this environment", "I was physically comfortable throughout the interview", "I felt uncomfortable providing information in this environment", "In this environment I feel able to speak freely", "I felt inhibited from speaking in this environment", "I felt at ease in this environment", "I felt uncomfortable in this environment", "In this environment I felt in control", "I felt like leaving this environment", and "This environment gives me a pleasant feeling". These questions were rated on a 7-point Likert-type scale ( $1=$ low amount of characteristic, 7 = high amount of characteristic), and analyzed as individual variables.

State-Trait Anxiety Inventory (STAI). The STAI is a measure of state and trait anxiety for adults (Spielberger et al., 1983). Form Y-1 consists of 20 state anxiety items, evaluating the current state of anxiety, using items that measure subjective feelings of apprehension, tension, nervousness, worry, and activation/arousal of the autonomic nervous system (e.g., 'I am presently worrying over possible misfortunes', 'I feel secure'). All items were rated on a 4-point Likert scale $(1=$ not at all to $4=$ very much so $)$. We aggregated all 20 items into one overall anxiety measure ( $\alpha$ $=.86$; a number of items were reverse-coded).

\section{Disclosure}

Participant statements were coded for quantity of information, determined by the total units of information provided. For example, the statement: "I was in an alleyway, I recognized it was an alleyway because the big tall buildings either side, brick buildings that, and there was some garbage and rubbish bins", contained five details. We also coded for quality of the statements based on the number of crime-related details provided (i.e., details such as descriptions of the shooter, conversations between shooter and victim). For example: "[...] I would say he was wearing jeans and some sort of a brown jacket" contained three crime-related details. Lastly, the quality of the statements was also evaluated based on completeness (i.e., how much of the key information the participants included in their statements), and accuracy.

Completeness was measured via an inventory consisting of 12 key aspects of the crime (e.g., alleyway location, presence of another potential witness at other end of alley, victim had a watch). To examine accuracy, we mimicked the procedure of De La Fuente Vilar et al. (2020). That 
is, we checked participants' statements against a comprehensive checklist of all details presented in the VR scenario. This list was different from the completeness checklist in that it included many more specific details, rather than just the 12 key ones (e.g., the alley had brick walls, perpetrator wore a blazer, victim's watch was on the right hand). We coded as correct all details that were reported as presented in the scenario, and incorrect if they were in error or confabulated. We calculated an overall accuracy score for each participant by dividing the number of correctly recalled details by the total number of details (e.g., the sum of the number of correctly reported details plus the number of incorrect details).

Two research assistants were trained in coding and practiced using a sub-sample of the participants' statements until they reached acceptable interrater agreement. Once the coders were reliable, the main coder coded all participant responses, and the second coded $20 \%$ of the sample, to calculate interrater reliability. Both coders reached appropriate agreement for total units of information provided, single measures intraclass correlation coefficient (ICC $=.96,95 \% \mathrm{Cl}$ $[.89, .99])$, crime-related details provided (ICC $=.95,95 \% \mathrm{Cl}[.85, .98])$, and statement completeness (ICC $=.92,95 \% \mathrm{Cl}[.76, .97])$, and statement accuracy $(\mathrm{ICC}=.74,95 \% \mathrm{Cl}[.38, .90])$.

\section{Data Analyses}

Missing data occurred at a low frequency for some of the interaction questionnaire measures: one participant did not fill out 10 of the questions and two participants did not complete one of the questions. Missing data were assessed using Little's Missing Completely at Random (MCAR) test, which was not statistically significant, $\chi^{2}(142)=147.52, p=.358$, indicating no evidence of bias due to missing data. Thus, missing data were replaced using an expectation maximization algorithm.

We compared the home and the formal interview settings using a series of $t$-tests. Analyses were supplemented by a Bayesian analysis and JZS Bayes factors (BFs) were computed. The JZS BF computes the likelihood of the observed data under the null hypothesis (i.e., no difference between conditions) compared to the alternative hypothesis, quantifying the degree to which the data favor one of the two hypotheses (Harms \& Lakens, 2018; Quintana \& Williams, 2018). As reported in the present study, $\mathrm{BF}_{01}$ denotes evidence in favor of the null, and $\mathrm{BF}_{10}$ denotes favor for the alternative hypothesis. We interpreted our results according to the cut-off thresholds provided by Jeffreys (1961). A BF of 1 indicates that the data fit equally well under both hypotheses, BFs between 1 and 3 suggest weak evidence, 3-10 suggest substantial evidence, 10-30 
suggest strong evidence, 30-100 very strong evidence, and 100+ decisive evidence. Bayesian $t$ tests were computed with the default Cauchy's prior with scaling factor $=0.707$ (Lakens, 2016).

\section{Results}

\section{Disclosure}

An independent-samples $t$-test was conducted with interview location (home vs. formal) as the independent variable and units of information as the dependent variable. Against our expectation, participants in the home condition provided a similar number of units of information (range: $32-109, M=39.69, S D=13.44)$ to those in the formal interview room condition $(M=44.74$, $S D=15.91), t(72)=1.47, p=.15, d=0.34,95 \% \mathrm{Cl}[-11.92,1.81]$. The $\mathrm{BF}_{01}$ of 1.65 provided more albeit weak - support for the lack of an effect on units of information. Moreover, participants in the formal interview room condition reported a similar number of crime-related details (range: 12$78, M=32.18, S D=11.57)$ to participants in the home condition $(M=28.14, S D=10.84), t(72)=$ $1.54, p=.13, d=0.36,95 \% \mathrm{Cl}[-9.25,1.18], \mathrm{BF}_{01}=1.50$. Participants interviewed in the interview room (range: $5-12, M=9.13, S D=1.76)$ also did not differ from those interviewed at home $(M=$ $8.74, S D=1.48)$ in terms of statement completeness, $t(72)=-1.01, p=0.32, d=0.24,95 \% \mathrm{Cl}[-$ $1.14, .37], \mathrm{BF}_{01}=2.68$. ). Lastly, statement accuracy was also not significantly different between participants in the interview room condition $(M=.83, S D=.07)$ and those interviewed at home ( $M$ $\left.=.82, S D=.08), t(72)=0.54, p=.58, d=0.12,95 \% \mathrm{Cl}[-.02, .04], \mathrm{BF}_{01}=3.65\right)$. Therefore, we rejected our first hypothesis.

\section{Rapport and Interview Experience}

We expected participants interviewed in their home setting to report experiencing more positive rapport. Our second hypothesis was not supported, with participants in the home condition (range: $93-181, M=141.03, S D=18.18$ ) perceiving similar rapport levels as those in the formal room condition $(M=134.87, S D=21.83), t(72)=1.31, p=0.19, d=0.30,95 \% \mathrm{Cl}[-3.20$, 15.53], $\mathrm{BF}_{01}=1.99$.

Regarding overall interview experience, ${ }^{7}$ participants in the home condition reported feeling significantly more at ease $(M=6.00, S D=1.24)$ than those in the formal interview room condition $(M=5.02, S D=1.29), t(72)=3.312, p=.001, d=0.77,95 \% \mathrm{Cl}[.39,1.56]$, with $\mathrm{BF}_{10}=$ 22.27 providing strong support. Participants at home reported feeling significantly more in control

\footnotetext{
${ }^{7}$ The other eight questions yielded non-significant results: Confined $(t(72)=.376, p=.708)$, Suffocated $(t(72)=.962, p$ $=.339)$, Spaciousness $(t(72)=.661, p=.511)$, Ease of self-disclosure $(t(72)=.108, p=.914)$, Uncomfortable providing information $(t(72)=-.362, p=.718)$, Inhibited $(t(72)=-1.757, p=.083)$, Uncomfortable in environment $(t(72)=1.589$, $p=.116)$, and I feel like leaving $(t(72)=1.361, p=.178)$.
} 
$(M=5.74, S D=1.34)$ than those in the formal interview room condition $(M=3.39, S D=1.21)$, $t(72)=7.98, p<.001, d=1.84,95 \% \mathrm{Cl}[1.77,2.95], \mathrm{BF}_{10}=3.89$. As expected, those in the home condition also reported it as significantly more pleasant $(M=5.40, S D=1.47)$ than those in the interview room condition $(M=3.72, S D=1.27), t(72)=5.25, p<.001, d=1.22,95 \% \mathrm{Cl}[1.04,2.32]$, $\mathrm{BF}_{10}=9623.94$.

\section{State Anxiety}

Participants in the home condition experienced similar levels of state anxiety (range: 21$59, M=34.68, S D=8.19)$ to those interviewed in the formal interview room $(M=35.95, S D=8.13$, $t(71)=-.664, p=0.509, d=-0.16,95 \% \mathrm{Cl}[-5.09,2.55]) . \mathrm{A} \mathrm{BF}_{01}$ of 3.42 indicated substantial evidence in favor of the null hypothesis, thus we also rejected our third hypothesis.

\section{Discussion}

This study investigated whether interviewing witnesses at their homes, instead of in a formal interview room, would be beneficial for the interview outcomes. Participants in the home interview condition reported feeling more at ease, more in control, and also reported the interview experience as more pleasant than those in the interview room condition. We did not, however, find differences in perceptions of rapport or level of state anxiety experienced between the two interview locations, nor did interview setting result in significant differences in the number of crime-related disclosure. Thus, we rejected our hypotheses.

The lack of difference in the number of crime-related disclosure between the interviews conducted at home and in the formal interview room could have practical relevance. Witnesses are interviewed in locations outside of formal environments for a variety of reasons-one being convenience. According to the Cognitive Interview instructions, investigators may generally choose an interview location that is convenient for the witness, which can include their homes (Fisher \& Geiselman, 1992). Home interviews may also be of convenience for the investigator. When an officer is already close to the witness' home, it may be opportune for them to stop by (Officer J. Hoeijmakers, personal communication, August 29, 2018). Unlike in our study, the practical reason for interviewing a witness in a particular environment may thus not always be to improve the quality of the interview. Based on our findings, there may be actually no serious risk of losing critical information or negatively influencing rapport-building if interviews are con-ducted at home instead of in a formal interview room. Thus, our findings support home interviewing for convenience factor. 
Our participants in the home condition reported feeling more in control and at ease, yet this did not translate to differences in perceived rapport. Perhaps as a consequence of the labbased paradigm, our study may have failed to elicit the interpersonal discomfort associated with being interviewed as a witness to a real crime. This could also explain why we found no differences in situational anxiety between the two conditions. Nonetheless, the current study does provide evidence indicating that manipulating the interview environment can change interviewees' perceptions of the interview's dynamic (e.g., feeling of control) and their affective experience (e.g., feeling at ease).Future studies could employ a paradigm with higher stakes and examine more closely how factors such as control and ease influence witnesses' disclosure and perceptions of rapport.

Relatedly, the operationalization and measurement of rapport has been the topic of recent discussions in the psycholegal field (e.g., Duke et al., 2018), acknowledging the lack of consensus regarding what specific aspects interviewees perceive as rapport. Therefore, there is room to explore how other concepts relate to rapport. Interviewees' feelings of control, for example, could be a strong predictor for their positive perception of rapport (i.e., a positive investigatorinterviewee relationship) as conceptualized by Collins et al. (2002). Rapport building can only happen if the investigator relinquishes some of their authority and share the control of the interview with the interviewee (Brimbal et al., 2019). However, to what extent control and rapport intertwine remains to be empirically examined, and thus we encourage further work on disentangling the two constructs. Moreover, Vallano and Compo's (2011) examination of rapport is built on the premise that a comfortable witness is a better witness, yet comfort is not among the characteristics included in the interaction questionnaire used as a measure of rapport in the current study. This also presents avenue for rapport research, providing a closer examination of how positive affective experiences (e.g., "being at ease") relate to interviewee's perceptions of rapport, and establishing their diagnostic value for measuring rapport.

An important limitation to this study was that we based our sample size on a large effect size estimate. It is possible that a smaller effect size estimation, and thus a larger sample, was needed to detect significant differences between conditions. Moreover, participants knew they would be interviewed about what they had witnessed in the VR scenario. Knowing that they were going to be interviewed may have led them to be hypervigilant during the VR experience or rehearse their memory in preparation for the interview during the week prior to the interview. This situation differs from actual witness situations, where the crime occurs unexpectedly and may 
not be as well remembered. Participants' hypervigilance or rehearsing may thus have masked any effects of interviewing location on quantity and quality of information disclosure.

Another limitation relates to the variations within the home environments in which we interviewed the participants. Some participants lived in dorm rooms, some in shared houses, and others lived alone. The interviews also took place in the area that participants felt most comfortable in-some happened in their bedrooms, some in the kitchen, or common areas. The varying home environments could have introduced confounding variables outside of our experimental control. For example, we did not control for how long they had lived in their current home, which could influence how home-like the environment felt to them.

Further, in our study we randomly assigned the participants to either home or formal location. Although we hypothesized that home interviewing would be beneficial for rapport and information disclosure, having police officers in one's house may also be distressing and hinder disclosure. Future studies could consider a more individualized approach, for example, by giving the witness the choice of where they would feel more comfortable being inter-viewed. Future studies should also account for potential individual (i.e., witness' vulnerabilities) or crime-related factors (i.e., nature and location of the crime) that ought to be considered when choosing the interview location.

Similarly, future studies could look into how other environments can help with different interview goals, for instance, to increase cooperation from reluctant witnesses. Based on anecdotal data, we know that investigators consider different locations for this purpose. A senior investigator from The Hague's Police Unit in the Netherlands stated that when handling reluctant witnesses, he does not interview them at the station, but rather takes them out for coffee to instill trust and create a relationship_or rapport-with the witnesses (De La Fuente Vilar, et al., 2018). Conducting and recording witness interviews at home could also be done for the purpose of capturing witnesses' emotional distress, whereby the video recording can then be used as evidence in court. In cases related to domestic violence, for example, Westera and Powell (2017) indicated that prosecutors believed interviews conducted near to the crime-scene would induce heighted emotional distress in witnesses, pro-viding stronger evidence for their credibility. We should note here, however, that although judges and jurors rely on emotional displays, these are not reliable indicators for credibility (Landström, Ask, \& Sommar, 2019)

Additionally, researchers should explore the role of distractions. In their review of UK interviewing practice, Clarke and Milne (2001) addressed the potential shortcomings of 
conducting investigative interviews at homes, arguing for the lack of control that the investigator has on possible distractions (e.g., noise, family members interrupting) may negatively impact interview quality. The authors recommended conducting interviews at police stations instead, where the investigator has more control. While, as aforementioned, in our study the investigator did not observe salient distractors and interruptions, it would be beneficial to systematically examine how to effectively conduct interviews in distraction-prone environments (Westera \& Powell, 2015).

In the present study we solely focused on the witnesses' perceived experience throughout the interview. Investigative interviews are, however, dynamic and bi-directional interactions. It is possible that investigators' own experiences in varying environments influence the dynamic they build with the witnesses. While we found that witnesses felt more comfortable and in control when interviewed at their homes, the opposite could be happening to the investigators, who are introduced to new, unfamiliar environments in which they lack the environmental control they are used to have (also see Kelly et al., 2019). Future research should also consider the investigator's experience. Moreover, all interviews in this study were conducted by the same investigator who was part of the research team. Because investigator characteristics can influence witnesses' perceptions, future research could account for the interplay between investigator characteristics, the environment and witnesses' experience. For example, com-pared to an officer in casual clothing, the presence of a uniformed frontline officer in a witness' home could have a stronger effect on their anxiety or comfort levels.

In conclusion, our study is the first to examine empirically the practical question of whether interviewing witnesses outside of a formal environment could be beneficial. We did not find evidence for an effect of interview location, which suggests that our two locations did not differ in influencing interview outcome. This proposes the practicality of interviewing witnesses outside the police interview room if it is deemed as more convenient. Nonetheless, because this is the first study in this area, we encourage academics to continue delving into this topic to help establish evidence-based recommendations. Research on interview environments has high practical relevance for police investigators. Understanding if and to what extent the interview environment can influence the interview process and its outcome, will allow us to provide practitioners with feasible recommendations that require minimal training efforts for improving investigative interviewing practice. 
CHAPTER 5

\section{DETAINEE AND LAYPERSON'S PERSPECTIVES AND PREFERENCES REGARDING POLICE INTERVIEW ROOMS}

This chapter draws from the following manuscript:

Hoogesteyn, K., Meijer, E.H., \& Vrij, A. (2020). Detainee and Layperson's Perspectives and Preferences Regarding Police Interview Rooms. PLOS One. Revision invited. 


\begin{abstract}
Emerging research on how suspects perceive the physical environment during investigative interviews yields contrasting findings. While previous studies have suggested that a room made to be physically comfortable may be optimal for interviewing suspects, another study found it can instead lead to higher suspicion of the investigator's intentions. The current study examined current detainees' and general population participants' beliefs about a room that resembled a "typical" interview room, and one decorated to be warm, inviting, and comfortable. Participants also provided descriptive information about their perceptions of police interview environments (e.g., preferences, expectations). We hypothesized that the decorated room would elicit higher ratings of suspicion and wariness compared to the "typical" room. Our findings showed that, overall, participants expected to be interviewed in the "typical" room but preferred the decorated one. Contrary to our expectations, they rated the "typical" room higher on feelings of suspicion than the decorated room. The decorated room also corresponded with what participants reported to be an environment that promotes disclosure. These results bode well for conducting investigative interviews in comfortable environments.
\end{abstract}

Keywords: Interview rooms; interview environment; detainees; self-report; expectancy violation theory. 


\section{Detainee and Layperson's Expectations and Preferences Regarding Police Interview Rooms}

Investigative interviews are vital to successful police investigations, and substantial psycholegal research focuses on the interpersonal dynamic between suspects and investigators. This interpersonal dynamic largely depends on the quality of communication between the suspects and investigators (Yeschke, 1997), and academics have provided a plethora of recommendations for proper questioning techniques (e.g., use of open-ended, non-suggestive questions; Clarke \& Milne, 2001), as well as for developing a constructive investigator-suspect relationship (i.e., through rapport-building; Abbe \& Brandon, 2013). Yet, one factor of the communication process that has been largely overlooked thus far is the environment in which the interviews occur.

That the physical environment affects the quality of communication becomes clear from interpersonal communication research (e.g., Hartley, 2002; Knapp et al., 2013). For example, if a conversation takes place in a room with harsh lighting, it can lead to eyestrain or fatigue, which can then cause the communicators to feel irritable or unsettled, which in turn can create irritability during the conversation (Hartley, 2002). Further, studies from the healthcare field, for example, have found that clients self-disclosed more personal details when interviewed in a 'soft', intimate environment decorated with pictures, comfortable chairs, and soft-lighting, compared to a 'hard', non-intimate environment characterized by block walls, uncomfortable chairs, and fluorescent lighting (Chaikin et al., 1976). Similarly, Gifford (1988) found that a more home-like decorated room fostered more communication concerning general and intimate topics, such as sexuality, than a more office-like decorated room. The overarching theme in these studies is that comfortable, pleasant environments encourage more social interaction than sterile environments (Gifford, 1988).

The positive findings from the communication and healthcare fields may translate to an investigative interviewing context, and a few studies on the physical environment specific to investigative interviews have emerged. From examining interviews with high-value detainees, Goodman-Delahunty and Sivasubramaniam (2013a) identified aspects that can be strategically used by investigators to exert coercion (e.g., the use of physical restraints, isolation, and extreme temperatures) or non-coercion (e.g., soft furnishings, having refreshments available). In a later study examining detainee's perceptions on the use of coercive and non-coercive interview techniques, the authors found that detainees rated their disclosure to be higher when interviewed 
in a comfortable environment (i.e., with non-coercive physical aspects present), noting that the comfortable environment may have fostered better rapport, which in turn facilitated disclosure (Goodman-Delahunty et al., 2014).

Moreover, two laboratory studies - reported in Dawson and colleagues (2017) - examined whether physical aspects could prime feelings of "openness" and lead to higher information disclosure in a mock-crime scenario. The "openness" manipulations included the room layout (i.e., a spacious setting), as well as décor that was metaphorically consistent with being "open" (i.e., pictures of open scenes, an open book). The interviews either took place in a larger room decorated with the openness primes, or a smaller, undecorated room. Participants interviewed in the larger room provided more crime-relevant information than those interviewed in the smaller room. In one of their studies, these results were mediated by participants' perceptions of spaciousness, that is, perceptions of greater spaciousness increased the odds of disclosure (but see Hoogesteyn et al., 2019). Thus, the benefits of the spacious environment depended on the participants own perceptions and active interpretations of the spaciousness as more comfortable.

A more comfortable environment could, however, also have an adverse effect on the quality of an investigative interview. In their second study, Dawson et al. (2017) found that participants interviewed in the decorated room expressed higher perceptions of suspicion, resulting in less information disclosure. A possible explanation for this finding is that the decorated room did not match participants' expectations of a police interview setting, leading to suspicion of manipulation, and causing participants to worry about the investigator's suspicion against them.

The Expectancy Violations Theory (EVT; Burgoon, 2015) could explain this interpersonal mechanism. EVT is an interpersonal communication theory, which posits that violations of our expectations can be positive or negative. Positive violations can elicit desirable, positive outcomes that are more advantageous than confirmations of expectations, while negative violations can elicit undesirable reactions, of less advantage than a confirmation. According to the EVT, individuals use these expectations to inform their perceptions and frame their interactions with others (Burgoon, 2015). Applied to Dawson and colleagues' study, EVT would predict that interviewees exposed to a room that was 'nicer' (i.e., decorated) than what they expected, would result in a negative expectancy violation, which could explain the higher suspicion and the decreased odds of disclosure following from that. 


\section{The Present Study}

Determining how police interview environments are perceived by suspects can provide insight into how interview rooms should be designed. Because perceptions of suspicion can be counter-productive to communication (Burgoon et al., 1996), we were interested in examining whether Dawson et al.'s (2017) results would replicate, that is, if individuals would report a comfortably decorated interview room to elicit higher feelings of suspicion. To examine this, we asked participants to compare two rooms, one resembling a "typical" interview room, and one decorated to be warm, inviting, and comfortable. We predicted that participants would expect to be interviewed in the "typical" room and, stemming from Dawson et al.'s (2017) findings, would rate the decorated room higher on suspicion compared to the "typical" room.

Further, we were interested in an additional exploration of what individuals' expectations are of what police interview rooms look like, and to gather their interview room preferences. We collected data from two groups: the general population and current detainees. We gathered responses from current detainees because they are the most representative of the 'target' individuals who are subjected to investigative interviews. While the majority of the research on interview strategies have relied on police investigators' data (e.g., Kassin et al., 2007; Kelly et al., 2015; Miller et al., 2018) few studies have examined detainees' perspectives (see Cleary \& Bull, 2019, and Goodman-Delahunty et al., 2014, for exceptions). Gathering information from the target population is essential, as cooperation is ultimately the suspect's decision (Cleary \& Bull, 2019).

\section{Method}

\section{Participants and Procedure}

This study was approved by our university's ethical committee. All data and materials are available through the Open Science Framework (OSF; https://osf.io/fbkmw/).

\section{Detainees}

Our sample consisted of 78 detainees. Their age range was 17 to 69 years ( $M=32.15$ years, $S D=13.52$ ) and the majority were male ( 58 men, 19 women, 1 preferred not to say). To gauge the level of familiarity detainees may already have with police interview environments, we asked them whether they had been interviewed by the police in previous occasions. Forty-four, out of the 78, reported that they had, and of those who provided the reason for the interviews, sixteen were due to theft, nine due to drug-related charges, six due to violating a restraining order, two 
due to quarreling, one for driving without a license, one for scamming, and one for being an accomplice.

All detainees were recruited from one detainee center in Amsterdam (NL). The term 'detainee' refers to individuals who have been arrested and are placed in custody for a set period of time, pending further development in their case (e.g., an official interview, a hearing, displacement to jail). The recruitment of the detainees took place within three months, in which a research assistant from the Dutch Police Academy approached incoming detainees in their cells and asked if they were willing to participate voluntarily in a research study. Some detainees had been detained for a day, others had just been arrested and placed in custody. The research assistant first provided detainees with an explanation of the study and asked for verbal consent. After consenting, the research assistant first asked the detainee how they were doing that day and proceeded to provide each question verbally while writing down the responses. Upon completion, the detainees were provided with an email address in case they had any questions or concerns and were thanked for their participation.

\section{General Population Sample}

We gathered a hundred and one responses through Amazon Mechanical Turk (MTurk), where the study was advertised as looking for people's thoughts regarding police interview rooms in exchange for 1 USD. Twenty-two responses had to be excluded due to improper responding to the open-ended questions, either by entering numbers or random sentences that were not consistent with the prompted question. Thus, our final general population sample consisted of 79 participants. Their age range was 20 to 58 years $(M=31.57$ years, $S D=8.94)$, the majority were male (49 men, 30 women). Before the survey started, we asked participants whether they had been previously questioned by police; those who said yes were excluded from participation. Our exclusion criteria were pre-registered through the OSF.

\section{Survey Questions}

The questionnaire comprised six questions (see Appendix B for the complete questionnaire). All questions were phrased through the lens of a suspect scenario. Two openended questions gathered 1) what participants' expectations were of suspect interview locations, and 2) what they thought this location should look like in order to promote disclosure. We then presented participants with photos of two nearly identical rooms of the same size. These photos were provided to us by Kelly and colleagues (2019) from the Southwest Detectives Division of the Philadelphia Police Department (US). One of the photos depicted an interview room in its current 
form, with no decorations, fluorescent lighting and uncomfortable chairs (which we refer to from now on as the typical room; see Figure 4). The other photo depicted a room that was altered and decorated in order to make the space more inviting, comfortable, and warm by including officelike decorations, warm lighting, and comfortable chairs (we refer to this room as the decorated room; see Figure 4).

For each interview room, participants were asked to indicate how it made them feel from a selection of 3) seven positive (i.e., comfortable, able to speak freely, cooperative) and 4) negative (i.e., suspicious, constrained, ready to get out, wary) characteristics, presented via 7-point Likerttype scales $(1=$ not at all to $7=$ extremely). The presentation of the two room photos was counterbalanced. Participants were then 5) asked to choose which of the two rooms most accurately represented what they expected a police interview room to look like as well as 6) which room they preferred to be interviewed in, providing descriptive explanations why.

We then averaged the seven characteristics into composite ratings, determined by both face-validity and high correlational values. "Suspicious" and "wary" were combined to form an overall suspicion score $(r=.645, p<.001)$, "able to speak freely" and "cooperative" were combined to form an overall cooperation score $(r=.736, p<.001)$, "constrained" an "ready to get out" were combined to form an overall constraint score $(r=.543, p<.001)$, we left "comfortable" on its own, as this is a more general characteristic (see Table 5 for all correlation values).

\section{Table 5}

Intercorrelations (Pearson's r) between all seven room characteristics.

Comfortable Suspicious Constrained Able to Cooperative Ready to Wary speak get out

\begin{tabular}{|c|c|c|c|c|c|c|c|}
\hline & & & & $\begin{array}{l}\text { speak } \\
\text { freely }\end{array}$ & & get out & \\
\hline Comfortable & - & $-.374^{* *}$ & $-.447^{* *}$ & $.548^{* *}$ & $.478^{* *}$ & $-.493^{* *}$ & $-.332^{* *}$ \\
\hline Suspicious & $-.374^{* *}$ & - & $.467^{* *}$ & $-.352^{* *}$ & $-.284^{* *}$ & $.400^{* *}$ & $.645^{* *}$ \\
\hline Constrained & $-.447^{* *}$ & $.467^{* *}$ & - & $-.379^{* *}$ & $-.300^{* *}$ & $.543^{* *}$ & $.411^{* *}$ \\
\hline $\begin{array}{l}\text { Able to speak } \\
\text { freely }\end{array}$ & $.548^{* *}$ & $-.352^{* *}$ & $-.379^{* *}$ & - & $.736^{* *}$ & $-.394^{* *}$ & $-.377^{* *}$ \\
\hline Cooperative & $.478^{* *}$ & $-.284^{* *}$ & $-.300^{* *}$ & $.736^{* *}$ & - & $-.362^{* *}$ & $-.376^{* *}$ \\
\hline Ready to get out & $-.493^{* *}$ & $.400^{* *}$ & $.543^{* *}$ & $-.394^{* *}$ & $-.362^{* *}$ & - & $.329^{* *}$ \\
\hline Wary & $-.332^{* *}$ & $.645^{* *}$ & $.411^{* *}$ & $-.377^{* *}$ & $-.376^{* *}$ & $.329^{* *}$ & - \\
\hline
\end{tabular}




\section{Coding}

All open-ended, unstructured responses to room expectations and preferences were coded into data-derived categories that best represented the data. The first author went through each of the responses identifying several underlying themes and created dominant categories per question, all overlapping responses were combined and condensed into the dominant categories. For example, the question on what the interview setting should look like to promote disclosure yielded 14 categories, including that the room should be open, that it should be inviting, and should have comfortable chairs.

To establish inter-rater reliability, the main coder (the first author) and a second independent coder coded a randomly selected $20 \%$ of the participants' open-ended responses into the appropriate categories, achieving acceptable reliability with percent agreements between 80 and $100 \%$.

\section{Figure 4}

Pictures of the typical (left) and decorated (right) rooms
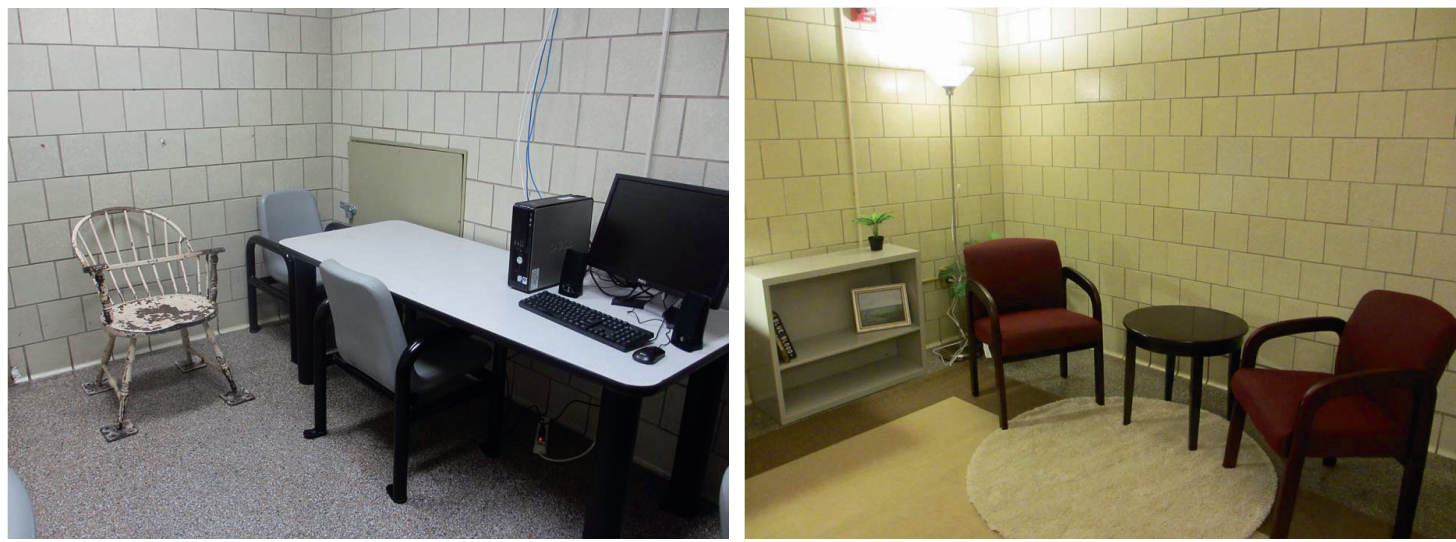

\section{Results}

The detainee sample was subject to omissions, particularly for the open-ended questions. Therefore, the number of categories endorsed do not equal the sample size. All percentages represent the proportion of respondents who answered the question as opposed to the whole sample, the number of total respondents to that question $(N)$ is noted next to all percentages. 


\section{Interview Room Expectations}

We asked participants to select which of the two rooms (i.e., decorated vs. typical) they would expect to be interviewed in as a suspect in a criminal case. As expected, the majority selected the typical room over the decorated one. Of the detainees, $72.5 \%(N=69)$ selected the typical room over the decorated one, and 60 provided some open-ended response as to why. The most reported explanation for expecting the typical room was that the decorated room looked too comfortable to be a suspect interview setting $(n=18)$, followed by that statements that the typical room simply reflected what an actual interview room looks like $(n=14)$, and that the typical room looked more authoritarian, stricter, or colder $(n=3)$. Of those participants who selected expecting to be interviewed in the decorated room $(27.5 \%, N=69)$ the most cited reason was that the typical room looked old and outdated $(n=11)$. A less frequently reported reason for expecting the decorated room was that it was more spacious than the typical room $(n=2)$.

Among the general population sample, $83.5 \%(N=79)$ reported expecting to be interviewed in the typical room, with the most provided reason being that it resembled what they see on television $(n=21)$, that the decorated room looked too comfortable to be a suspect interview room $(n=17)$, and that the typical room reflected authority, strictness, or the coldness associated with suspect interviews $(n=17)$. Of those that reported expecting to be interviewed in the decorated room $(16.5 \%, N=79)$, the most reported reason was that it looked more comfortable and humane $(n=7)$. As one participant wrote: "[the decorated room] is more comfortable. When you investigate anyone, to try to speak freely, you don't scare him.... [the decorated room] looks like home, then they will speak freely".

\section{Interview Room Ratings}

We hypothesized that participants from both groups would rate the decorated room higher on suspicion compared to the typical room. Since we were interested in examining how individuals compared the two rooms across the characteristics (i.e., suspicious, cooperative, constrained, comfortable), we conducted a series of within-subjects $t$-tests with the detainee sample and the general population sample analyzed separately (presented in Tables 6 and 7) Opposite to our expectation, detainees rated the typical room significantly higher on suspicion ( $M$ $=5.61, S D=1.12)$ compared to the decorated room $(M=4.64, S D=1.42) ; t(74)=6.34, d=0.74, p$ $<.001,95 \% \mathrm{Cl}[.66,1.27])$. The general population participants also rated the typical room higher on suspicion $(M=4.79, S D=1.48)$ compared to the decorated room $(M=3.13, S D=1.62 ; t(78)=$ 7.67, $d=0.86, p<.001,95 \% \mathrm{Cl}[1.23,2.09])$. Therefore, we rejected our hypothesis. 
Both detainees and general population participants also rated the decorated room higher on feelings of comfort and cooperation, and lower on feelings of constraint, compared to the typical room (Table 6 and 7). Regarding cooperation, for a more fine-grained examination, we conducted additional $t$-tests splitting the detainee participants by previous interview experience (yes/no). Detainees who had not been previously interviewed by police reported "feelings of cooperation" significantly higher in the decorated room $(M=5.40, S D=1.29)$ than the detainees who had already been previously interviewed $(M=4.06, S D=1.63 ; t(67)=3.65, d=0.91, p=$ $.001,95 \% \mathrm{Cl}[.60,2.06])$. This difference was also present for cooperation ratings of the typical room, such that detainees who were not interviewed by police reported "feelings of cooperation" to a higher extent $(M=4.65, S D=1.54)$ than the detainees who had already been previously interviewed $(M=3.62, S D=1.75 ; t(67)=2.54, d=0.62, p=.013,95 \% \mathrm{Cl}[.22,1.84])$. Overall, previously interviewed detainees reported lower cooperation levels than those who had yet to be interviewed, although we note the overall moderate average ratings.

\section{Table 6}

Within-subject comparisons of detainees' ratings for each room.

\begin{tabular}{l|ccccccc}
\multicolumn{1}{l}{} & $\begin{array}{c}\text { Typical } \\
\text { room } \\
M(S D)\end{array}$ & $\begin{array}{c}\text { Decorated } \\
\text { room } \\
M(S D)\end{array}$ & $n$ & $t$ & $d$ & $p$ & $95 \% \mathrm{Cl}$ \\
\hline Suspicious & $5.61(1.12)$ & $4.64(1.42)$ & 75 & 6.34 & 0.74 & $<.001$ & {$[.66,1.27]$} \\
Cooperation & $4.06(1.73)$ & $4.62(1.63)$ & 69 & -4.12 & 0.49 & $<.001$ & {$[-.84,-.29]$} \\
Constrained & $4.41(1.60)$ & $2.99(1.60)$ & 68 & 8.10 & 0.98 & $<.001$ & {$[1.07,1.77]$} \\
Comfortable & $2.40(1.67)$ & $5.44(1.42)$ & 73 & -12.31 & 1.44 & $<.001$ & {$[-3.53,-2.55]$}
\end{tabular}

Note. Out of the 78 detainees, not all responded to all questions, we provide the $n$ for each rating.

All ratings were measured on a 1 (not at all) to 7 (extremely) Likert-type scale. 


\section{Table 7}

Within-subject comparisons of the general population sample's ratings for each room.

\begin{tabular}{l|ccccccc}
\multicolumn{1}{l}{} & $\begin{array}{c}\text { Typical room } \\
M(S D)\end{array}$ & $\begin{array}{c}\text { Decorated } \\
\text { room } \\
M(S D)\end{array}$ & $n$ & $t$ & $d$ & $p$ & $95 \% \mathrm{Cl}$ \\
\hline Suspicious & $4.79(1.48)$ & $3.13(1.62)$ & 79 & 7.67 & 0.86 & $<.001$ & {$[1.23,2.09]$} \\
Cooperation & $2.90(1.53)$ & $4.64(1.49)$ & 77 & -7.65 & 0.87 & $<.001$ & {$[-2.19,-1.28]$} \\
Constrained & $5.27(1.46)$ & $3.29(1.57)$ & 79 & 8.53 & 0.96 & $<.001$ & {$[1.52,2.44]$} \\
Comfortable & $2.57(1.59)$ & $4.61(1.63)$ & 79 & -8.61 & 0.97 & $<.001$ & {$[-2.51,-1.57]$}
\end{tabular}

Note. All ratings were measured on a 1 (not at all) to 7 (extremely) Likert-type scale.

\section{Interview Room Preference}

Most of the detainees reported preferring to be interviewed in the decorated room as suspects to a crime $(98.6 \%, N=70)$, and 62 detainees provided some open-ended response as to why. The most reported reasons were that the decorated room was warmer or nicer $(n=20)$, more comfortable $(n=13)$, and would put them more at ease $(n=6)$ than the typical room. Other less cited reasons for preferring the decorated room was that it looked home-like $(n=4)$, more humane $(n=2)$, and more spacious $(n=2)$ than the typical room. The one participant that selected preferring the "typical" room $(1.4 \%, N=70)$ did not provide an open-ended response as to why.

Similarly, $91.1 \%(N=79)$ of the general population reported preferring the decorated room. Out of the reasons reported, the most cited were feelings of higher comfort $(n=33)$, more ease $(n=20)$, more open to talk $(n=17)$, more personable or inviting $(n=14)$, and warmer or nicer $(n=14)$ than the typical room. Other less cited reasons for preferring the decorated room were that it was more humane $(n=4)$, less suspicious $(n=2)$, and home-like $(n=2)$ than the typical room. For example, one participant stated: "There is already a high base level of anxiety involved in being questioned by police officers. I don't want to be subjected to an environment that accentuates that feeling of anxiety any further, because most likely I am innocent and the last thing I want to do is give them a reason to suspect otherwise". 
Out of the $8.9 \%(N=79)$ of general population participants who selected preferring the typical room over the decorated one, three participants stated that the typical room looked more "to the point", meaning that that the room's purpose was clear, as, for example, a participant stated: "The [typical room], does not pretend to be something it is not".

\section{What Do People Think Police Interview Settings Look Like?}

We also asked participants to describe what they thought a police interview setting looks like through an open-ended prompt. From the detainees who provided some open-ended response $(N=60)$, the most reported ones related to furniture (i.e., number of chairs, table present, and computers; $n=34)$, followed by the interview room being bare or unadorned $(n=7)$, resembling an office $(n=7)$, or resembling what they see on television $(n=4)$, small in size $(n=2)$, and having angry policemen inside $(n=2)$.

In the general population sample $(N=79)$, the most reported responses also related to the interview room furniture $(n=45)$, being a bare or unadorned room $(n=38)$, small in size $(n=18)$, dark $(n=16)$, having a one-way mirror $(n=15)$, florescent lighting $(n=9)$, gray $(n=8)$, windowless $(n=7)$, having uncomfortable chairs $(n=6)$, resembling what they see on television $(n=6)$, cold ( $n$ $=4)$, and with concrete floors or walls $(n=4)$. Lastly, some of the general population participants reported the interview room as an intimidating setting $(n=3)$, as one participant described: "Cold, empty, not much to look at. Not very comforting. A prison cell without the bars".

\section{What Should the Police Interview Setting Look Like to Promote Disclosure?}

Participants were asked to report on what they thought an interview setting should look like to promote disclosure through an open-ended, descriptive prompt. Out of the 52 detainees who provided responses, the most reported answer was that the rooms were fine as they currently are $(n=12)$, others responded that the rooms should have some color or decoration ( $n=$ 9), should have items, such as coffee, water, or snacks available $(n=4)$, and should have windows $(n=3)$. Furthermore, some detainees reported that the room simply did not matter to them $(n=$ 3).

The general population group $(N=79)$ the most reported characteristic that a room should have was to be comfortable or relaxing $(n=23)$, bright $(n=16)$, have comfortable chairs $(n=15)$, and some color or decoration $(n=12)$. Other responses included that the rooms should resemble an office or home-like space $(n=9)$, have windows $(n=8)$, be spacious $(n=7)$, and overall should be inviting $(n=7)$. For example, one participant stated: "I think the room should be more inviting per se. Not everyone being interviewed is necessarily guilty of a crime, so I don't feel that it's right 
to have them in an intimidating environment. People would probably talk more if they were treated like less of a criminal". Conversely, some participants reported that the rooms should look authoritarian or sterile $(n=7)$.

\section{Discussion}

In this study, we examined the beliefs and attitudes of detainee and general population individuals on two different police interview environments, one typical room, and one designed to be more comfortable and inviting. Unsurprisingly, detainee and general population participants mostly expected to be interviewed in the typical room, as opposed to the decorated one. However, against our expectation, the decorated room did not elicit higher suspicion or wariness compared to the typical room.

In contrast to Dawson and colleagues' (2017) suggestion that a decorated room may elicit higher suspicion because it violates participants' expectations of what an interview room looks like, we found that while participants did believe the decorated room to appear too comfortable to be a suspect interview room, it did not result in higher suspicion. Rather, the decorated room corresponded with what the majority of them described qualitatively to be an environment that promotes disclosure, which according to participants should be relaxing, include comfortable chairs, decorations, and appear homier. If explained through the EVT, this expectancy violation was positive - that is, the unexpected room environment was interpreted as a favorable environment. Such positive expectancy violations are promising, as the EVT posits that a violation triumphs a confirmation of an expectation, as long as it is a positive violation (Burgoon, 2015). Since the decorated room did not elicit higher suspicion, and was regarded as more conducive to cooperation, we encourage academics and practitioners to closely examine how a more physically comfortable interview room could facilitate information disclosure.

Our finding that both groups preferred to be interviewed in the decorated room fits with recent interest in determining what constitutes effective police interview environments (Goodman-Delahunty et al., 2014; Meissner et al., 2015) and our qualitative data provides insight into what such an environment may be. The majority of participants indicated that interview rooms should be made more comfortable, including a general population participant who indicated, "I'd be more open to speaking in a generally non-threatening location that is warm and promotes civil conversation" Notably, recent data also indicates that police investigators support making interview environments more comfortable and less sterile (Hoogesteyn et al. 2020), suggesting that some current interviewing contexts should be amended. Beyond perceptions of 
comfort, research also suggests that detainee disclosure may be enhanced in a more physically comfortable environment (Goodman-Delahunty et al., 2014). Therefore, a more comprehensive examination of actual suspects' disclosure in different interviewing contexts is warranted.

Relatedly, we also found that both detainees and participants from the general population rated the decorated room as eliciting higher feelings of cooperation. This finding provides preliminary evidence that the interview room's environment could influence suspects' cooperation efforts, echoing Goodman-Delahunty and colleagues' (2014) findings. Of note, detainees who had previous experience with the police rated their cooperation levels lower, regardless of the room. Similarly, Snook and colleagues' (2015) found that detainees' self-reported levels of cooperation were lower when they had previous experience with the criminal justice system compared to those who had not. It is possible that their (possibly negative) previous experience, and the circumstances of findings themselves again in police custody, makes them cautious, even distrustful, of reporting on cooperation. However, this must be taken with a grain of salt as we relied on self-reports, and studies that incorporate other forms of objective data, such as the actual amount of information disclosure, should be conducted to better assess how self-reported levels of cooperation predict actual cooperation.

We found that the general population participants expected to be interviewed in "typical" room partly because it reflected the authority, strictness, or the coldness associated with suspect interviews. One participant stated, "I would expect police to treat suspects to an environment where they are not too comfortable and to keep them on the edge to incite mistakes in interview". An explanation for this expectation could be the participants associating the criminal justice system with punishment. Our general population group came from mostly came from the United States, where public opinion on criminal justice matters is known to be punitive (Cullen, Fisher, \& Applegate, 2000). None of the detainees, who came from the Netherlands, reported such reasons for expecting the "typical" interview room. Besides the situational differences between the general population and detainees, there could be underlying distinctions in public opinions regarding the criminal justice system between Americans and the Dutch. It would be interesting for future research to delve into cross-cultural differences in opinions pertaining to criminal justice matters and how these may guide individuals' perceptions of investigative interviewing environments.

Notably, the images of the decorated room we showed participants was manipulated by Kelly and colleagues (2019) in many ways, including the lighting, the furniture and its 
arrangement, as well as the décor. While our results bode well for conducting investigative interviews in comfortable environments, it would be useful, particularly for informing police agencies, for future research to establish which specific room manipulations are essential to create a comfortable environment. Based on our findings, for example, detainees and the general population mentioned the use of colors and decorations. In Kelly and colleagues' (2020) study, the decorated room included several decorations, however, the room was used to conduct witness interviews, while in our study we focused on suspect scenarios. Some decorations may be more or less appropriate depending on who the interviewee is, especially considering safety precautions.

Another direction for future studies is to more closely examine investigators' thoughts about interview environments. While our study focused on suspects' expectations and preferences, investigative interviews are dynamic and bi-directional interactions. It is possible that a decorated room negatively violates the expectations of investigators, depending on the interview room they are accustomed to conducting their practice in. Future studies should also account for how investigators perceive the environment, and whether this influences their interviewing behavior (see Kelly et al. 2019).

This study was subject to limitations. First, our design was analogous to a vignette study, asking participants to rate and compare two interview room photos. While this design made it feasible to obtain data from the detainee population, vignette studies also limit the level of involvedness participants may experience (Hughes \& Huby, 2012). Additionally, the data collection method for our two samples differed. Detainees were asked the questions in person for no compensation at the detention center, while MTurkers completed the questionnaire online and with a small monetary compensation. There is recent interest on the methodological validity of MTurk studies compared to data collected via conventional methods (e.g., data collected personally by the researchers). Thus far, the quality of MTurk data has shown to be acceptable and equivalent to data collected with conventional methods (Crump et al. 2013; Kees et al. 2017). We also found that our MTurk data were more complete, while detainees provided less detailed responses and had higher rates of missing data. However, the difference in response rates may be due to the current situation of the detainees, as well as other individual variables (e.g., lack of sleep, mental illness).

To conclude, we found that detainees and general population individuals expected a police interview setting to resemble a typical room, that is, including the bare minimum furnishings (i.e., a table, chairs) and to be simple, sterile and undecorated. Yet, they reported preferring an 
interview room to be decorated, warm, and comfortable, in order to create an environment that fosters information disclosure. Against our expectations, and previous findings by Dawson and colleagues (2017), being presented with a decorated, as opposed to a typical room, did not appear to negatively violate participants' expectations of a suspect interview room. Rather, we found that the expectancy violation was positive. Thus, future studies should examine how a more nicely decorated, physically comfortable, environment may be useful for facilitating the suspectinvestigator relationship as well as for eliciting information. For example, in this survey, participants mentioned that decorations, colors, comfortable chairs, and windows are aspects that can help create an atmosphere conducive to disclosure. These alterations are feasible and largely under the control of practitioners (Goodman-Delahunty et al., 2014) and can offer implications for planning interviews and (re)designing police interview rooms. 
CHAPTER 6

GENERAL DISCUSSION 


\section{General Discussion}

This dissertation explored an array of aspects related to the physical environment in which investigative interviews take place. That the physical environment influences our perceptions, behaviors, and interpersonal communication is both intuitive and empirically established, with support coming from areas outside of legal psychology, such as the communication (Hartley, 2002; Knapp, Hall, \& Horgan, 2013) and healthcare fields (Chaikin et al., 1976; Okken et al., 2012, 2013). The aim of this dissertation was to examine whether the physical environment influences the investigative interview, and whether environmental aspects can be purposefully manipulated by investigators as means to enhance their information elicitation and rapport-building efforts.

\section{Summary of Findings}

In Chapter 2, we established the practical relevance of research on environmental techniques by surveying police investigators on their use and beliefs about their effectiveness. We conducted an international survey with investigators from Sweden, The Netherlands, US, Canada, and England. The majority of participants reported the interview environment to be of importance, with most investigators reporting to employ some environmental techniques in their practice already. Specifically, considering the seating arrangements, investigators' clothing, and having items handy to provide suspects with (i.e., water, coffee, and tissues) were three environmental aspects most considered at the planning stage of the interviews. The most reported reasons for these considerations were to facilitate the suspect-investigator interaction, as well as to increase the suspect's comfort. We also gathered investigators' beliefs about the context manipulation techniques outlined in the taxonomy proposed by Kelly et al. (2013). We found that considering seating distances (i.e., arrangements) and clothing were reported as most useful, taught during trainings, and part of their practice. Another finding from this survey was that investigators' responses aligned more with an information-gathering, rather than an accusatorial approach to interviewing.

We then experimentally examined specific aspects of the interview environment. In Chapter 3, we sought to expand previous findings from the psycholegal and related fields on physical spaciousness, and its influence on information disclosure (i.e., Dawson et al., 2017; Okken et al., 2012, 2013). We manipulated physical spaciousness through to room size and interpersonal distance. Participants took part in a virtual-reality mock crime and were subsequently interviewed about their involvement in either a larger or smaller room, at a closer or wider interpersonal 
distance. Unlike previous related research, we did not find our spaciousness manipulations to facilitate either the quantity or the quality of information provided by participants. Furthermore, we expanded our study to examine whether physical spaciousness had an influence on participants' perceptions of rapport-building, and indeed, we found initial evidence that participants interviewed in the larger room (but not at a wider distance) reported its spaciousness as more comfortable, which in turn mediated higher positive perceptions of rapport.

Next, we sought to explore the potential influence of the environment in a wider sense, and in Chapter 4 we tested two different interview locations: home residences and a formal setting akin to a police interview room. In this study, participants were treated as witnesses, rather than suspects, because conducting interviews at witnesses' homes is more common in police practice (Clarke \& Milne, 2001). Participants took part in the same virtual-reality mock crime as in Chapter 3 and were interviewed about what they had witnessed one week later, either at their home or in the formal interview room. Given the associations of home and comfort, we expected participants interviewed at home to report more positive rapport with the interviewer and to disclose more information than those interviewed in the formal interview room. However, interviews conducted at home yielded similar rapport-ratings, as well as quantity and quality of information compared to those conducted in the formal room. These findings provide some evidence that investigators can interview witnesses in the convenience of their homes without risk of hindering rapport or losing critical disclosure of information.

While some literature has suggested that a room made to be comfortable is optimal for interviewing suspects (e.g., Goodman-Delahunty et al., 2014), others have suggested that decorations increase feelings of suspicion (Dawson et al., 2017; Kelly et al., 2019). Suspicion may arise when the interview room does not conform to the suspect's expectations of an interview room, resulting in a negative expectancy violation. Therefore, in Chapter 5, we gathered selfreport responses on expectations and preferences regarding suspect interview rooms from current detainees and from individuals in the general population through a questionnaire. Participants also provided ratings regarding two interview rooms, one which resembled a typical room (i.e., no decoration, fluorescent lighting and uncomfortable chairs) and one designed to be more inviting and comfortable (i.e., including office-like decoration, warm lighting, and comfortable chairs). Although we found that the majority of participants from the detainee and general population groups expected a police interview setting to resemble the typical room, the 
decorated room evoked less suspicion. Participants also reported preferring a decorated, warm, and comfortable room to create a disclosure supportive environment.

In sum, the current studies provide evidence that 1) police investigators use environmental manipulation techniques and believe them to be useful, 2) interviewees are perceptive of differences in interview environments, 3 ) more comfortably spacious environments may be associated with better rapport-building, and 4) that detainees and lay individuals perceive more comfortable interview rooms to be more productive. However, 5) we did not find support for the effect of our experimental manipulations of room spaciousness and interview location on information disclosure in 'suspects' and 'witnesses' of an experimental mock crime, respectively.

\section{Interviewees Are Perceptive of the Environment. What are the Implications?}

A general finding from Chapters 3, 4 and $\mathbf{5}$ is that interviewees were perceptive of the interview environment, meaning, they were aware of how the physical surrounding made them feel. In the experimental studies participants responded more positively to both a spacious (i.e., more positive perception of rapport; Chapter 3 ) and a home-like environment (i.e., feeling more in control and at ease; Chapter 4). In Chapter 5, detainees and general population participants clearly preferred the decorated and inviting environment, and, to some extent, believed it to be conducive to a more productive interview (i.e., to elicit higher cooperation).

That interviewees were perceptive of the environment is noteworthy because previous research on environmental influences suggests the environmental influence to be subtle, and that it occurs at an unconscious level (Hartley, 2002). Thus, it is possible to manipulate the environment to a degree that directly and positively influences interviewees' experience. The question remains though, to what degree the manipulation of the physical environment actually has a meaningful impact on interview outcomes? Neither of our two experimental studies, nor Kelly et al.'s (2019) field study, resulted in a significant gain in information elicitation as a consequence of environmental manipulation.

Although information gain is the primary goal of investigative interviews (Vrij et al., 2017), and obviously one of the main outcomes of interest in our experimental studies, providing interviewees with a positive interview experience should also be a goal. This notion is validated by the incorporation of "soft" interview rooms across many police stations (e.g., Bologna, 2019; Connelly, 2019; Girgis, 2019; Oligschlaeger, 2015). These rooms, aimed at providing comfort, are typically reserved for interviewing victims and witnesses. Rather than based on empirical 
evidence, the incorporation of soft rooms stems from the intrinsic realization that the physical environment should reflect the support that victims and witnesses deserve (Bologna, 2019; Oligschlaeger, 2015). At most, findings from the current studies provide initial empirical support that comfortable environments, comparable to the soft interview rooms, are indeed perceived by interviewees (both witnesses and suspects) as increasing the quality of their experience while providing information.

Importantly, the positive influence that environmental manipulations have on interviewees' experience does not need to be confined to the interview room, nor disregarded with reference to suspects. There has been a recent momentum toward redesigning suspect/detainee spaces to also reflect a more humanitarian approach. Deanna van Buren, an architect based in the US, began an initiative to redesign detention centers with restorative justice principles in mind:

For nearly a year, difficult conversations between [detained] son, father and other family members took place in a serene setting with sky-blue walls, pine floors, a communal kitchen and lots of natural light. These touches came out of a community design process led by Deanna Van Buren, an architect who has dedicated her career to rethinking the architecture of justice.

It's a very calming space so I felt comfortable opening up, [the detainee] observed. It's like a base in a baseball game - a safety spot. (Brown, 2020).

Both our detainee findings (Chapter 5) and findings from Goodman-Delahunty et al. (2014) suggest that detainees perceive comfortable, inviting environments to be conducive to a more productive interview. These two studies only included self-report data, so it remains to be established whether their perceptions actually translate to better interview outcomes such as disclosure of investigative relevant details. Nonetheless, if we wholeheartedly advocate for a rapport-based information-gathering interviewing approach, it follows that interview environments should also reflect the humanitarian aspect of the approach.

\section{The Lack of Differences in Disclosure Rates}

One reason for the lack of significant differences between our environmental manipulations could be our conceptualization. In our two experimental studies (Chapter $\mathbf{3}$ and 4), we presumed that aspects of the environment can be isolated and manipulated in order to produce an effect on interviewees' disclosure. However, because of the complexity and dynamic 
nature of investigative interviews, it is also likely that environmental factors function closely in tandem with other variables (e.g., both the investigators' and interviewee's individual traits, investigators' strategies, the interview protocol used). Rather than expecting direct effects, it is more fruitful to focus on moderators or indirect relationships, as we found to be the case for participants' perceptions of spaciousness and rapport in Chapter 3.

Kelly and colleagues' (2013) taxonomy model illustrates the highly dynamic interaction between the environment or contextual factors, and an investigative interview. The context manipulation domain can be both influenced by and/or exert its own influence on the other domains (e.g., rapport-building, evidence presentation). The direction and strength of these influences are constantly changing as the dynamic of the interview unfolds. For example, when the suspect is initially placed in the interview room, they may be more focused on the context as they assess their new environment. As the interview begins, their focus shifts to the investigator, where rapport potentially develops, the aim of the interview is settled, and the investigatorsuspect interactive dynamic develops. The suspect's initial assessment of the interview room may affect certain cognitive and emotional states (e.g., level of distrust, discomfort) that frame how they interpret other aspects of the interview, and this is why we think the environment to be important. However, the influence of the environment is not an isolated phenomenon; it intertwines with the suspect's preconceptions, perceptions of the investigator, the interpersonal dynamic and rapport that is developed, and the actual interview inquiries. For example, in Chapter 5 we found that detainees reported that the typical interview room (i.e., a dull and stark environment) evoked higher feelings of suspicion, compared to a more inviting, decorated room. If suspects were to already experience an apprehension toward police prior to the interview, entering an environment that exacerbated their feelings of suspicion could be detrimental to the interview process.

It is also arguable that the effects of the environment would be more prominent if the manipulations had been more salient, for example, if the room's spaciousness were to be so vital to participants' comfort that it remained predominant throughout the interview. However, as in most social psychological research (Funder \& Ozer, 2019; Richard et al., 2003), based on the (limited) research so far, it appears that effect sizes of environmental manipulations tend to be small. In our first experimental study (Chapter 2), while participants were perceptive of the room's size, the difference between conditions on their perceived comfort was rather small $(r=.215)$. Even in Dawson and colleagues' (2017) studies, participants were found to provide more 
information when interviewed in the larger room as opposed to the small room, yet the difference yielded a small effect size $(d=0.33)$. The lack of differences between location conditions in Chapter $\mathbf{3}$ could perhaps also be attributed to the likelihood that the manipulations, if effective, would have yielded a small effect size, and we were powered to only detect a larger one.

The argument can be made that if environmental influences are estimated to be small, whether such effects would have any real-life application. Anderson, Kelley, and Maxwell (2017) suggested that, when examining practical questions, researchers should consider a large effect size because only very salient findings will be compelling to practitioners and are worthy of wide implementation. If aspects like room spaciousness and the interview location would only yield small effects, is this highly practical field of research worth pursuing then? We argue that small effect sizes in critical scenarios, such as criminal investigative interviews are still informative and useful, particularly given the robust theoretical associations between the environment and communication (e.g., Hartley, 2002), and their practical relevance (Chapter 2).

Another possible reason for the lack of significant differences on disclosure relates to participants' length of exposure to our environmental manipulations. In both of our experimental studies, the interviews lasted between 5 and 10 minutes, and thus, they involved a relatively small dose of exposure to the environment compared to what a suspect would be exposed to in an actual investigative interview (e.g., sitting all day in a small and sterile room). Thus, there may be a dose-response association whereby the effects of environmental manipulations are more salient (and larger in size) contingent on longer periods of exposure.

\section{Implications for Research}

\section{Null Findings and the 'Replication Crisis'}

Research on investigative interviewing environments is scarce - only a few studies were published by the time we designed this dissertation research. Therefore, these published studies, reported in Dawson et al. (2017), were highly influential to ours. Especially, in our first experimental study (Chapter 3), we sought to replicate Dawson and colleagues' findings on physical spaciousness and information disclosure, and we were unable to. We take this opportunity to discuss the implications of failed replications, and our thoughts on publishing null findings at the time of the so-called 'replication crisis' in psychology (Yong, 2018).

According to Francis (2014): “...experimental replication is the final arbiter in determining whether effects are true or false" (p.585). Recently, several failed attempts to replicate prominent 
findings in psychology have cast doubt on the trustworthiness of psychological research (e.g., Lynott et al., 2014; Klein et al., 2018; Verschuere et al., 2018), and thus the 'replication crisis' emerged. Consequently, there has been much discussion as to which factors led to the 'crisis' and what we ought to do about it. Whereas before, pure replication studies were seen as less prestigious than original studies, there is now an ongoing effort to conduct replications, and with that, more sound supporting evidence across many subfields of psychology (Earp \& Trafimow, 2015). With the acknowledged need for replication, there has also been much debate as to what a replication is, and how it can be informative.

One relevant distinction is between "direct" and "conceptual" replications. A "direct" replication means that the replicating study maintains all aspects, including the procedure, equipment and materials, the cultural background, the gender of the experimenter, etc., as similar as possible to the original study. The purpose of a direct replication is to "check" the robustness of the original results (Simons, 2014). In contrast, a "conceptual" replication seeks to validate, or examine whether the phenomena found in the original study expand to other conditions, and so certain elements of the original experiment are intentionally altered (Earp \& Trafimow, 2015). In Chapter 3, our attempt to replicate Dawson and colleagues' (2017) findings were far from direct, there were considerable differences between the experiments. As a consequence, our results reveal little about the robustness of the original study.

Still, the fact that we did not fully replicate Dawson and colleagues' (2017) findings on spaciousness and disclosure is timely, especially given the novelty of this line of research. Because we know so little about the potential environmental influences in investigative interviews, it is imperative to begin building this line of research through appropriate, optimal, and transparent research practices, which include replication efforts, even if they fail to support previous findings. Notably, failures to replicate do not mean that the original study isn't trustworthy. Novel research is vulnerable to nonreplicable results because it may have less development in its theoretical underpinnings, thus requiring less restraints from theory (Wilson \& Wixted, 2018), and has few previous findings to inform its hypotheses on (Lewandowsky \& Oberauer, 2020). Moreover, replication studies also have considerable limitations: the different results may have been a product of unaccounted moderator variables, for example (Klein et al., 2018). Rather, failed replications highlight the importance of accumulative evidence, particularly in applied research areas, such as this one where the goal is to offer practical recommendations to investigators. 


\section{The Issue of Ecological Validity}

The majority of experimental research in the legal psychology field includes a lack of ecological validity as a limitation, at least to some extent. Our studies are no exception. There are specific challenges pretraining to this dissertation's topic of research that are worth discussing. It is quite obviously challenging to simulate the physical environment of police custody. Participants arrive at a lab room within a university building, not a police station. They sit down in a lab room, potentially similar to ones they've been inside before for other experiments, and they get interviewed by a person who is clearly not a police investigator, soon after signing a consent form. This is not to say that these limitations aren't present in all experimental investigative interviewing research, but when the primary focus of the studies is the environment itself, achieving some level of realism is considerably more difficult. Perhaps even more importantly though is the difficulty of simulating the affective experience of being in a police interview room. The environment in which the actual police interviews occur is an extension, a physical and visual representation, of the current situation interviewees find themselves in. While specific elements within the environment may exert significant influence on interviewee's affect, perceptions, and even behaviors, they are ultimately embedded in the situational context, that is, an interview with the police regarding a crime-related event.

To illustrate this point, we will discuss a study that was not included in this dissertation. Following Brandon, Wells, and Seale's (2018) suggestion that "because a sense of freedom to choose, or autonomy, facilitates rapport with the interviewer, the subject might be allowed to choose his chair and where he sits from among several options-and should not be put in a corner where he feels trapped" (p.136), we designed a study in which participants ( $N=103)$ either chose their seating prior to the start of the interview (choice condition), or were directed to a specific seat (no-choice condition). The interviews were related to a bike theft, in which the participants were considered to be accomplices. Those in the no-choice condition were sat against a wall and interviewed at a standard $122 \mathrm{~cm}$ distance from the investigator, following the Reid manual recommendation. We expected that having the choice of were to sit, at their own preferred distance, would foster higher feelings of comfort and autonomy. However, we did not confirm our hypothesis, even though we did find that those in the choice condition on average selected a distance of $159.72 \mathrm{~cm}$, almost $38 \mathrm{~cm}$ more than the Reid manual recommendation. The subtlety of our choice manipulation may have been a reason for the lack of difference, which is likely exacerbated by the low ecological validity. That autonomy and feeling in control are 
important elements for interviewees in police custody is certain (e.g., Vrij et al., 2006). However, in an experimental setting, with participants placed in a mock interview that elicits a low level of arousal, their sense of autonomy and control is not realistically challenged, choice and power over their environment may be less significant to them. For these reasons, it is necessary to study environmental influences in the field.

Relatedly, the subtlety of non-coercive environmental manipulations may be more difficult to study in the lab. As depicted through Tommy Ward's case highlighted in Chapter 1, by promoting isolation and a sense of loss of control, interview rooms can be used as a mean of coercion (Gudjonsson, 2003). In their study with high-value detainees, Goodman-Delahunty and colleagues' (2014) distinction between what aspects were considered coercive and non-coercive was quite dramatic. The detainee is either put in isolation, under physical restraints, and under extreme temperatures, or they are placed in a comfortable room with soft seating, allowed breaks and given refreshments (Goodman-Delahunty \& Sivasubramaniam, 2013a). It is easy to understand why detainees would report preferring the non-coercive environment and respond more productively to investigators' efforts in such conditions compared to the coercive ones, because coercion increases resistance (Vrij et al., 2017). Thus, the benefits of a non-coercive environment over a coercive one are clear. However, without the actual experience of this sharp contrast, non-coercive manipulations may not be salient enough.

\section{Suggestions for Future Research}

Several suggestions for future research can be made to advance our knowledge on optimizing investigative interviewing environments. First, it would be fruitful to explore potential mediation and moderation effects that occur between environmental factors and other variables associated with investigative interviews, to gain a fine-grained and integrated understanding of the role of the environment. An example, related to the Chapter 4 discussion, could be to explore how certain environmental manipulations may be more salient among individuals high on personality traits, such as social anxiety.

In our experimental studies, we focused on interviewees' perceptions. However, investigative interviews are bi-directional interactions, and future research should account for investigators as an independent factor as well. The interview rooms form part of investigators' daily work environment, and work environments can affect work satisfaction and personal wellbeing (Kamarulzaman et al., 2011; Vischer, 2008). Considering the substantial amount of time 
investigators spend inside interview rooms, an environment that is dull, intimidating and uncomfortable (both mentally and physically) can have consequences for both their interviewing practice and their overall wellbeing. Police from West Valley, Utah (US), who implemented a "soft" interview room, acknowledged that the room's environment is not only useful to increase interviewees' comfort, but investigators' as well (Oligschlaeger, 2015).

Relatedly, as aforementioned, there may be a dose-response association between the exposure to the interview environment and interviewee/investigator behavior that we did not account for. For instance, referencing back to the lighting example from Hartley (2002; Chapter 1), conducting the first interview of the day in a room with harsh, fluorescent lighting may not readily affect the investigator. However, by the fifth interview under this lighting, the investigator (or interviewee if we consider repeated interviews) may experience eyestrain and fatigue, which in turn could lead to irritability and, as such, a problematic communication style. Future research will benefit from exploring how the environment influences both perceptions and behaviors after longer periods of environmental exposure.

In our experimental studies, we focused on self-reported perceptions, or interviewees' subjective experience, during the interviews. Future research could expand to explore covert responses to environmental aspects. Back to the lighting example, there is evidence for the effect of different types of lighting conditions on individuals' alertness and task performance (Barkmann et al., 2012; Shamsul et al., 2013). In an educational setting, for instance, one study found that students' performance on computer tasks was higher when conducted under cool white light compared to warm white light (Shamsul et al., 2013). Cooler colors have a stimulating effect that leads to increased concentration levels (Barkmann et al., 2012; Viola et al., 2008). The same study also found that students tested under the cool white lighting also self-reported higher comfort levels. Examining what lighting conditions are most optimal for investigative interviewing, both in relation to the task of recalling information as well as perceived physical comfort, would be an interesting avenue for future research, with practical relevance for (re)designing interview rooms.

We also only examined a few aspects of the physical environment (i.e., room size, interpersonal distance, and interview location). There is obviously a plethora of aspects relevant to investigative interviewing practice that future research should explore. For example, based on responses from detainees and the general population (Chapter 4), simple changes to the interview room's color may create a more comfortable environment that fosters disclosure. Future research should establish the degree to which physical comfort is predictive of cooperation and information 
disclosure. Similarly, investigators reported to consider their clothing prior to interviews, yet there is no empirical evidence for the benefits of wearing uniforms versus informal clothes when interviewing suspects or witnesses (e.g., in reducing interviewees' anxiety; Chapter 2).

Most importantly though, as discussed above, future research on interview environments would benefit from field research. We need studies conducted in actual police interview environments to more appropriately gauge how interviewees interpret the physical environment, and whether it can be used to facilitate information disclosure. Field validation is necessary to provide a better understanding of the mechanisms by which the physical environment influences the interview outcome, especially when the ultimate goal is to provide practical recommendations on room (re)design and interviewing techniques. For example, researchers can work together with practitioners on examining whether the "soft" interview rooms employed by some police stations (e.g., Bologna, 2019; Connelly, 2019) are indeed more effective in reducing the stress associated with police interviews, in fostering rapport-building and information elicitation. Moreover, while individuals expect suspects to be interviewed in more authoritarian, sterile police rooms (Chapter 5; Feld, 2014) findings from our police survey (Chapter 2) showed that many investigators wished their current rooms were less sterile and emphasized the need for creating a more comfortable and relaxing setting. Field studies could examine interviews with suspects conducted in these "soft" rooms compared to those in the typical suspect rooms, in order to address the limitations of ecological validity present in the current studies. Field settings are also ideal for examining interactive processes between interviewees and investigators' individual differences, interviewing techniques, and situational factors (e.g., Surmon-Böhr, et al., 2020).

Related to rapport-building, there are also noteworthy consideration for future research. Acknowledging the lack of current consensus as to what specific characteristics interviewees perceive as rapport (Abbe \& Brandon, 2013), future studies should examine more closely how rapport interacts with the interview environment (Kelly et al., 2013). Providing a closer examination of how aspects of the physical environment (e.g., spaciousness, physical comfort) as well as other positive affective experiences (e.g., feeling at ease, feeling in control) relate to interviewees' perceptions of rapport, can help establish their diagnostic value for its measurement. 


\section{Implications for Police Practice}

As aforementioned, it is imperative to express caution when providing generalizations and practical recommendations based on studies that have yet to be replicated and expanded to the field. That being said, this dissertation provides some noteworthy considerations that, with the support of future research, can provide relevant, practical recommendations to law enforcement agencies, particularly for (re)designing interview rooms. In the Netherlands, for example, the Police Services Center is currently developing new guidelines on how to build and design police interview rooms, detention cells, and prisons. In collaboration with researchers, the police are seeking ways to design humanitarian environments that, while serving their custodial function, can also reduce stress in suspects and optimize police practice (Geijsen, 2018; Piotrowska, 2017). This example highlights how research in this area is timely and highly practical toward the enhancement of police practice.

One noteworthy finding from Chapter 2 was that majority of investigators indicated being unsatisfied with their current interview rooms for two main reasons. One reason was the lack of adaptability within the room set up (i.e., furniture available as well as its arrangement, moving auxiliary equipment around). The need for adaptability is not surprising given the dynamic nature of investigative interviews. Investigators acknowledge that their interviewing strategies often depend on the suspect and situation at hand. Therefore, when (re)designing interview rooms, special attention could be given to the functionality of the room and how different aspects within it (i.e., furniture, auxiliary equipment, lighting, and temperature) can be designed to provide investigators with more control and vary these aspects.

A second reason for investigators' dissatisfaction with their current interview rooms was the rooms' sterility. Particularly, investigators reported that creating a comfortable, informal, or relaxing setting was most important when designing interview rooms. This notion was corroborated by detainees and individuals from the general population (Chapter 5), who reported preferring a decorated, comfortable and warm room, as opposed to a typical, sterile room. For example, some participants mentioned decoration, colors, comfortable chairs, and windows as aspects that can help create an environment that supports disclosure. It thus may be beneficial for practitioners to pay closer attention to physical aspects that could increase interviewees' perceptions of comfort and ease of disclosure, aspects that are feasible to implement and largely under the control of practitioners (Goodman-Delahunty et al., 2014). 
Furthermore, investigators indicated that conducting suspects' interviews outside the police station as a useful interviewing technique, partially for convenience. Chapter 4, albeit in a witness scenario, provided some evidence in favor of the convenience factor. If conducting interviews outside of the police station is deemed convenient by investigators, there may be little risk of hindering the rapport-building process as well as the disclosure of relevant information. However, as aforementioned, these, and all findings from this dissertation need to be replicated before any appropriate practical recommendations can be provided.

Chapter 3 provided some evidence that the physical spaciousness of the interview room can aid rapport-building efforts. Participants actively interpreted the larger room's spaciousness as more comfortable, which in turn fostered more positive perceptions of rapport. Thus, (re)designing interview rooms to be spacious may be advantageous. Investigators' responses in Chapter 2 also expressed room size as an important aspect to consider when designing interview rooms. Considering the room's spaciousness makes sense given the established detrimental effects that a lack of personal space can have on interpersonal interactions (e.g., Altman, 1975; Saegert, 1973). Individuals tend to react to being approached "too" closely by distancing themselves (Saegert, 1973). We also note here the findings from the study we discussed on providing interviewees with the choice of where to sit. On average, interviewees chose a seating distance that was larger than the one the Reid manual recommends. While personal space preferences also depend on the particular situation as well as on individual and cultural differences, interview rooms that allow interviewees to maintain their desired level of personal space could be helpful in fostering more positive rapport. A larger interview room allows investigators to get closer to the interviewee if needed, but if the interviewee needs space, a small room does not allow for options.

\section{Limitations}

There are limitations throughout this dissertation that need addressing. First, one of our main outcomes of interest in our two experimental studies (Chapter $\mathbf{2}$ and $\mathbf{3}$ ) was rapportbuilding. The importance of building rapport with interviewees has been reiterated by both academics (Clarke \& Milne, 2001; Fisher \& Geiselman, 1992) and practitioners (Kassin et al., 2007), yet there are notable shortcomings in rapport research. One shortcoming is, as aforementioned, the lack of a clear operational definition specific to investigative interviewing contexts (Abbe \& Brandon, 2013). For the purposes of this dissertation, and in line with previous definitions 
provided (e.g., Abbe \& Brandon, 2013; Walsh \& Bull, 2012), we defined rapport as a positive and constructive relationship between investigator and interviewee.

Second, at present there is no general consensus on how to most appropriately measure rapport (Duke et al., 2018). In our studies, we relied on participants' self-reports through the interaction questionnaire proposed by Vallano and Scheiber-Compo (2015). The interaction questionnaire has been used in previous rapport-related studies (e.g., Ewens et al., 2017; Kieckhaefer et al., 2014), however, the suitability of this questionnaire for measuring rapport, as well as its reliability and validity, remains to be established (see Duke et al., 2018).

Another rapport-related limitation in this dissertation is that in both our experimental studies (Chapter 3 and 4) rapport building was implemented at the beginning of each interview, rather than throughout. In both experiments, the investigator began with a rapport-building phase, where the interviewee was asked about their day, their studies, and future plans before moving onto the crime-related questioning phase. While our studies were standardized to maintain experimental control, rapport building is a fluid process that should be maintained and nurtured throughout the entire interview, for optimal effects (Abbe \& Brandon, 2013; Collins \& Carthy, 2018; Wash \& Bull, 2012).

Moreover, the generalizability of the experimental findings of this dissertation is limited. In Chapters 3 and $\mathbf{4}$, both experiments were conducted with student populations, within university grounds (except for the home interviews in Chapter 3). Simulating police investigations, especially with suspects, carries ethical concerns that limits the options for recreating the high-stakes of real police interviews (Hartwig et al., 2005). As aforementioned in The Issue of Ecological Validity section, field studies, with actual suspects and witnesses, are necessary to supplement the lower generalizability and ecological validity of our lab-based studies.

\section{Conclusions}

Across the four studies outlined in this dissertation, we employed various methodologies (i.e., lab-based experiments, survey questionnaires) and assessed an array of populations (i.e., university students, general population, police investigators, detainees) to comprise a wide examination of potential environmental influences in investigative interview scenarios. Investigative interviews are complex interpersonal interactions, and investigators can benefit from evidence-based recommendations to help maximize the interview process and its outcome, which includes utilizing the interview environment to investigators' advantage. 
We found that police investigators believe the interview environment to be of importance and they already employ some context manipulation techniques, such as considering the impact of their clothing on suspects, and the seating arrangements in their interview rooms. This survey thus established the practical relevance of this line of research. Through experimental studies, we also found initial evidence that physical spaciousness could facilitate rapport building, although unlike previous studies (Dawson et al., 2017), spaciousness did not foster higher information disclosure. Furthermore, we found that witnesses interviewed at their home provided similar amounts of information, and perceived rapport as equally positive as those interviewed in a formal room akin to a police interview suite. It is therefore possible that, if convenient, home interviews are a reliable way to obtain information from witnesses. We also found that detainees and general population individuals alike expect a suspect interview room to be bare, sterile, and undecorated, yet, they prefer a decorated, inviting, and comfortable room, as well as consider it to be more productive.

In sum, investigators and interviewees seem to be perceptive of their surroundings during interviews, and this dissertation provides some evidence for the environment's impact on interviewees perceived experience. Environmental aspects require a more conscious and systematic consideration in investigative interviewing practice. As Gifford (2014) stated, "Wherever you go, there you are-and it matters ... We are always embedded in a place" (p. 543). 


\section{REFERENCES}

Abbe, A., \& Brandon, S. E. (2013). The role of rapport in investigative interviewing: A review. Journal of Investigative Psychology and Offender Profiling, 10(3), 237-249. https://doi.org/10.1002/jip.1386

Adcock, C. (2020, March 3). Attorneys in Ada 'Innocent Man' case request judge vacate Ward's conviction and sentence, point to newly uncovered evidence. The Frontier. https://www.readfrontier.org/stories/attorneys-in-ada-innocent-man-case-request-judgevacate-wards-conviction-and-sentence-point-to-newly-uncovered-evidence/

Anderson, S. F., Kelley, K., \& Maxwell, S. E. (2017). Sample-size planning for more accurate statistical power: A method adjusting sample effect sizes for publication bias and uncertainty. Psychological Science, 28(11), 1547-1562.

\section{https://doi.org/10.1177/0956797617723724}

Alison, L. J., Alison, E., Noone, G., Elntib, S., \& Christiansen, P. (2013). Why tough tactics fail and rapport gets results: Observing Rapport-Based Interpersonal Techniques (ORBIT) to generate useful information from terrorists. Psychology, Public Policy, and Law, 19(4), 411. https://10.1037/a0034564

Almerigogna, J., Ost, J., Bull, R., \& Akehurst, L. (2007). A state of high anxiety: How non-supportive interviewers can increase the suggestibility of child witnesses. Applied Cognitive Psychology, 21(7), 963-974. https://doi:10.1002/acp.1311

Altman, I. (1975). The environment and social behavior: Privacy, personal space, territory, and crowding. Brooks/Cole Publishing Company.

Altman, I. (1990). Conceptualizing 'rapport'. Psychological Inquiry, 1(4), 294-297. https://10.1207/s15327965pli0104_2

Ball, P. (2018, August 27) High-profile journals put to reproducibility test. Nature. https://www.nature.com/articles/d41586-018-06075-z

Bologna, G. (2019, December 10). Officials hope 'soft' interview room will help victims speak with Springfield police. Springfield News-Leader. https://eu.newsleader.com/story/news/crime/2017/10/03/officials-hope-soft-interview-room-help-victimsspeak-springfield-police/727467001/

Bower, B. (2012). The hot and cold of priming: Psychologists are divided on whether unnoticed cues can influence behavior. Science News, 181(10), 26-29. https://10.1002/scin.5591811025 
Barkmann, C., Wessolowski, N., \& Schulte-Markwort, M. (2012). Applicability and efficacy of variable light in schools. Physiology \& behavior, 105(3), 621-627. https://doi.org/10.1016/j.physbeh.2011.09.020

Brandon, S. E., Wells, S., \& Seale, C. (2018). Science-based interviewing: Information elicitation. Journal of Investigative Psychology and Offender Profiling, 15(2), 133-148. https://10.1002/jip.1496

Brimbal, L., Kleinman, S.M., Oleszkiewicz, S., Meissner, C.A. (2019). Developing rapport and trust in the interrogative context: an empirically supported and ethical alternative to customary interrogation practices. https://www.researchgate.net/publication/329815253_Developing_rapport_and_trust_i n_the_interrogative_context_An_empiricallysupported_and_ethical_alternative_to_customary_interrogation_practices

Brown, P.L. (2020, March 6). What would a world without prisons look like? New York Times. https://www.nytimes.com/2020/03/06/arts/design/prison-architecture.html

Bull, R., \& Milne, B. (2004). Attempts to improve the police interviewing of suspects. In G. D. Lassiter (Ed.), Interrogations, confessions, and entrapment (pp. 181-196). New York, NY: Kluwer Academic

Burgoon, J. K. (2015). Expectancy violations theory. In C. R. Berger \& M. E. Roloff (Eds.), The international encyclopedia of interpersonal communication. John Wiley. https://onlinelibrary.wiley.com/doi/10.1002/9781118540190.wbeic102/full

Camerer, C. F., Dreber, A., Holzmeister, F., Ho, T. H., Huber, J., Johannesson, M., ... \& Altmejd, A. (2018). Evaluating the replicability of social science experiments in Nature and Science between 2010 and 2015. Nature Human Behaviour, 2(9), 637. https://10.1038/s41562-0180399-z

Chaikin A. L., Derlega V. J., Miller S. J. (1976). Effects of room environment and self-disclosure in a counseling analogue. Journal of Counseling Psychology, 23(5), 479-481. https://10.1037/0022-0167.23.5.479

Clarke, C., \& Milne, R. (2001). A national evaluation of the PEACE Investigative Interviewing Course. London: Home Office.

Cleary, H. M., \& Bull, R. (2019). Jail inmates' perspectives on police interrogation. Psychology, Crime \& Law, 25(2), 157-170. https:// 10.1080/1068316X.2018.1503667 
Crump, M. J., McDonnell, J. V., \& Gureckis, T. M. (2013). Evaluating Amazon's Mechanical Turk as a tool for experimental behavioral research. PloS One, 8, e57410. https://doi.org/10.1371/journal.pone.0057410

Collins, R., Lincoln, R., \& Frank, M. G. (2002). The effect of rapport in forensic interviewing. Psychiatry, Psychology, and Law, 9(1), 69-78. https://10.1375/pplt.2002.9.1.69

Connelly, K. (2019, October 24). LRPD's new 'soft interview room' designed to comfort victims. Public Radio from UA Little Rock News \& Culture for Arkansas.

https://www.ualrpublicradio.org/post/Irpds-new-soft-interview-room-designed-comfortvictims

Cullen, F. T., Fisher, B. S., \& Applegate, B. K. (2000). Public opinion about punishment and corrections. Crime and Justice, 27, 1-79. https://doi.org/10.1086/652198

Dawson, E., Hartwig, M., Brimbal, L., \& Denisenkov, P. (2017). A room with a view: Setting influences information disclosure in investigative interviews. Law and human behavior, 41(4), 333. https://10.1037//hb0000244

De La Fuente Vilar, A., Horselenberg, R., \& van Koppen P.J. (2018, July). What if witnesses are uncooperative? - A Glimpse on current interviewing practice in the Netherlands. Paper presented at the meeting of the International Investigative Interviewing Research Group, Porto, Portugal.

De La Fuente Vilar, A., Horselenberg, R., Strömwall, L. A., Landström, S., Hope, L., \& van Koppen, P. J. (2020). Effects of cooperation on information disclosure in mock-witness interviews. Legal and Criminological Psychology. Advanced Online Publication. https:// doi/pdf/10.1111/lcrp.12167

Department of the Army. (2006). Human Intelligence Collector Operations: Field Manual No. 2-22. 3 (No. 2). Mundus Publishing.

Dianiska, R. E., Swanner, J. K., Brimbal, L., \& Meissner, C. A. (2019). Conceptual priming and context reinstatement: A test of direct and indirect interview techniques. Law and Human Behavior, 43(2), 131. https://doi.org/10.1037//hb0000323

Duke, M. C., Wood, J. M., Bollin, B., Scullin, M., \& LaBianca, J. (2018). Development of the Rapport Scales for Investigative Interviews and Interrogations (RS3i), Interviewee Version. Psychology, Public Policy, and Law, 24(1), 64. https://10.1037/law0000147

Earp, B. D., \& Trafimow, D. (2015). Replication, falsification, and the crisis of confidence in social psychology. Frontiers in Psychology, 6, 621. https://10.3389/fpsyg.2015.00621 
Evans, J. R., Meissner, C. A., Brandon, S. E., Russano, M. B., \& Kleinman, S. M. (2010). Criminal versus HUMINT interrogations: The importance of psychological science to improving interrogative practice. The Journal of Psychiatry \& Law, 38(1-2), 215-249.

Ewens, S., Vrij, A., Mann, S., Leal, S., Jo, E., \& Houston, K. (2017). The effect of the presence and seating position of an interpreter on eliciting information and cues to deceit. Psychology, Crime \& Law, 23(2), 180-200. https://doi.org/10.1080/1068316X.2016.1239100

Feld, B. C. (2014). Kids, cops, and confessions: Inside the interrogation room. NYU Press.

Fisher, R. P., \& Geiselman, R. E. (1992). Memory enhancing techniques for investigative interviewing: The cognitive interview. Charles C Thomas Publisher.

Fisher, R. P., Geiselman, R. E., \& Amador, M. (1989). Field test of the Cognitive Interview: enhancing the recollection of actual victims and witnesses of crime. Journal of Applied Psychology, 74(5), 722. https://10.1037/0021-9010.74.5.722

Francis, G. (2012). The psychology of replication and replication in psychology. Perspectives in Psychological Science, 7(6), 585-594. https://10.1177/1745691612459520

Geijsen, K. (2018). Persons at risk during interrogations in police custody: Different perspectives on vulnerable suspects (Doctoral dissertation, Maastricht University).

Geiselman, R.E., Fisher, R.P., Firstenberg, I., Hutton, L.A., Sullivan, S.J., Avetissian, I.V. \& Prosk, A.L. (1984). Enhancement of eyewitness memory: An empirical evaluation of the cognitive interview. Journal of Police Science and Administration, 12(1), 74-80.

Gifford, R. (1988). Light, decor, arousal, comfort and communication. Journal of environmental psychology, 8(3), 177-189.

Gifford, R. (2014). Environmental psychology matters. Annual review of psychology, 65, 541-579. https://doi.org/10.1146/annurev-psych-010213-115048

Girgis, L. (2019, November 11). APD introduces soft interview rooms for sexual assault survivors. The Daily Texan. https://thedailytexan.com/2019/11/11/apd-introduces-soft-interviewrooms-for-sexual-assault-survivors

Goodman-Delahunty, J., \& Sivasubramaniam, D. (2013a). Investigative and intelligence interviewing in Asia-Pacific jurisdictions. Report to the US Department of Justice, Federal Bureau of Investigation and Centre for Law and Human Behaviour University of Texas, El Paso. Manly: Charles Sturt University 
Goodman-Delahunty, J., Martschuk, N., \& Dhami, M. K. (2014). Interviewing high value detainees: Securing cooperation and disclosures. Applied Cognitive Psychology, 28(6), 883-897. https://10.1002/acp.3087

Hall, E. (1990). The hidden dimension, reprint. New York: Anchor Books.

Harms, C., \& Lakens, D. (2018). Making “Null Effects" Informative: Statistical Techniques and Inferential Frameworks. Journal of Clinical and Translational Research, 3(Suppl 2), 382. https://10.17605/OSF.IO/48ZC Hartley, P. (2002). Interpersonal communication. Routledge. Hartwig, M., Anders Granhag, P., \& Vrij, A. (2005). Police interrogation from a social psychology perspective. Policing \& Society, 15(4), 379-399. https://10.1080/10439460500309956 Heyer, J. A., \& Traufetter, G. (2011). The Breivik interrogations: Norway massacre suspect reveals all but motive. Spiegel Magazine. http://www.spiegel.de/international/spiegel/the-breivikinterrogations-norway-massacre-suspect-reveals-all-but-motive-a-793923.htm

Hoogesteyn, K., Meijer, E.H., Vrij, A. (2019). The Influence of Room Spaciousness on Investigative Interviews. Legal and Criminological Psychology, 24(2), 215-228.

https://doi.org/10.1111//crp.12156

Hoogesteyn, K., Meijer, E., \& Vrij, A. (2020). Utility and Effectiveness of the Context Manipulation Techniques: Police Investigators' Perspectives. Journal of Police and Criminal Psychology, 1-8. https://doi.org/10.1007/s11896-020-09374-2

Hughes, R., \& Huby, M. (2012). The construction and interpretation of vignettes in social research. Social Work and Social Sciences Review, 11(1), 36-51.

https://dx.doi.org/10.1921/swssr.v11i1.428

Ignatius, E., \& Kokkonen, M. (2007). Factors contributing to verbal self-disclosure. Nordic Psychology, 59(4), 362-391. https://10.1027/1901-2276.59.4.362.

Inbau, F. E., Reid, J. E., Buckley, J. P., \& Jayne, B.C. (2013). Essentials of the Reid technique. Jones \& Bartlett Publishers.

Jeffreys, H. (1961). Theory of Probability. Oxford University Press.

Johnson, C. F., \& Dabbs Jr, J. M. (1976). Self-disclosure in dyads as a function of distance and the subject-experimenter relationship. Sociometry, 39(3), 257-263. https://www.jstor.org/stable/2786518 
Kassin, S. M., Leo, R. A., Meissner, C. A., Richman, K. D., Colwell, L. H., Leach, A. M., \& La Fon, D. (2007). Police interviewing and interrogation: A self-report survey of police practices and beliefs. Law and human behavior, 31(4), 381-400. https://10.1007/s10979-006-9073-5

Kelly, C. E., Dawson, E., \& Hartwig, M. (2019). Context manipulation in police interviews: a field experiment. Journal of Experimental Criminology, 1-20. https://10.1007/s11292-019-093898

Kelly, C. E., Miller, J. C., Redlich, A. D., \& Kleinman, S. M. (2013). A taxonomy of interrogation methods. Psychology, Public Policy, and Law, 19(2), 165-178. https://10.1037/a0030310

Kelly, C. E., Redlich, A. D., \& Miller, J. C. (2015). Examining the meso-level domains of the interrogation taxonomy. Psychology, Public Policy, and Law, 21(2), 179-191. https://10.1037/law0000034

Kieckhaefer, J. M., Vallano, J. P., \& Schreiber Compo, N. (2014). Examining the positive effects of rapport building: When and why does rapport building benefit adult eyewitness memory?. Memory, 22(8), 1010-1023. https://10.1080/09658211.2013.864313

Knapp, M. L., Hall, J. A., \& Horgan, T. G. (2013). Nonverbal communication in human interaction. Cengage Learning.

Klein, R. A., Vianello, M., Hasselman, F., Adams, B. G., Adams Jr, R. B., Alper, S., ... \& Batra, R. (2018). Many Labs 2: Investigating variation in replicability across samples and settings. Advances in Methods and Practices in Psychological Science, 1(4), 443-490. https://10.1177/2515245918810225

Lakens, D. (2016, January 14). Power analysis for default Bayesian t-tests [Blog post]. http://daniellakens.blogspot.com/2016/01/power-analysis-for-default-bayesian-t.html Lakoff, G. (2012). Explaining embodied cognition results. Topics in cognitive science, 4(4), 773-785. https://10.1111/j.1756-8765.2012.01222.x

Lebaron, C. D., \& Streeck, J. (1997). Built space and the interactional framing of experience during a murder interrogation. Human studies, 20(1), 1-25. https://10.1023/A:1005305331171

Lewandowsky, S., \& Oberauer, K. (2020). Low replicability can support robust and efficient science. Nature Communications, 11(1), 1-12.

Lynott, D., Corker, K. S., Wortman, J., Connell, L., Donnellan, M. B., Lucas, R. E., \& O’Brien, K. (2014). Replication of "Experiencing physical warmth promotes interpersonal warmth" by Williams and Bargh (2008). Social Psychology, 45, 216-222. https://doi.org/10.1027/18649335/a000187. 
Richard, F. D., Bond Jr, C. F., \& Stokes-Zoota, J. J. (2003). One hundred years of social psychology quantitatively described. Review of General Psychology, 7(4), 331-363. https://doi.org/10.1037/1089-2680.7.4.331

Marr, C., Sauerland, M., Otgaar, H., Quaedflieg, C., \& Hope, L. (2018) The effect of acute stress on memory: How it helps and how it hurts. The Inquisitive Mind Magazine, 38/2018. http://www.in-mind.org/article/the-effect-of-acute-stress-on-memory-how-it-helps-andhow-it-hurts

Meissner, C. A., Kelly, C. E., \& Woestehoff, S. A. (2015). Improving the effectiveness of suspect interrogations. Annual review of law and social science, 11, 211-233. https://doi.org/10.1146/annurev-lawsocsci-120814-121657

Meissner, C. A., Redlich, A. D., Michael, S. W., Evans, J. R., Camilletti, C. R., Bhatt, S., \& Brandon, S. (2014). Accusatorial and information-gathering interrogation methods and their effects on true and false confessions: A meta-analytic review. Journal of Experimental Criminology, 10(4), 459-486. https://10.1007/s11292-014-9207-6

Meissner, C. A., Surmon-Böhr, F., Oleszkiewicz, S., \& Alison, L. J. (2017). Developing an evidencebased perspective on interrogation: A review of the U.S. government's high-value detainee interrogation group research program. Psychology, Public Policy, and Law, 23(4), 438-457. https://10.1037/law0000136

Meyers-Levy, J., Zhu, R. (2007). The influence of ceiling height: The effect of priming on the type of processing that people use. Journal of Consumer Research, 34(2), 174-186. https://doi.org/10.1086/519146

Miller, J. C., Redlich, A. D., \& Kelly, C. E. (2018). Accusatorial and information-gathering interview and interrogation methods: a multi-country comparison. Psychology, Crime \& Law, 24(9), 935-956. https://10.1080/1068316X.2018.1467909

Oberfeld, D., Hecht, H., \& Gamer, M. (2010). Surface lightness influences perceived room height. The Quarterly Journal of Experimental Psychology, 63(10), 1999-2011. https://10.1080/17470211003646161

Okken, V., van Rompay, T., \& Pruyn, A. (2012). Exploring space in the consultation room: Environmental influences during patient-physician interaction. Journal of Health Communication, 17(4), 397-412. https://10.1080/10810730.2011.626498 
Okken, V., van Rompay, T., \& Pruyn, A. (2013). Room to move: On spatial constraints and selfdisclosure during intimate conversations. Environment and Behavior, 45(6), 737-760. https://10.1177/0013916512444780

Okken, V., Van Rompay, T., \& Pruyn, A. (2013b). When the world is closing in. Effects of perceived room brightness and communicated threat during patient-physician interaction. Health Environments Research and Design Journal, 7(1), 35-51. https://doi.org/10.1177/193758671300700104

Oligschlaeger, A. (2015, April 22). New 'soft' interview room to help victims of violence in West Valley. KSL. https://www.ksl.com/article/34348189/new-soft-interview-room-to-helpvictims-of-violence-in-west-valley

Piotrowska, K. (2017). Humanisation of cell complexes. (Master's thesis). Academy of Arts, Utrecht, the Netherlands. https://issuu.com/katepiotrowska/docs/k.piotrowska humanisation of cell

Quintana, D. S., \& Williams, D. R. (2018). Bayesian alternatives for common null-hypothesis significance tests in psychiatry: a non-technical guide using JASP. BMC psychiatry, 18(1), 178. https://10.1186/s12888-018-1761-4

Saegert, S. C. (1973). Crowding, cognitive overload and behavioral constraint. In N. Prieser (Ed.), Environmental design and research. PA: Dresden, Hutchinson and Ross.

Shamsul, B. M. T., Sia, C. C., Ng, Y. G., \& Karmegan, K. (2013). Effects of light's colour temperatures on visual comfort level, task performances, and alertness among students. American Journal of Public Health Research, 1(7), 159-165. https://10.12691/ajphr-1-7-3

Shepherd, E. \& Griffiths, A. (2013). Investigative Interviewing. The Conversation Management Approach (2nd ed.). Oxford: Oxford University Press

Simons, D. J. (2014). The value of direct replication. Perspectives on Psychological Science, 9(1), 7680. https://doi.org/10.1177/1745691613514755

Snook, B., Brooks, D., \& Bull, R. (2015). A lesson on interrogations from detainees: predicting selfreported confessions and cooperation. Criminal Justice and Behavior, 42(12), 1243-1260. https:// 10.1177/0093854815604179

Spielberger, C. D., Gorsuch, R. L., Lushene, R., Vagg, P. R., \& Jacobs, G. A. (1983). Manual for the State-Trait Anxiety Inventory. Consulting Psychologists Press. 
Sundstrom, E. (1975). An experimental study of crowding: Effects of room size, intrusion, and goal blocking on nonverbal behavior, self-disclosure, and self-reported stress. Journal of Personality and Social Psychology, 32(4), 645. https://10.1037/0022-3514.32.4.645 Surmon-Böhr, F., Alison, L., Christiansen, P., \& Alison, E. (2020). The right to silence and the permission to talk: Motivational interviewing and high-value detainees. American Psychologist. Advance online publication. https://dx.doi.org/10.1037/amp0000588

U.S. Army. 2006. FM 2-22.3 (FM 34-52), Human Intelligence Collector Operations. Washington, DC: Headquarters, Department of the Army.

Vallano, J. P., \& Compo, N. S. (2011). A comfortable witness is a good witness: Rapport building and susceptibility to misinformation in an investigative mock-crime interview. Applied Cognitive Psychology, 25(6), 960-970. https://10.1002/acp.1789

Vallano, J. P., Evans, J. R., Schreiber Compo, N., \& Kieckhaefer, J. M. (2015). Rapport-building during witness and suspect interviews: A survey of law enforcement. Applied Cognitive Psychology, 29(3), 369-380. https://10.1002/acp.3115

Verschuere, B., Meijer, E. H., Jim, A., Hoogesteyn, K., Orthey, R., McCarthy, R. J., ... \& Barbosa, F. (2018). Registered replication report on Mazar, Amir, and Ariely (2008). Advances in Methods and Practices in Psychological Science, 1(3), 299-317. https://10.1177/2515245918781032

Vischer, J. C. (2008). Towards an environmental psychology of workspace: How people are affected by environments for work. Architectural Science Review, 51(2), 97-108. https://doi.org/10.3763/asre.2008.5114

Viola, A. U., James, L. M., Schlangen, L. J., \& Dijk, D. J. (2008). Blue-enriched white light in the workplace improves self-reported alertness, performance and sleep quality. Scandinavian Journal of Work, Environment \& Health, 297-306. https://10.5271/sjweh.1268

Vrij, A., Hope, L., \& Fisher, R. P. (2014). Eliciting reliable information in investigative interviews. Policy Insights from the Behavioral and Brain Sciences, 1(1), 129-136. https://10.1177/2372732214548592

Vrij, A., Meissner, C. A., Fish er, R. P., Kassin, S. M., Morgan III, C. A., \& Kleinman, S. M. (2017). Psychological perspectives on interrogation. Perspectives on Psychological Science, 12(6), 927-955. https://10.1177/1745691617706515

Westera, N., \& Powell, M. (2015). Improving communicative practice: Beyond the cognitive interview for adult eyewitnesses. In G. Oxburgh, T. Myklebust, T. Grant \& R. Milne (Eds.), 
Communication in investigative and legal contexts: Integrated approaches from forensic psychology, linguistics and law enforcement (pp. 337-358). Chichester, UK: Wiley Blackwell. Westera, N., Kebbell, M. R., \& Milne, R. (2011). Interviewing rape complainants: Police officers' perceptions of interview format and quality of evidence. Applied Cognitive Psychology, 25(6), 917-926. https://10.1002/acp.1770

Williamson, T. M. (1993). From interrogation to investigative interviewing; strategic trends in police questioning. Journal of Community \& Applied Social Psychology, 3(2), 89-99. https:// 10.1002/casp. 2450030203

Wilson, B. M., \& Wixted, J. T. (2018). The prior odds of testing a true effect in cognitive and social psychology. Advances in Methods and Practices in Psychological Science, 1(2), 186-197. https://10.1177/2515245918767122

Yeschke, C. L. (1997). The art of investigative interviewing: A human approach to testimonial evidence. Boston: Butterworth-Heinemann.

Yong, E. (2018, November 19). Psychology's replication crisis is running out of excuses. The Atlantic. https://www.theatlantic.com/science/archive/2018/11/psychologys-replicationcrisis-real/576223/ 


\section{APPENDICES}




\section{APPENDIX A}

\section{POLICE SURVEY (CHAPTER 2)}

Information regarding the study:

We would like to invite you to complete an online questionnaire regarding your perceptions, knowledge, and current use of techniques specific to the environment/setting in which investigative interviews take place. Your responses to this questionnaire will contribute to helping scholars understand to what goal and extent environmental manipulation techniques are used in the field, and how effective they are when employed during suspect interviews.

The questionnaire includes 13 questions, and will take approximately 20 minutes to complete. This questionnaire has been reviewed and approved by the Ethics Committee at Maastricht University. The questionnaire will be completed confidentially, and you are not required to provide your name or personal/identifying information. You will be asked for some basic demographic information that will not uniquely identify you.

We have taken all reasonable steps to ensure confidentiality in line with the Maastricht University procedures. You are free to withdraw at any stage if you do not wish to submit your responses. By completing this questionnaire, you consent to participate in this study and that your data be shared in future studies.

If you have any questions or would like to learn more about the results of the research, please contact me, Katherine Hoogesteyn (PhD candidate at Maastricht University) at k.hoogesteyn@maastrichtuniversity.nl, or my supervisors Ewout Meijer (Assistant professor of Forensic Psychology at Maastricht University) at eh.meijer@maastrichtuniversity.nl and Prof. Aldert Vrij (Professor of Applied Social Psychology at the University of Portsmouth) at aldert.vrij@port.ac.uk. 


\section{Demographics:}

1) Please indicate your age

2) Please indicate your gender

Male

Female

3) Please indicate country of residence

4) Please indicate your native language

5) Please indicate your English proficiency level

Beginner

Intermediate

Advanced

Native

6) Please indicate your current rank

7) Please indicate your total years of experience interviewing suspects

8) Have you received any special training/workshop/seminar on conducting interviews? If yes, which specific trainings?

Yes

No

9) Law enforcement agency/unit in which you currently work

10) To what extend do you consider yourself up to date with the scientific literature on suspect interview methods?

Not at all

Somewhat up to date

Moderately up to date

Mostly up to date

Extremely up to date 
Thank you for taking the time to complete the following short questionnaire. This survey will focus on your perceptions, knowledge, and current use of techniques specific to the environment/setting in which investigative interviews take place. Please answer thoroughly and truthfully.

1) Is there anything you do on purpose, in relation to the interview environment/setting, to prepare for a suspect interview? For example, arranging the chairs in a particular way, deciding on a specific location to conduct the interview, changing out of uniform to wear something informal, etc.

1.

2.

3.

4.

5.

6.

For each thing you mentioned above, place a number from 1 to 7 in the box to indicate how effective you consider this to be ( 1 = not effective, $4=$ neutral, $7=$ very effective) .

On the 'Purpose' column, please write why you consider it effective. For example, for making the interviewee more comfortable, or for showing interest in what they have to say, etc.

\begin{tabular}{|l|l|l|}
\hline & $\begin{array}{c}\text { Effectiveness } \\
1=\text { not effective, } 4=\text { neutral, } \\
7=\text { very effective }\end{array}$ & $\begin{array}{c}\text { Purpose } \\
\text { Why you consider it } \\
\text { effective? }\end{array}$ \\
\hline 1. & & \\
\hline 2. & & \\
\hline 3. & & \\
\hline 4. & & \\
\hline 5. & & \\
\hline 6. & & \\
\hline
\end{tabular}


2) In your opinion, how important do you consider the environment/setting of the interview to be during an investigative interview. Please check one:

Extremely important

Very important

Moderately important

Slightly important

Not at all important

3) Thinking about the aims and purposes of an interview, what do you consider to be the most important characteristics when designing an interview room?

The following questions will ask you about a specific interview domain: context manipulation. This term refers to the altering of the physical and temporal space where the interviewing occurs to maximize the probability of a successful outcome (the techniques listed below all fall under the context manipulation category). 


\begin{tabular}{|c|c|c|c|c|}
\hline 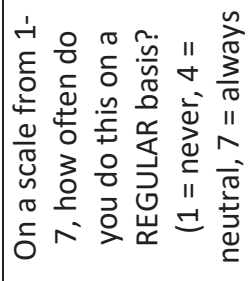 & & & & \\
\hline 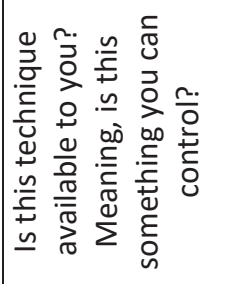 & $\frac{\stackrel{0}{z}}{\stackrel{\tilde{u}}{\nu}}$ & 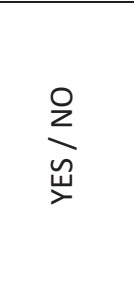 & $\frac{\stackrel{0}{z}}{\stackrel{\breve{m}}{\rightleftharpoons}}$ & 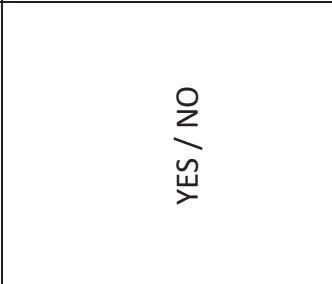 \\
\hline 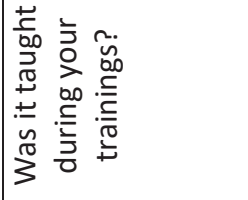 & $\frac{\stackrel{0}{z}}{\underset{y}{\breve{x}}}$ & $\frac{\stackrel{0}{z}}{\stackrel{\underline{u}}{y}}$ & $\frac{\stackrel{0}{z}}{\stackrel{\breve{m}}{\rightleftharpoons}}$ & $\frac{\stackrel{0}{z}}{\stackrel{\breve{y}}{y}}$ \\
\hline 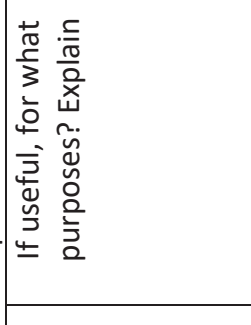 & & & & \\
\hline 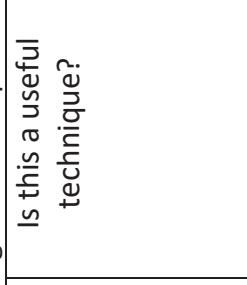 & $\frac{\stackrel{0}{z}}{\stackrel{\breve{w}}{\rightleftharpoons}}$ & $\frac{\stackrel{0}{z}}{\stackrel{\breve{m}}{\rightleftharpoons}}$ & $\frac{\stackrel{0}{z}}{\stackrel{\breve{m}}{\rightleftharpoons}}$ & 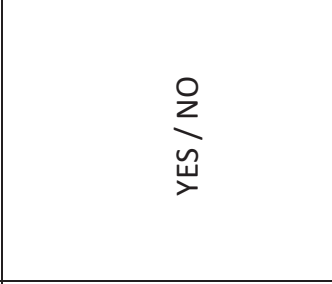 \\
\hline 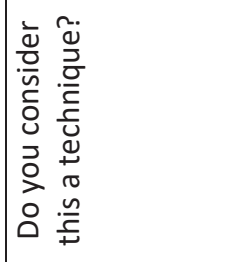 & $\frac{\stackrel{0}{z}}{\stackrel{\tilde{u}}{\nu}}$ & 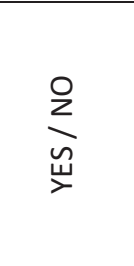 & $\frac{\stackrel{0}{z}}{\stackrel{\breve{m}}{\rightleftharpoons}}$ & $\frac{\stackrel{0}{z}}{\stackrel{\breve{y}}{\rightleftharpoons}}$ \\
\hline & 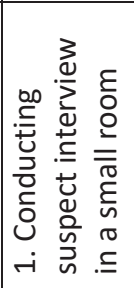 & 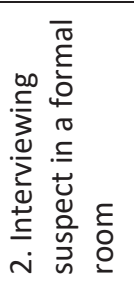 & 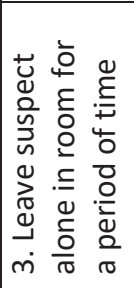 & 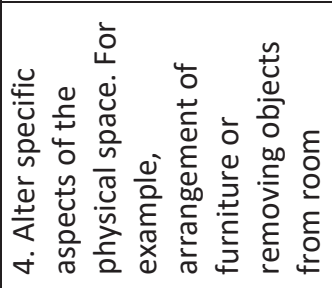 \\
\hline
\end{tabular}




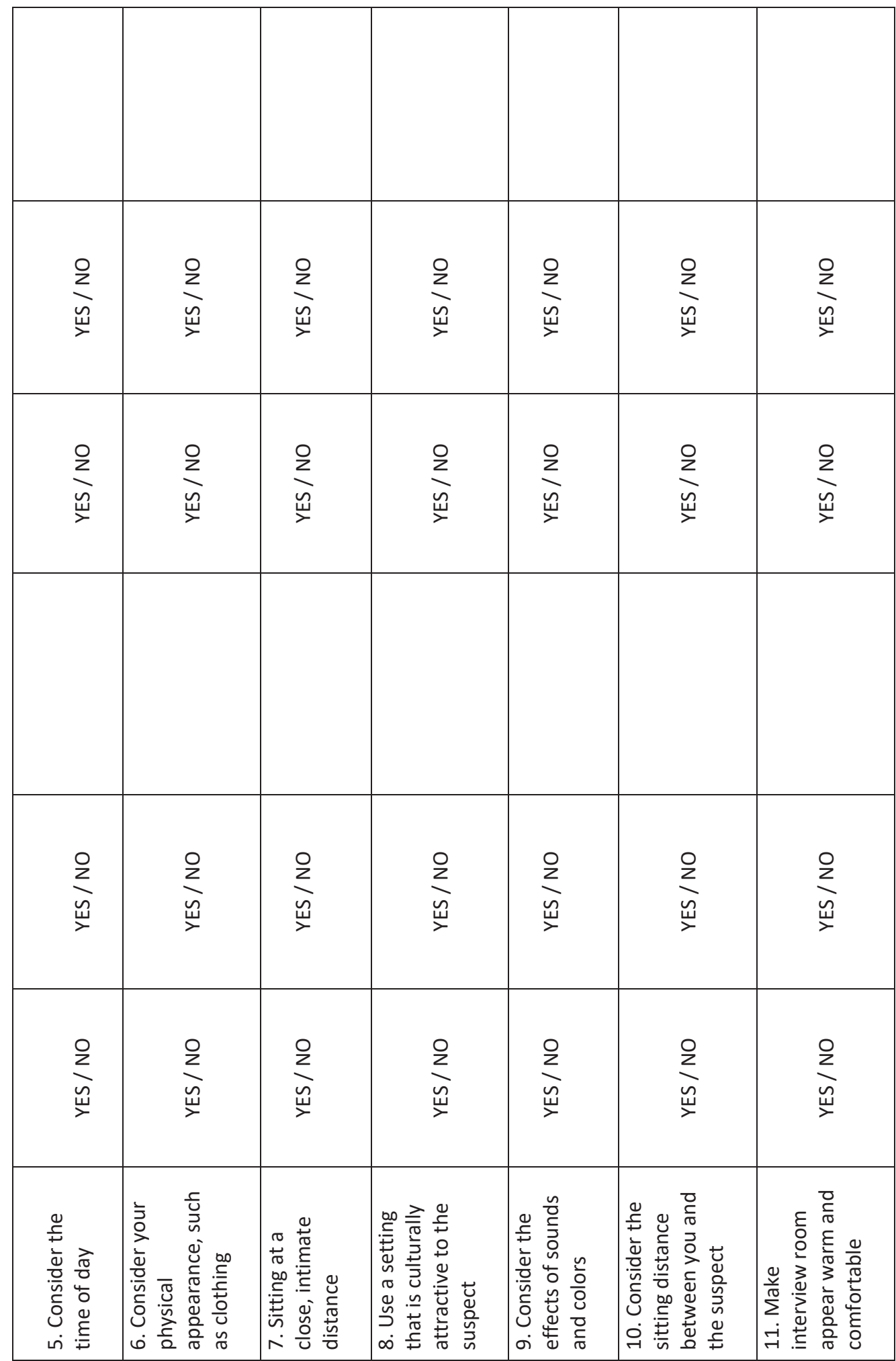




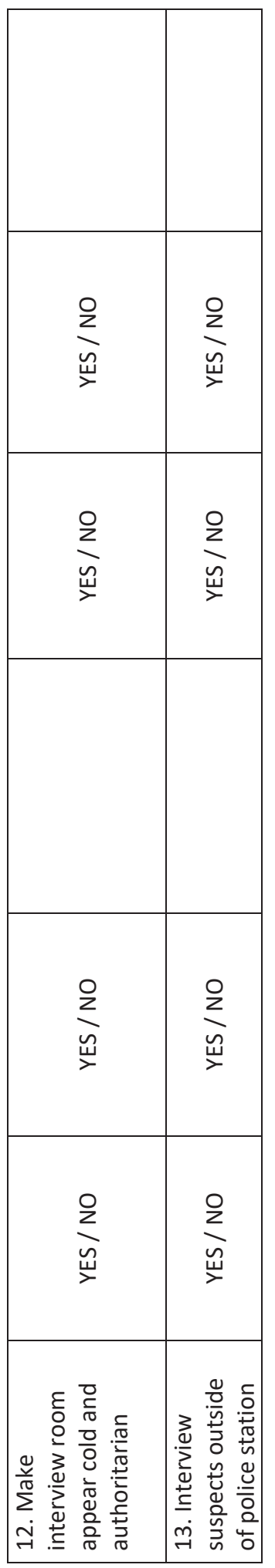


5) Are you currently satisfied with the interview rooms in your station? If not, what would you change?

Yes

No 


\section{Debriefing Statement}

Thank you for completing this questionnaire!

In this questionnaire, we were mainly interested in understanding police officers' knowledge and opinions on interview environments and the potential of context manipulation techniques.

Research examining the influence of the context - or environment - in investigative interviews has only recently started. However, we consider the advantages of environmental manipulations worthy of consideration. Your responses in this survey will help us continue this line of research.

Additionally, we were interested in examining a questioning method, the Crosswise Model, for obtaining honest responses compared to just simply asking direct questions. Some of you received the Crosswise questions, while others receive the direct questions. The questions were all the same, just the way they were asked differed.

Your responses will be kept confidential, and no report resulting from this data will be linked to you.

If you would like to know more about this study or have any concerns, please contact me:

Katherine Hoogesteyn (k.hoogesteyn@maastrichtuniversity.nl) or my supervisors Ewout Meijer (eh.meijer@maastrichtuniversity.nl) and Aldert Vrij (aldert.vrij@port.ac.uk).

Again, many thanks!

Katherine Hoogesteyn

PhD Candidate

Maastricht University \& University of Portsmouth 


\section{APPENDIX B}

\section{DETAINEE QUESTIONNAIRE (CHAPTER 5)}

Hello, my name is Katherine Hoogesteyn, and I am a PhD student at Maastricht University and University of Portsmouth. I am conducting a study to better understand how people feel about police interview rooms, and I invite you to complete the short questionnaire that was provided to you. I am interested in your perceptions and expectations regarding interview rooms. This questionnaire should take approximately 7 minutes to complete, and your complete and honest responses would be very informative regarding police practice and the investigative interview process. Please keep in mind that the questionnaire is designed to preserve your anonymity. In other words, your individual responses will not be shared with the police, or anyone other than me, the experimenter. At the end of the study, your responses will be combined with others who also participated and will be reported as averages in our publication.

Thank you very much for your attention; your thoughts regarding interview rooms are valuable and I am deeply appreciative for the information you provide. 


\section{Demographics:}

Age:

Gender:

Have you been officially interviewed by the police before?

If so: Day Month Year

For what purposes were you last interviewed by police?

In what location were you last interviewed by police?

Have you been admitted to prison before?

If so: Day Month Year

For what offenses were you last admitted to prison?

The following questions will ask about your opinions about police interview rooms. Please read the questions carefully, and answer thoroughly and honestly.

1) Can you please describe in your own words what you expect a suspect interview location to look like?

2) Can you please describe in your own words how you think a suspect interview location should look like in order to encourage you to be talkative? 
Take a careful look at the following photos of Room $A^{8}$

ROOM A:
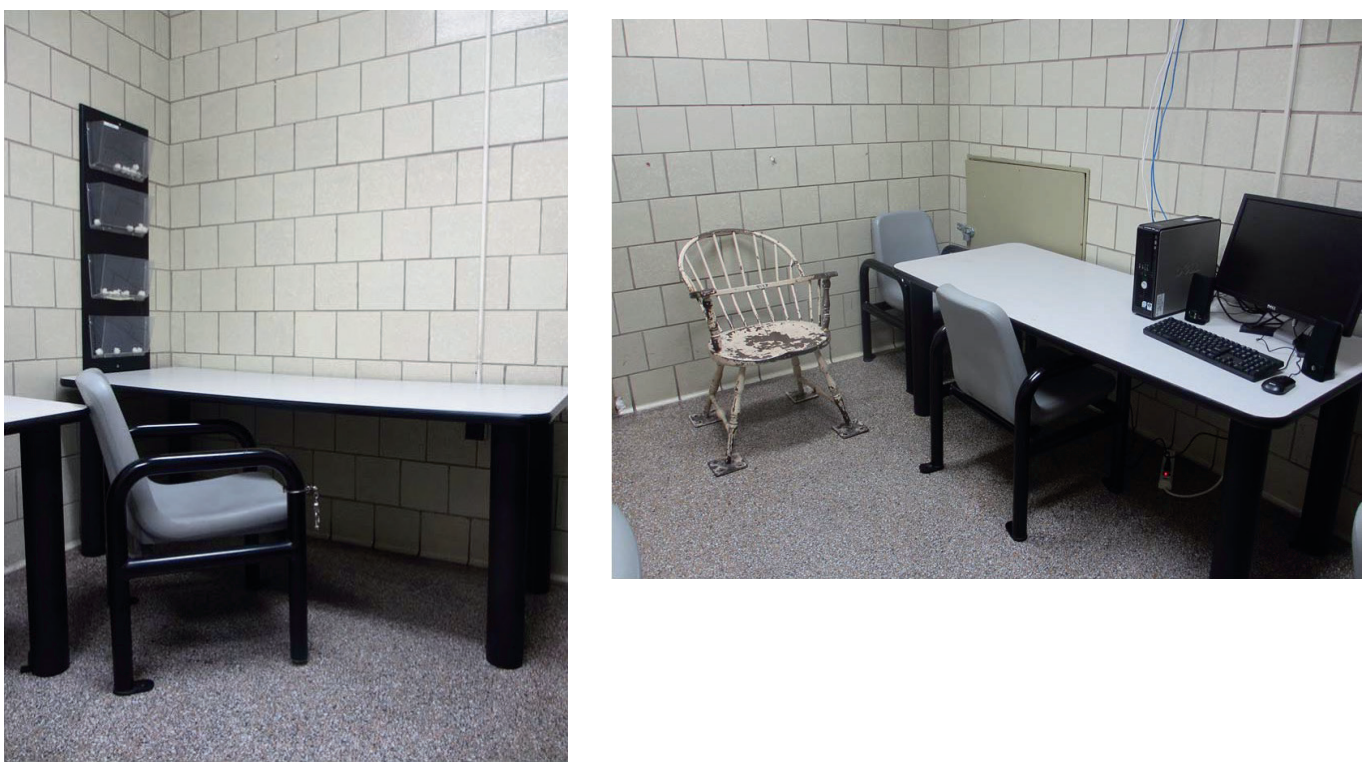

3) If you were interviewed in ROOM A. How would you feel? Please answer all that apply:

a. Comfortable

\begin{tabular}{|c|c|c|c|c|c|c|}
\hline $\begin{array}{c}1 \\
\text { Not at all }\end{array}$ & 2 & 3 & $\begin{array}{c}4 \\
\text { Somewhat }\end{array}$ & 5 & 6 & $\begin{array}{c}7 \\
\text { Extremely }\end{array}$ \\
\hline
\end{tabular}

b. Suspicious

\begin{tabular}{|c|c|c|c|c|c|c|}
\hline $\begin{array}{c}1 \\
\text { Not at all }\end{array}$ & 2 & 3 & $\begin{array}{c}4 \\
\text { Somewhat }\end{array}$ & 5 & 6 & $\begin{array}{c}7 \\
\text { Extremely }\end{array}$ \\
\hline
\end{tabular}

c. Constrained

\begin{tabular}{|c|c|c|c|c|c|c|}
\hline $\begin{array}{c}1 \\
\text { Not at all }\end{array}$ & 2 & 3 & $\begin{array}{c}4 \\
\text { Somewhat }\end{array}$ & 5 & 6 & $\begin{array}{c}7 \\
\text { Extremely }\end{array}$ \\
\hline
\end{tabular}

d. Able to speak freely

\begin{tabular}{|c|c|c|c|c|c|c|}
\hline $\begin{array}{c}1 \\
\text { Not at all }\end{array}$ & 2 & 3 & $\begin{array}{c}4 \\
\text { Somewhat }\end{array}$ & 5 & 6 & 7 \\
Extremely \\
\hline
\end{tabular}

e. Cooperative

${ }^{8}$ Presentation of Room A and Room B were counter-balanced 


\begin{tabular}{|c|c|c|c|c|c|c|}
\hline $\begin{array}{c}1 \\
\text { Not at all }\end{array}$ & 2 & 3 & $\begin{array}{c}4 \\
\text { Somewhat }\end{array}$ & 5 & 6 & 7 \\
Extremely \\
\hline
\end{tabular}

f. Ready to get out

\begin{tabular}{|c|c|c|c|c|c|c|}
\hline $\begin{array}{c}1 \\
\text { Not at all }\end{array}$ & 2 & 3 & $\begin{array}{c}4 \\
\text { Somewhat }\end{array}$ & 5 & 6 & $\begin{array}{c}7 \\
\text { Extremely }\end{array}$ \\
\hline
\end{tabular}

g. Wary

\begin{tabular}{|c|c|c|c|c|c|c|}
\hline $\begin{array}{c}1 \\
\text { Not at all }\end{array}$ & 2 & 3 & $\begin{array}{c}4 \\
\text { Somewhat }\end{array}$ & 5 & 6 & 7 \\
Extremely
\end{tabular}

Take a careful look at the following photos of Room B

\section{ROOM B:}
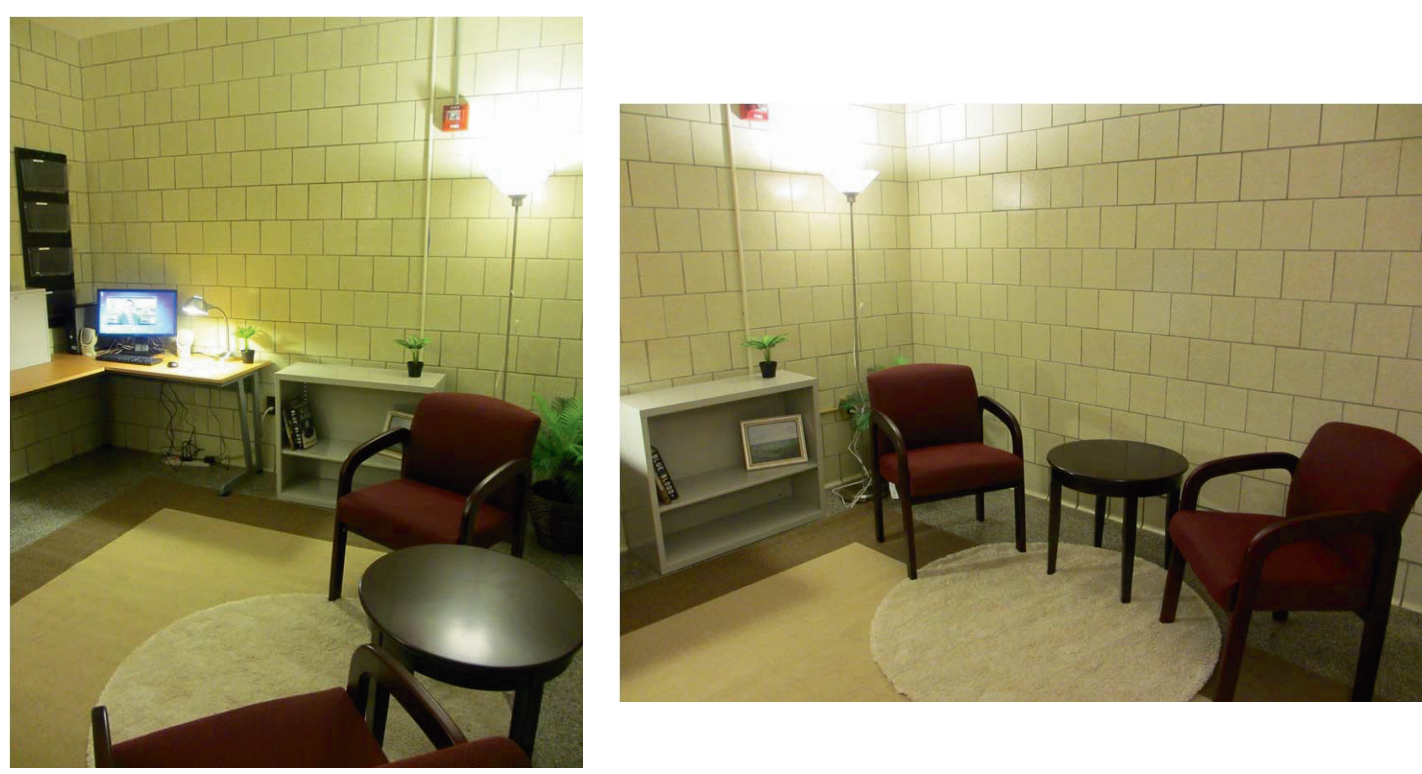

4) If you were interviewed in ROOM B. How would you feel? Please answer all that apply

a. Comfortable

\begin{tabular}{|c|c|c|c|c|c|c|}
\hline $\begin{array}{c}1 \\
\text { Not at all }\end{array}$ & 2 & 3 & $\begin{array}{c}4 \\
\text { Somewhat }\end{array}$ & 5 & 6 & $\begin{array}{c}7 \\
\text { Extremely }\end{array}$ \\
\hline
\end{tabular}

b. Suspicious

\begin{tabular}{|c|c|c|c|c|c|c|}
\hline $\begin{array}{c}1 \\
\text { Not at all }\end{array}$ & 2 & 3 & $\begin{array}{c}4 \\
\text { Somewhat }\end{array}$ & 5 & 6 & $\begin{array}{c}7 \\
\text { Extremely }\end{array}$ \\
\hline
\end{tabular}


c. Constrained

\begin{tabular}{|c|c|c|c|c|c|c|}
\hline $\begin{array}{c}1 \\
\text { Not at all }\end{array}$ & 2 & 3 & $\begin{array}{c}4 \\
\text { Somewhat }\end{array}$ & 5 & 6 & $\begin{array}{c}7 \\
\text { Extremely }\end{array}$ \\
\hline
\end{tabular}

d. Able to speak freely

\begin{tabular}{|c|c|c|c|c|c|c|}
\hline $\begin{array}{c}1 \\
\text { Not at all }\end{array}$ & 2 & 3 & $\begin{array}{c}4 \\
\text { Somewhat }\end{array}$ & 5 & 6 & 7 \\
Extremely \\
\hline
\end{tabular}

e. Cooperative

\begin{tabular}{|c|c|c|c|c|c|c|}
\hline $\begin{array}{c}1 \\
\text { Not at all }\end{array}$ & 2 & 3 & $\begin{array}{c}4 \\
\text { Somewhat }\end{array}$ & 5 & 6 & $\begin{array}{c}7 \\
\text { Extremely }\end{array}$ \\
\hline
\end{tabular}

f. Ready to get out

\begin{tabular}{|c|c|c|c|c|c|c|}
\hline $\begin{array}{c}1 \\
\text { Not at all }\end{array}$ & 2 & 3 & $\begin{array}{c}4 \\
\text { Somewhat }\end{array}$ & 5 & 6 & $\begin{array}{c}7 \\
\text { Extremely }\end{array}$ \\
\hline
\end{tabular}

g. Wary

\begin{tabular}{|c|c|c|c|c|c|c|}
\hline $\begin{array}{c}1 \\
\text { Not at all }\end{array}$ & 2 & 3 & $\begin{array}{c}4 \\
\text { Somewhat }\end{array}$ & 5 & 6 & $\begin{array}{c}7 \\
\text { Extremely }\end{array}$ \\
\hline
\end{tabular}

5) In which room would you expect to be interviewed in as a suspect to a crime? Please circle one.

Room A

Room B

Please explain why:

6) In which room would you prefer to be interviewed in as a suspect to a crime? Please circle one.

Room A

Room B

Please explain why:

Thank you for taking the time to complete this questionnaire. Your responses will be kept confidential, and no report resulting from this data will linked to you. 


\section{ENGLISH SUMMARY}

Successful information elicitation largely relies on the interpersonal dynamic and quality of communication between the investigators and interviewees. One aspect of that dynamic that has been underexplored is the physical environment in which the interview takes place. That the physical environment exerts an influence in our perceptions, behaviors, and communication is not only intuitive, but also substantiated by research outside of legal psychology, such as in the communication, education, and health care fields. Therefore, in this dissertation we examined potential influences of the physical environment specific to the investigative interview domain. We investigated 1) police investigators' perceptions regarding interview rooms, and the use and effectiveness of context manipulation techniques 2 ) the influence of physical spaciousness as well as 3) interview location on interviewee's perceptions of rapport-building and information disclosure, as well as 4) detainee and lay individuals expectations and preferences regarding police interview rooms.

To gain a more complete understanding of how contextual techniques are employed by practitioners in the field, Chapter 2 reports police interviewers' thoughts and knowledge about context manipulation techniques, collected through an international survey. A sample of 81 police investigators completed the survey. Our findings provided evidence that investigators believe the interview setting to be important, and investigators reported to already employ certain context manipulation techniques, particularly related to seating arrangement, investigators' clothing, and item availability for suspects such as water and cigarettes.

We then report the effect of spaciousness in Chapter 3. Participants engaged in a virtual reality (VR) scenario depicting a crime and were interviewed as suspects in either a larger or smaller room, at a closer or longer distance. We found no links between room size and sitting distance on disclosure quantity or quality. However, participants interviewed in the larger room reported a more positive interview experience, which led to higher perceptions of rapport, compared to those interviewed in the smaller room. We also examined different interview locations for a witness interview context (Chapter 4). Participants experienced a VR mock crime, and one week later were interviewed in either their own homes, expected to elicit higher comfort, or in a formal room akin to a real-world police interview room. While participants in the home interview setting reported feeling more at ease and in control, we found no differences between interview location on the quantity and quality of information disclosure or participants' perceptions of rapport-building. 
Lastly, in Chapter 5, we explored individuals' thoughts and expectations regarding police interview rooms. While previous studies suggested that a room made to be 'nice' and comfortable may be optimal for interviewing suspects, another study found it can instead lead to higher suspicion of the investigator's intentions. Therefore, we conducted a survey with current detainees and individuals from the general population who provided descriptive information about their preferences and expectations of police interview environments and compared photos of two rooms; one which resembled a "typical" interview room, and one decorated to be warm, inviting and comfortable. Overall, detainees and general population individuals reported expecting to be interviewed in the "typical" room, but to prefer the decorated one. The decorated room elicited more positive feelings of comfort and cooperation, and lower feelings of suspicion than the "typical" room.

Overall, investigators and interviewees seem to be perceptive of their surroundings during interviews, and this dissertation provides evidence for the environment's impact on interviewees perceived experience, yet no support for its influence on their information disclosure. We hope that this body of work serves as a foundation for future research in this limited, yet very practical aspect of interviewing practice. 


\section{RESUMEN EN ESPAÑOL}

La obtención exitosa de información depende en gran medida de la dinámica interpersonal y la calidad de la comunicación entre los investigadores y los entrevistados (ya sean testigos, sospechosos, o victimas). Un aspecto de esta dinámica que ha sido poco explorado es el entorno físico en el que ocurre la entrevista. El hecho de que el entorno físico ejerza una influencia en nuestras percepciones, comportamientos y comunicación no solo es intuitivo, sino que también está respaldado por investigaciones fuera de la psicología legal, como en los campos de comunicación, educación y salud. Por lo tanto, en esta disertación examinamos las posibles influencias del entorno físico específico para el dominio de la entrevista de la investigación policial. Investigamos 1) Las percepciones de los investigadores policiales con respecto a las salas de entrevistas, el uso y la eficacia de las técnicas de manipulación de contexto (u el entorno físico) 2) La influencia de la amplitud física de las salas de entrevista al igual que 3) La ubicación de la entrevista en las percepciones de los entrevistados sobre la construcción de una buena relación con el investigador y la divulgación de información. Por último 4) Las expectativas y preferencias de los detenidos y miembros de la población general sobre las salas de entrevistas policiales.

Para obtener una comprensión más completa de cómo los profesionales en el campo emplean las técnicas contextuales, el Capítulo 2 informa sobre los pensamientos y el conocimiento de los investigadores policiales sobre las técnicas de manipulación del contexto, recopilados a través de una encuesta internacional. Completaron la encuesta 81 investigadores policiales. Nuestros hallazgos proporcionaron evidencia de que los investigadores consideran que el entorno físico de la entrevista es importante, e informaron que ya se emplean ciertas técnicas de manipulación del contexto, particularmente relacionadas con la disposición de los asientos, la ropa de los investigadores y la disponibilidad de artículos para sospechosos como agua y cigarrillos.

Luego investigamos el efecto de la amplitud física en el Capítulo 3. Los participantes se involucraron en un escenario de realidad virtual (RV) que representa un crimen y fueron entrevistados como sospechosos unos en una habitación más grande, y otros en una más pequeña, a una distancia interpersonal más cercana o más larga. No encontramos vínculos entre el tamaño de la habitación y la distancia interpersonal con la cantidad o calidad de la divulgación. Sin embargo, los participantes entrevistados en la sala más grande dijeron tener una experiencia durante la entrevista más positiva, lo que condujo a percepciones de la relación con el investigador mas positivas también, en comparación con los entrevistados en la sala más pequeña. 
También examinamos diferentes locaciones de entrevistas en un contexto de testigos (Capítulo 4). Los participantes experimentaron un simulacro de delito en RV, y una semana después fueron entrevistados en sus propios hogares, con la expectativa de obtener una mayor comodidad, o en una sala formal similar a una sala de entrevistas policiales del mundo real. Si bien los participantes en el entorno de la entrevista domiciliaria informaron sentirse más cómodos y en control, no encontramos diferencias entre la locación de la entrevista en cuanto a la cantidad y calidad de la divulgación de información o las percepciones de los participantes sobre la construcción de una buena relación.

Por último, en el Capítulo 5, exploramos los preferencias y expectativas de las personas con respecto a las salas de entrevistas policiales, especificas a un contexto de sospechosos. Si bien los estudios anteriores sugirieron que una habitación hecha para ser agradable y cómoda podría ser óptima para entrevistar a sospechosos, otro estudio encontró que, en cambio, puede generar una mayor sospecha de las intenciones del investigador. Por lo tanto, realizamos una encuesta con detenidos actuales e individuos de la población general que proporcionaron información descriptiva sobre sus preferencias y expectativas de los entornos de entrevistas policiales. Los participantes también compararon fotos de dos habitaciones; una que parecía una sala de entrevistas "típica", y una decorada para ser cálida, acogedora y cómoda. En general, los detenidos y los individuos de la población general informaron que esperaban ser entrevistados en la sala "típica", pero preferían la decorada. La habitación decorada provocó sentimientos más positivos de comodidad y cooperación y sentimientos más bajos de sospecha que la habitación "típica".

En general, los investigadores y los entrevistados parecen ser perceptivos de su entorno físico durante las entrevistas. Esta disertación proporciona evidencia del impacto del entorno físico en la experiencia percibida de los entrevistados, pero no respalda su influencia en la divulgación de la información. Esperamos que este trabajo sirva de base para futuras investigaciones en este aspecto limitado pero útil en la práctica de las entrevistas policial. 


\section{VALORISATION ADDENDUM}

"No research without action, no action without research" - Kurt Lewin

Lewin's quote captures the direction of my research program: action. According to Lewin, action research happens when individuals seek to influence the community in which they are embedded (Lewin, 1946, in Scheider, Gruman \& Coutts, 2012). Through this dissertation, the research I conducted on investigative interviewing environments was grounded in the hope that it could contribute to investigative interviewing practice.

The relevance of this dissertation lies in its applied implications. Interview rooms are a central aspect of all interview scenarios because it is where the primary communication between investigators and interviewees take place. It follows that we should establish if there are specific physical conditions that are most effective for police investigators to interact with interviewees. While research in this area is still in its infancy, the findings from this dissertation serve as a foundation toward this goal. This program of research gathered perspectives on interview environments from a variety of pertinent populations (police investigators, mock interviewees, detainees, and the general public) and provided initial evidence that environmental aspects, such as spaciousness and location, can impact interviewee's affective experience while providing information.

Consequently, the target audience for this dissertation are police investigators.

Undoubtedly, conducting interviews is a difficult and taxing task and, as academics, we aim to help investigators carry out interviews more effectively by establishing evidence-based interviewing practices. Eventually, when we develop a more robust body of research in this area, the aim is to supply the dearth of information in interviewing manuals regarding how to set up interview rooms, and potential context techniques to employ during interviews. This research is also of interest to police agencies, particularly when (re)designing interview rooms. In this regard, an important consideration should be toward the investigators who spend numerous hours inside these rooms. We found that the majority of the surveyed sample of investigators indicated being dissatisfied with their stations' rooms. Investigators' comfort and satisfaction should be prioritized, as it can have a significant impact on their work performance as well as overall wellbeing (Hanway, Akehurst, Vernham, \& Hope, 2019).

The research program in this dissertation is innovative in that there is currently little research available on interview environments, and all four studies built upon the limited extant data to advance our understanding of this research area. 
Importantly, the two survey studies in this dissertation would not have been possible to conduct if it was not for the collaborations of Officer John Tedeschini (Canada), Detective Matthew Jones (United States), Officers Koen Geijsen, Johan Hoeijmakers, Bert-Jan Kreulen (the Netherlands), and members of the Sweden police. Going forward, my goal is to maintain and create active collaborations with police practitioners, as this is imperative for the progress and implementation of research on interview environments and, in general, applied legal psychology. To refer back to Lewin's action research, knowledge is best achieved through cooperation between academics and those who work in the field, bridging together the expertise of both. After all, as McGough (2019) pointed out, who better to judge how to best apply research to practice than the practitioners themselves? 


\section{References}

Hanway, P., Akehurst, L. A., Vernham, Z., \& Hope, L. (2019, June). The effects of increased cognitive demands on interviewers' perceived cognitive load and recall of a witness's verbal

statement. Poster session presented at the 13th meeting of the Society for Applied Research in Memory and Cognition, Brewster, MA.

McGough, M. Q. (2019, January). Research in the ranks: Empowering law enforcement to drive their own scientific inquiry. National Institute of Justice Journal, 280. https://www.nij.gov/ journals/280/Pages/research-in-the-ranks.aspx.

Schneider, F., Gruman, J., \& Coutts, L. (2012) Applied social psychology: Understanding and addressing social and practical problems. 2nd ed. Thousand Oaks, CA: SAGE Publications, Inc. 


\section{ACKNOWLEDGEMENTS}

I would first like to thank the House of Legal Psychology and the brilliant minds that made this program happen, without which this experience would not have been possible. I would also like to thank Chantal, and all those who kept the House running, thank you for your patience and support through transitioning into this program.

To my first supervisor, Ewout, your integrity and values as both a person and an academic are inspiring. Thank you for making me a better writer and analytical thinker, and for the autonomy and trust you allowed me since the beginning of my PhD. To my second supervisor, Aldert, thank you for the support you provided during my time in Portsmouth. I always looked forward to our Monday meetings - I enjoyed our talks about travelling, politics, and old British TV shows (and research of course!). I would also like to thank my UoP examiners, Christopher Kelly and Claire Nee, and my UM promotor, Corine de Ruiter, for their valuable time and feedback.

The past three years have been the most exciting, challenging, adventurous, at times frustrating, but ultimately rewarding years of my life. One of the biggest rewards was meeting the incredible people who have been a constant source of encouragement, and this acknowledgements section would be incomplete without giving them proper credit. Bri - my buddy, my person - it is impossible to put down in words the gratitude I feel for you. Since the very first day, you have been there through all the highs and lows, and I could not think of a better person to have travelled through this experience with. Ale, you were always ready with a big hug when I needed it the most. Thank you for listening to me on my good and not-so-good days, for your advice, and for keeping me closer to home by having someone to speak Spanish with gracias, amiga. Irena, mi Vero, you (and Zi, aka Ramón) have always been there, ready to help, but most importantly, ready to listen - thank you for the love, support, and acceptance. Sergii, you continue to be a source of pure positivity. Thank you for your quirkiness, for reminding me to maintain an open mind, and of course, for our late night work dates. Enide, thanks to you I continued to enjoy the amazing nightlife that Maastricht has to offer (sarcasm of course). But honestly, thank you for always being present, supportive, and reminding me that it is okay to have work-life balance. Nina, we got to share many interests, like podcasts, Lizzo, American commonalities, but most importantly, the joy that is the YouTube beauty community - all of these made this time much more enjoyable. To the rest of the people who made this experience so memorable - Robin, Renan, House, UM, and UoP friends - I appreciate you all. 
To my parents and sister, it is because of to your sacrifices that I was able to embrace this opportunity. You taught me persistence, resilience, and the value of hard work, all of which were indispensable throughout this journey. Este logro es gracias a ustedes. Los amo.

And to Victor, mi amor, my rock. While these past four years have been full of change, you have been my constant, my well of tranquility. Thank you for the unwavering support and belief that I could achieve this, especially at times when I did not. You continue to remind me of what is truly important in life. 


\section{CURRICULUM VITAE}

Katherine Hoogesteyn was born on January 14 ${ }^{\text {th }}, 1993$ in Caracas, Venezuela. In 2011, she completed her secondary education at Nova High School, Davie Florida, United States. Katherine then continued to complete her bachelor's degree in Psychology with honors at Florida International University, Miami. During this time she volunteered as a research assistant and lab manager in various research projects in the Legal Psychology department. Upon obtaining her bachelor's degree, she continued to work at Florida International University as a project assistant in the Center for Children and Families until 2016 when she was accepted to the Erasmus Mundus Joint Decorate program by the House of Legal Psychology at Maastricht University and University of Portsmouth (United Kingdom). Her graduate studies examining if and how the physical environment of investigative interviews could influence police practice and interview outcomes was supervised by Dr. Ewout Meijer and Prof. dr. Aldert Vrij. After three years, in November 2019, Katherine successfully defended her doctorate thesis at the University of Portsmouth. Currently, Katherine is a researcher funded by the United Kingdom's Center for Research and Evidence on Security Threats. 


\section{DISSEMINATION}

\section{PUBLICATIONS}

Hoogesteyn, K., Meijer, E.H., \& Vrij, A. (2020). Examining witness interviewing environments. Journal of Investigative Psychology and Offender Profiling. Advance online publication. https://doi.org/10.1002/jip.1549

Hoogesteyn, K., Meijer, E.H, \& Vrij, A. (2020). Utility and effectiveness of the context manipulation techniques: police investigators' perspectives. Journal of Police and Criminal Psychology, 1-8. https://doi.org/10.1007/s11896-020-09374-2

Hoogesteyn, K., Meijer, E.H., Vrij, A. (2019). The influence of room spaciousness on investigative interviews. Legal and Criminological Psychology, 24, 215-228. https://doi.org/10.1111/lcrp.12156

Hoogesteyn, K., Meijer, E.H, Vrij, A., Merckelbach, H.M.J. (2018) Improving the disclosure of information in an investigative interview: Rapport building and the physical environment. In-Mind, 36/2018. (see http://www.in-mind.org/article/improving-the-disclosure-of-information-in-aninvestigative-interview-rapport-building-and).

\section{COLLABORATIONS}

Verschuere, B., Meijer, E.H., Jim, A., McCarthy, R., Hoogesteyn, K., Skowronski, J., Orthey, R., Acar, O. A , (...), Yıldız, E. (2018). Registered Replication Report: Mazar, N., Amir, O., \& Ariely, D. (2008). Advances in Methods and Practices in Psychological Science, 1, 299-317. https://doi.org/10.1177/2515245918781032

McCarthy, R. J., Skowronski, J. J., Verschuere, B., Meijer, E. H., Jim, A., Hoogesteyn, K., ... \& Barbosa, F. (2018). Registered replication report on Srull and Wyer (1979). Advances in Methods and Practices in Psychological Science, 1, 321-336. https://doi.org/10.1177/2515245918777487

\section{UNDER REVIEW}

Hoogesteyn, K., Meijer, E., \& Vrij, A. (2020). Detainee and layperson's perspectives and preferences regarding police interview rooms. PLOS One. Revision invited.

\section{CONFERENCE PRESENTATIONS}

Hoogesteyn, K. Meijer, E.H., Vrij, A. (2019, July). A look at investigators' use of environmental techniques. Paper presented at the annual meeting of the European Association of Psychology and Law (EAPL) Santiago de Compostela, Spain.

Hoogesteyn, K., Meijer, E.H., Vrij, A. (2019, March). The Influence of Room Spaciousness on Investigative Interviews. Poster presented at the annual meeting of the American Psychology-Law Society (AP-LS), Portland, Oregon. 
Hoogesteyn, K., Meijer, E.H., Vrij, A., Baldwin, S. (2018, June). Environmental Influences in Witness Investigative Interviews. Paper presented at the annual meeting of the European Association of Psychology and Law (EAPL) Turku, Finland.

Hoogesteyn, K., \& De La Fuente Vilar, A. (2017, December). Memory Challenges in Witness Interviews. Presentation at the UWL Crime and Minds: Psychology and the Law event. London, UK.

Hoogesteyn, K., Meijer, E.H., Vrij, A., \& Merckelbach, H.M.J. (2017, May). Increasing the Disclosure of Information in a Forensic Interview. Pitch presentation at the annual meeting of the European Association of Psychology and Law (EAPL) Mechelen, Belgium. 
Cover design by Jackson Tupper 



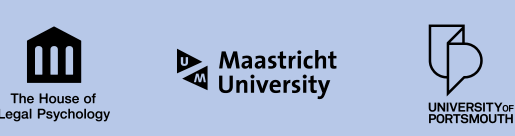

